\title{
Fitness Implications of the Mating System and Reproductive Ecology of Tuatara
}

Jennifer Ann Moore

\begin{abstract}
A thesis submitted to
Victoria University of Wellington

in fulfilment of the requirement for the degree of

Doctor of Philosophy in Ecology and Biodiversity
\end{abstract}

Victoria University of Wellington

Te Whare Wānanga o te Üpoko o te Ika a Māui

2008 


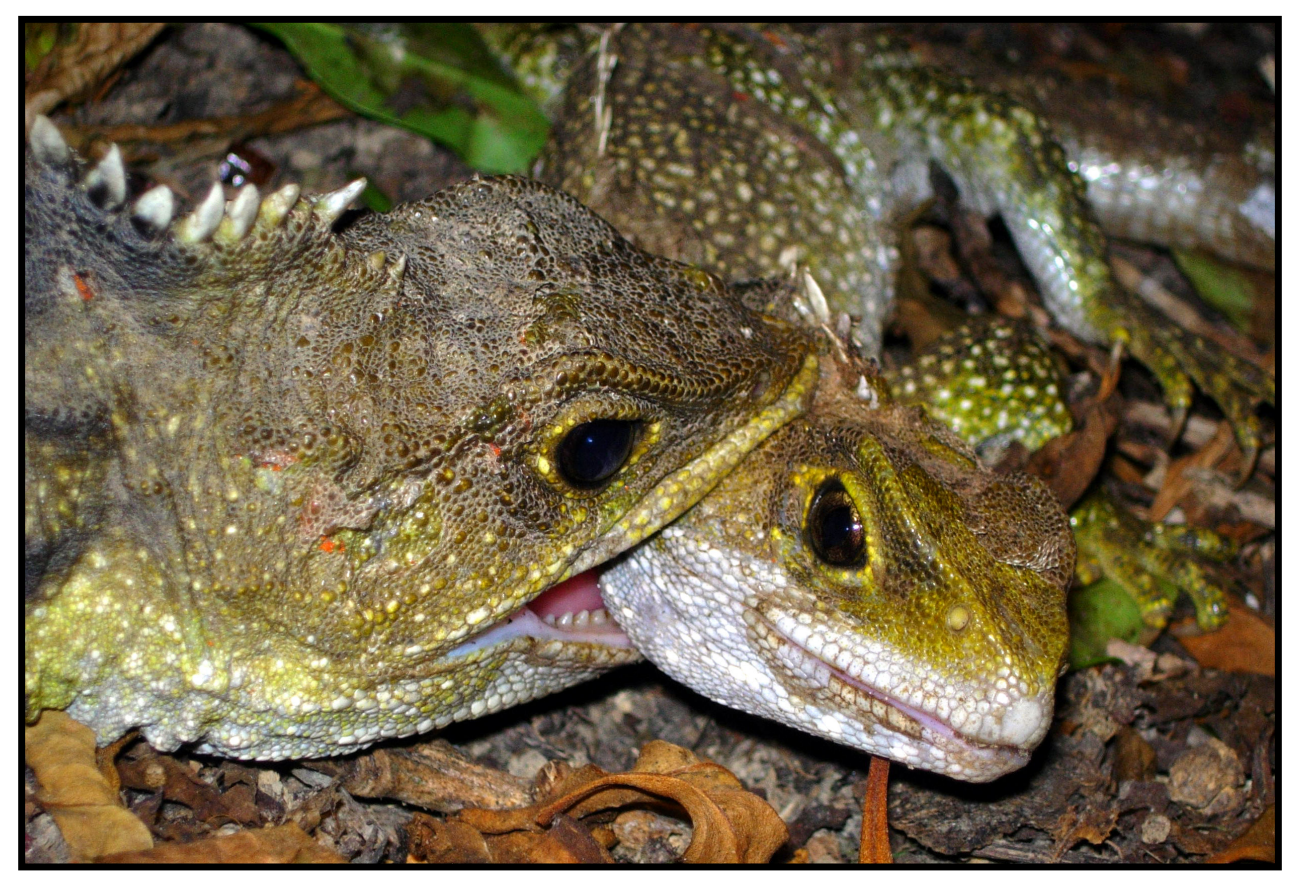

No matter how much cats fight, there always seem to be plenty of kittens.

Abraham Lincoln 
Sexual selection and reproductive strategies affect individual fitness and population genetic diversity. Long-standing paradigms in sexual selection and mating system theory have been overturned with the recent integration of behavioural and genetic techniques. Much of this theory is based on avian systems, where a distinction has now been made between social and genetic partners. Reptiles provide contrast to well-understood avian systems because they are ectothermic, and phylogenetic comparisons are not hindered by complicated patterns of parental care. I investigate the implications of the mating system and reproductive ecology on individual fitness and population genetic diversity of tuatara, the sole extant representative of the archaic reptilian order Sphenodontia. Long-term data on individual size of Stephens Island tuatara revealed a density-dependent decline in body condition driven by an apparently high population growth rate resulting from past habitat modification. Spatial, behavioural, and genetic data from Stephens Island tuatara were analysed to assess territory structure, the mating system, and variation in male fitness. Large male body size was the primary predictor of 1) physical access to females, 2) competitive ability, and 3) mating and paternity success. Seasonal monogamy predominates, with probable long-term polygyny and polyandry. Annually, male reproduction is highly skewed in the wild and in captivity. Over $80 \%$ of offspring from a captive population on Little Barrier Island were sired by one male and multiple paternity was found in approximately $18 \%$ of these clutches, although it was not detected in any wild clutch. The dominance structure has lead to reduced genetic variation in the recovering Little Barrier Island population. Stephens Island tuatara show fine-scale population genetic structuring that appears to be driven by past habitat modification and a sedentary lifestyle in the absence of sex-biased dispersal or migration. These results will improve conservation management of tuatara by providing guidelines for maximising genetic diversity of small and captive populations and will aid in selecting founders for translocated populations. Because of the archaic phylogenetic position of tuatara, this study provides a baseline for comparisons of mating system evolution in reptiles. 


\section{Acknowledgements}

My $\mathrm{PhD}$ has been a long journey that has only been possible with help and support from loads of wonderful people and organisations. I would first like to thank my supervisors, Nicky Nelson and Charlie Daugherty. I am extremely grateful for the guidance and support that Nicky and Charlie have provided throughout my $\mathrm{PhD}$. They have inspired me both professionally and personally, and their constant encouragement was often what kept me going. My fantastic friends have also been there through it all, supporting me mentally (the thesis and papers!) and physically (the climbing and biking!). Special thanks go to Kelly Hare, Kim Miller, Hilary Miller, Sue Keall, Kristina Ramstad, Jo Hoare, Dave Chapple (the token male), Jeanine Refsnider, Libby Liggins, Katie McKenzie, and Gail Porter. Our 9:30 am downloads over coffee were priceless, and sometimes the only thing that got me into the office in the morning!

I am especially grateful to Jim Gillingham and Steph Godfrey. With his research in the 1980's, Jim laid the groundwork for this project and helped immensely in its development and execution. Jim also provided much comic relief along the way! Steph was my partner in crime throughout this project and many long nights were spent processing tuatara and laughing at each other in a sleepy daze. Many thanks go to Alan Dixson, Fred Allendorf, and Alison Cree for discussions that gave me much food for thought. The herpetological 'hatchet' group has also been immensely helpful in reviewing, editing, and constructively criticising. I am also grateful to Shirley Pledger for providing statistical advice.

I am indebted to a number of people from the Department of Conservation (DoC), especially Pete Gaze, Mike Aviss, Clare Allen and Jon Devries. Pete was quick to respond to permit requests, and I always appreciated his willing and supportive attitude. Clare and Jon were unimaginably supportive on Stephens Island/Takapourewa. They helped me immensely with field work, were fantastic company, provided veggies and fish bait in a pinch, and even whipped up great island lattes at 'Keeper's café'. Pete Barrow, Chris Smuts-Kennedy, Will Scarlet, 
Irene Petrove, Rosalie Stamp, and Richard Griffiths provided permits and collected eggs and samples from Little Barrier Island/Hauturu.

This project was funded by the Zoological Society of San Diego, the New Zealand Department of Conservation, the Society for Research on the Amphibians and Reptiles of New Zealand, the Allan Wilson Centre for Molecular Ecology and Evolution, and Victoria University of Wellington. Education New Zealand provided me with financial support in the form of a doctoral scholarship. My work was also supported by Ngāti Koata iwi with permission from DoC (permits AK-18518-RES, TAK 10/05, LIZ 0410, TAK0402, TAK 0501, NM-18922-CAP), and the VUW Animal Ethic Committee (permit \#2006R12).

Lastly, I would like to thank my husband Mike, and my mom, dad and brother for their unwavering support of whatever seemingly crazy venture I undertake. My admiration of my brother Dave, from day one, is probably the reason I ended up studying reptiles in the first place. I could not have made it through this degree without constant support and encouragement from Mike and my parents, to whom I am forever grateful. 


\section{Table of Contents}

$\begin{array}{lr}\text { Abstract } & \text { i } \\ \text { Acknowledgements } & \text { ii } \\ \text { Table of Contents } & \text { iv }\end{array}$

Chapter One. Reptile Mating Systems and Sexual Selection: A Synthesis

1.1 Introduction $\quad 7$

$\begin{array}{ll}1.2 \text { Sexual selection and mating system theory } & 7\end{array}$

$\begin{array}{ll}1.3 \text { Reptile mating systems } & 10\end{array}$

1.4 Reproductive ecology and social behaviour of tuatara 11

$\begin{array}{ll}1.5 \text { Thesis structure } & 14\end{array}$

Chapter Two. Monitoring Over 54 Years Shows a Decline in Body Condition of a Long-lived Reptile (tuatara, Sphenodon punctatus)

$\begin{array}{ll}2.1 \text { Abstract } & 17\end{array}$

$\begin{array}{ll}2.2 \text { Introduction } & 17\end{array}$

$\begin{array}{lr}2.3 \text { Methods } & 19\end{array}$

2.3.1 Long term body condition trends 19

2.3.2 Seasonal body condition trends 23

2.4 Results 25

2.4.1 Long term body condition trends 25

2.4.2 Seasonal body condition trends 28

$\begin{array}{ll}2.5 \text { Discussion } & 30\end{array}$

Chapter Three. Large Male Advantage: Phenotypic and Genetic Correlates of Territoriality and Female Access in an Ancient Reptile (tuatara, Sphenodon punctatus)

3.1 Abstract

3.2 Introduction $\quad 35$

$\begin{array}{ll}3.3 \text { Methods } & 37\end{array}$

3.3.1 Study animals and study site $\quad 38$

3.3.2 Density and sex ratio estimation 38

3.3.3 Spatial structure $\quad 40$

3.3.4 Genetic analyses $\quad 42$

3.3.5 Statistical analyses $\quad 43$

3.4 Results 44 
3.4.1 Density and sex ratio

3.4.2 Social structure and female access 44

3.4.3 Activity centres / spatial proximity 46

3.4.4 Male-male agonistic interactions 46

3.5 Discussion 49

Chapter Four. High Reproductive Skew, Size-Assortative Mating, and Seasonal Monogamy in a Territorial Reptile (tuatara)

4.1 Abstract

4.2 Introduction $\quad 54$

$\begin{array}{ll}4.3 \text { Methods } & 57\end{array}$

4.3.1 Focal animal marking $\quad 57$

4.3.2 Field data collection $\quad 58$

4.3.3 Data analysis $\quad 59$

4.3.4 Paternity analysis $\quad 60$

$\begin{array}{ll}4.3 \text { Results } & 61\end{array}$

$\begin{array}{ll}4.4 \text { Discussion } & 65\end{array}$

4.4.1 Mating system $\quad 65$

4.4.2 Variance in male reproductive success 66

4.4.3 Size-assortative mating $\quad 67$

$\begin{array}{ll}\text { 4.4.4 Fertilization success } & 68\end{array}$

4.4.5 Conservation and management implications 69

Chapter Five. Implications of Social Dominance and Multiple Paternity for the Genetic Diversity of a Captive-Bred Reptile Population (tuatara)

$\begin{array}{ll}5.1 \text { Abstract } & 71\end{array}$

$\begin{array}{ll}5.2 \text { Introduction } & 71\end{array}$

$\begin{array}{ll}5.3 \text { Methods } & 74\end{array}$

5.3.1 Sample collection and genotyping 75

5.3.2 Data analysis $\quad 75$

$\begin{array}{ll}5.4 \text { Results } & 78\end{array}$

$\begin{array}{ll}5.5 \text { Discussion } & 80\end{array}$

5.5.1 Conservation / management implications 83

Chapter Six. Fine-scale Genetic Structure of a Long-lived Reptile Reflects Recent Habitat Modification

6.1 Abstract 85

6.3 Materials and Methods 88

6.3.1 Sample collection $\quad 88$

6.3.2 Genotyping and genetic analyses 90

6.3.3 Population patterns of genetic diversity 91

6.3.4 Individual dispersal and migration 93 
6.4 Results $\quad 94$

6.4.1 Genetic analyses $\quad 94$

6.4.2 Population patterns of genetic diversity 95

6.4.3 Individual dispersal and migration 97

$\begin{array}{ll}6.5 \text { Discussion } & 99\end{array}$

\section{Chapter Seven. Thesis Summary and Applications}

$\begin{array}{ll}7.1 \text { Introduction } & 104\end{array}$

$\begin{array}{ll}7.2 \text { Summary of major findings } & 104\end{array}$

$\begin{array}{ll}7.3 \text { Conservation implications } & 106\end{array}$

$\begin{array}{ll}7.4 \text { Directions for future research } & 108\end{array}$

7.4.1 Does multiple paternity exist in wild populations of tuatara? 108

7.4.2 Do postcopulatory reproductive phenomena exist is tuatara? 109

7.4.3 How does density affect the mating system of tuatara on different islands?

References

Appendix One. The Debate on Behavior in Conservation: New Zealand Integrates Theory with Practice 


\section{Reptile Mating Systems and Sexual Selection: A Synthesis}

\subsection{Introduction}

Sexual selection is unequivocally acknowledged as one of the most powerful evolutionary forces affecting populations. A large body of work has developed around understanding the evolution of mating systems and sexual selection of birds (Orians 1969, Griffith et al. 2002), fish (Avise et al. 2002) and insects (Thornhill and Alcock 1983), but reptile systems remain poorly understood. Detailed investigations of mating systems combining behavioural and genetic techniques are changing many long-standing paradigms. For instance, in recent years, the early assumption that monogamy predominates in avian mating systems has been radically overturned (Griffith et al. 2002). Most reptiles are assumed to be polygynous, and research was mostly male focussed before the regular use of DNA paternity testing. We now know that reptiles have the highest rates of multiple paternity of any vertebrates (Uller and Olsson 2008), and many studies of reptile mating systems are revealing unexpected complexities (Bull et al. 1998, Bull 2000, Olsson et al. 2007). Knowledge of sexual selection and the mating system can also be critical for conservation of threatened or endangered species where management often requires direct manipulation of the few remaining individuals in a population (Hughes 1998, DeWoody 2005). This thesis aims to advance current understanding of reptile sexual selection and evolutionary ecology by investigating the unknown reproductive ecology and mating system of an archaic representative of reptiles, the tuatara.

\subsection{Sexual selection and mating system theory}

Many scientific advances have been made since Darwin proposed the theory of sexual selection in 1871. Darwin (1871) defined sexual selection as "the advantage which certain individuals have over other individuals of the same sex and species", and explained that "trivial" extravagant male characteristics that seemed to have no 
apparent function and often put the male at risk were the result of sexual selection. Sexual selection arises from differential reproductive success caused by mate choice (intersexual selection) or mate competition (intrasexual selection) (Darwin 1871). However, the dichotomy between mate competition and mate choice, as the mechanisms driving sexual selection, is not always as clear as Darwin first proposed.

Success in competition and mate choice is crucial for fitness and the ability of an individual to transfer its genes to the next generation. Mate competition takes many forms, including scrambles, physical contests, endurance, or any other form of rivalry (Andersson 1994). Competition is particularly important for polygynous mating systems, and usually results in the acquisition of many mates for some males, and none for others (Emlen and Oring 1977). Successful males are therefore genetically over represented in future generations, leading to selection for characters that initially enabled breeding success. Competition for mates often selects for large body size, strength, and weapons such as antlers, horns and spurs. These same traits may also be selected by female mate choice (Tregenza and Wedell 2000, Kokko et al. 2003), thus leading to sexual dimorphism.

Competition and choice do not always end at copulation. Post-copulatory sperm competition occurs in some polyandrous systems, where females have multiple partners (Birkhead 1998; Ben-Ari 2000, Jennions and Petrie 2000, Tregenza and Wedell 2000, Eberhard and Cordero 2003). Sperm competition was first viewed as a postcopulatory male-male contest where females were passive participants as sperm from multiple males competed to fertilise as many eggs as possible (Ben-Ari 2000). More recently, females have been shown to exhibit a more active role in fertilisation. Postcopulatory, or cryptic (Thornhill 1983), choice occurs when a female selects which male's sperm fertilises her eggs (Thornhill 1983, Eberhard 1985, Birkhead 1998, Reyer et al. 1999, Calsbeek and Sinervo 2004). Differentiating between these two phenomena is difficult, and they are not always mutually exclusive, which is why early studies failed to recognise the existence of cryptic female choice.

Mate choice may be exercised by either sex, but females are often the choosier sex because they invest more in gametes (Jennions and Petrie 1997). Female choice may be based on direct benefits such as the size and/or quality of a male's territory (e.g., 
Wikelski et al. 2001), the 'nuptial gift' the male presents to the female, or the quality of parental care the male provides (Westneat and Mays 2005). Alternatively, males may be chosen based on traits reflecting genes that will confer greater fitness to the offspring (i.e., the 'sexy son' or 'good genes' hypotheses; Penn and Potts 1999, Jennions and Petrie 2000, Kokko et al. 2003). Many studies have inferred that female choice has evolved from indirect benefits conferred to offspring, but these inferences remain controversial (Jennions and Petrie 2000). Recently, studies of female mate choice have focused on the concept of genetic compatibility, particularly of the major histocompatibility complex (MHC), a cluster of genes primarily involved in immune response regulation (Penn and Potts 1999, Roberts and Gosling 2003). With genetic compatibility, a male is not chosen based on his universally superior genes, but instead on the compatibility of his genotype to that of the female (Zeh and Zeh 1997, Penn and Potts 1999, Tregenza and Wedell 2000, Westerdahl 2004). The specific combination of male and female haplotypes, which are usually complementary to increase variation, dictates offspring fitness. For instance, reptile clutches from parents with the same MHC haplotypes can have reduced hatching success (Wittzell et al., 1999).

Female mate choice has been documented in numerous taxa but has rarely been shown conclusively in reptiles (Olsson and Madsen 1995, Tokarz 1995). In the few proven cases, females choose large male body size, which is usually correlated with dominance (Cooper and Vitt, 1993; Censky, 1997). Body size is also important in intrasexual interactions, whereby larger, more dominant males are able to secure larger, higher quality territories (Olsson and Madsen, 1998). Territory size often correlates with reproductive success, as high quality or large territories attract females and can reflect the genetic quality of the resident male (e.g., iguanids, Uta palmeri, Hews 1990; ornate dragon lizards, Ctenophorus ornatus, Lebas 2001; sideblotched lizards, Uta stansburiana, Calsbeek and Sinervo 2002). Choice may also be based on phenotypic traits other than size or resources, although conclusive results demonstrating this in reptiles are limited. These traits may include display behaviour (Crews 1975) and/or parasite and disease resistance (Hamilton and Zuk 1992, Moller et al. 1999). 
Advances in genetic techniques since the early 1980's have revolutionised our understanding of animal mating systems. Recently, important distinctions have been made in some species between social and genetic mating systems (Reynolds 1996, Hughes 1998). For instance, paternity analyses show that both sexes in many species regularly mate with multiple partners regardless of what is apparent based on social interactions alone (Pearse and Avise 2001, Avise et al. 2002, Griffith et al. 2002, Akcay and Roughgarden 2007, Uller and Olsson 2008).

The mating system determines which genes are represented in future generations and thus affects the evolutionary trajectory of a population. Different reproductive strategies and mating systems have profound effects on the genetic diversity of a population. For instance, high reproductive skew, where only a small proportion of males sire all offspring in a population (Emlen and Oring 1977), can severely decrease genetic diversity (Anthony and Blumstein 2000), whereas multiple paternity can increase it (Sugg and Chesser 1994). Therefore, understanding reproductive ecology and the mating system is particularly important for small or declining populations and mating systems should be incorporated into management and recovery plans for threatened or endangered species (Anthony and Blumstein 2000).

\subsection{Reptile mating systems}

Because of their extreme variation in morphology, behaviour, and ecology, reptiles exhibit diverse reproductive tactics. In contrast to birds, parental care is lacking or minimal in reptiles, and males provide no obvious direct resources to females before, during or after mating. Female reproductive intervals vary from days to years between species of reptile, and clutch sizes can be large (e.g., over 100 eggs for some turtles and crocodilians, Greer 1975). Overall, complex mating systems are rare in reptiles. Around $80 \%$ of reptile mating systems that have been studied are promiscuous (Olsson and Madsen 2001), with both sexes having multiple partners with no prolonged pair bond (Stamps 1983, Tokarz 1995, Olsson and Madsen 1998). The form of promiscuity varies and is usually dependent upon the spatial organisation and dispersion of females, and competitive and guarding ability of males. If females are moderately aggregated in space and receptive over a relatively 
long period of time, a variety of mating systems are possible. All forms of promiscuity are present in reptiles, including polyandry where females mate with multiple males (e.g., Madsen et al. 2005, Uller and Olsson 2008) and polygyny where males mate with multiple females (e.g., Cooper and Vitt 1997, Zamudio and Sinervo 2000). Monogamy, or long-term cooperative pairing, is uncommon in reptiles (Bull 2000) and has only been shown conclusively in five species in one lizard group (including Tiliqua rugosa, Bull 2000; Egernia saxatilis, O'Connor and Shine 2003; Egernia cunninghami, Stow and Sunnucks 2004a; Stow and Sunnucks 2004b; Egerni stokesii, Gardner et al. 2001; and Egerni whittii, Chapple and Keogh 2005).

Paternity studies have shown that polyandry in reptiles commonly results in clutches of offspring with multiple sires represented, or with a sire that was not observed mating with the female (Abell 1997, Gullberg et al. 1997, Davis et al. 2001, Gibbs and Weatherhead 2001, Lebas 2001, Olsson and Madsen 2001, Pearse and Avise 2001, Stapley and Keogh 2005). Reptiles have the highest rates of multiple paternity of any vertebrate group (Uller and Olsson 2008), which is mostly due to strong selection for multiple mating in males, very little precopulatory mate choice by females, high mate encounter rates, and low cost to females for multiple mating (Uller and Olsson 2008). Combining behavioural data with genetic data is necessary to understand all aspects of a mating system including social interactions and fertilisation success (Hughes 1998).

\subsection{Reproductive ecology and social behaviour of tuatara}

Reptiles are excellent models to advance sexual selection and mating system theory, as many species are amenable to studies in both the wild and the laboratory, they are often conspicuously sexually dimorphic in morphology and behaviour, and broad phylogenetic comparisons are not hindered by complex patterns of parental care (Andersson and Simmons 2006). Tuatara (Sphenodon punctatus), in particular, are conspicuous to a trained observer, and can occur at high enough densities (e.g., on Stephens Island) to conduct robust behavioural and molecular studies. Further, because tuatara represent a distinct group of reptiles that diverged from their sister group (the squamates) approximately 230 mya (Rest et al. 2003), understanding the 
reproductive ecology of tuatara may help to shed light on possible phylogenetic patterns of sexual selection or mating system evolution.

The mating systems of squamates (snake and lizards) are relatively well understood, but no reptile group is comparable to tuatara (Sphenodon spp.), because the two currently recognized species ( $S$. guntheri and $S$. punctatus) comprise their own order (Sphenodontia). Tuatara are ecologically similar to insectivorous lizards, but they also have many morphological and physiological differences. For instance, unlike all other reptiles, tuatara lack an intromittent or copulatory organ (Dawbin 1982b, Cree and Thompson 1988, Healy and Jamieson 1992). Therefore, predictions about the mating system can only be based on evolutionarily distant and ecologically similar relatives (i.e., squamate lizards).

Like many lizards (Olsson et al. 2002), tuatara are sexually dimorphic, with larger males than females (Dawbin 1982b). Tuatara actively defend territories, and their social behaviour resembles that of ecologically similar lizard species in that courtship and defence involve intricate, stereotyped display patterns (Gans et al. 1984, Gillingham et al. 1995). Male tuatara erect large crests and inflate their bodies to appear larger during inter- and intrasexual social interactions (Gillingham et al. 1995). Agonistic interactions between males are common to maintain territory boundaries, often resulting in physical damage, including tail loss. Male territories can encompass female territories, which probably enables a male to have exclusive access to those females for mating. The potential role of female choice remains an enigma for tuatara.

Stephens Island holds the largest and most studied population of tuatara (an estimated $30-50,000$ individuals, Newman 1987), and is the focal island for this thesis research. Stephens Island is a 150 ha island with a history of human habitation and intensive habitat modification (Brown 2000). Due to intensive farming, grazing and burning that began with the construction of a lighthouse in the late 1800's, an estimated $80 \%$ of the island had been deforested (Dieffenbach 1843, Brown 2000). Anecdotal evidence supports a decline in tuatara numbers during the early 1900's from collection pressure and habitat modification (Brown 2000). Further, conversion of forest to grazing pastures has altered tuatara behaviour. Pasture tuatara, that lack 
any cover from natural predators, do not regularly emerge from their burrows during the day, whereas forest tuatara are semi-active during the day (J. Moore, pers. obs.; Gillingham et al. 1995). Likewise, female tuatara are now able to nest in pastures that would have been too cold to support egg development when forested (Thompson 1990). Population expansion may be causing the tuatara population to exceed its carrying capacity (similar to what is occurring on neighbouring North Brother Island, Hoare et al. 2006). All livestock have recently been removed from Stephens Island and the New Zealand Department of Conservation instigated a revegetation programme in 1989.

On Stephens Island, courtship begins around January, correlating with elevated testosterone levels in males (Cree et al. 1992, Gillingham et al. 1995). Mating follows until March or April. An average of $25 \%$ of females are sexually receptive in any year (Saint Girons and Newman 1987, Guillette et al. 1990, Cree et al. 1991a, Cree et al. 1991b, Cree et al. 1992). Approximately 8 - 10 months after) mating, female tuatara migrate to nesting rookeries and lay eggs. Polygyny has been inferred for tuatara and is likely because males have no parental investment other than gamete contribution. The prediction in a polygynous system is that dispersal is male-biased, and that this should spatially segregate closely related individuals, thereby avoiding inbreeding (Pusey and Wolf 1996). Furthermore, in territorial, polygynous systems, males holding the largest territories typically have the highest mating success, especially in the absence of alternative mating tactics (Andersson 1994). Under these circumstances, females are not expected to exhibit mate choice because mating with the territory-holder ensures a high quality mate due to the male's previous success in intrasexual competition (Cox and Le Boeuf 1977). Only one study has examined paternity in tuatara, from eight clutches collected from wild females on Stephens and North Brother islands (Hay and Lambert 2008). Hay and Lambert (2008) only examined the genetics of these females and clutches, and did not find multiple paternity in any clutch.

Much of what we know about mating system theory is the result of laboratory studies and therefore provides little information on the fitness consequences of various mating strategies for wild populations. One aim of this study is to address the fitness consequences of the mating system for small populations of tuatara, and their 
implications for conservation. Understanding social behaviour and the mating system was identified as a research priority in the tuatara recovery plan (Gaze 2001). The results of this thesis will not only provide information for managers to improve captive breeding and population recovery efforts, but will also enhance the poor understanding of reptile mating system evolution and sexual selection. The overarching questions addressed in this thesis are as follows:

1) What are the social and genetic mating systems of tuatara, and how do these compare to other reptiles?

2) What factors affect male fitness and reproductive skew and what are the implications for small populations?

3) How do the mating system and reproductive strategies of tuatara affect population-wide patterns of genetic diversity and gene flow, and thus the evolutionary trajectory of populations?

\subsection{Thesis structure}

Understanding the mating system first requires knowledge of the underlying ecological factors affecting a population. Thus, Chapter Two investigates long-term and seasonal trends in morphology of tuatara on Stephens Island. Using long-term (spanning 50+ years), and seasonal datasets, I explored the relationship between increasing population density and decreasing body condition in tuatara. This chapter is published as:

Moore, J.A., J.M Hoare, C.H. Daugherty, and N.J. Nelson. 2007. Waiting reveals waning weight: monitoring over 54 years shows a decline in body condition of a long-lived reptile (tuatara, Sphenodon punctatus). Biological Conservation 135: 181-188.

The spatial structure and organisation of conspecifics has important effects on the mating system, especially in simple systems. Thus, Chapter Three investigates the territory structure of tuatara on Stephens Island. By combining behavioural observations, geographic information system (GIS) mapping, and spatial and genetic data, I analyse the male traits that affect access to females and territory size and distribution. I also assess population density and sex ratios on Stephens Island (using 
data originally collected by Nicola Nelson). This chapter is currently in review in Journal of Herpetology as:

Moore, J.A., C.H. Daugherty and N.J. Nelson. In review. Large male advantage: phenotypic and genetic correlates of territoriality in tuatara. Journal of Herpetology.

Chapter Four investigates the social and genetic mating system of tuatara on Stephens Island. Specifically, I characterise the mating system and investigate variation in male reproductive success. Data on parasite loads were collected by Stephanie Godfrey, and co-authors for publication are Stephanie Godfrey, Charles Daugherty and Nicola Nelson.

Chapter Five examines the paternity of a captive-bred group of tuatara on Little Barrier Island. This chapter provides a strong example of how the mating system and reproductive skew can affect genetic diversity for a small, recovering population. This chapter has been published as:

Moore, J.A., N.J. Nelson, S.N Keall, and C.H. Daugherty. 2008. Implications of social dominance and multiple paternity for the genetic diversity of a captive-bred reptile population (tuatara). Conservation Genetics 9: 1243-1251.

The last data chapter, Chapter Six, investigates genetic population structure and dispersal patterns of Stephens Island tuatara. Fine-scale genetic population structure depends on the mating system, dispersal, and demography. Thus, this chapter incorporates information from previous data chapters (two through five) to investigate population-wide patterns of genetic diversity, dispersal, and relatedness. This manuscript has been published in Molecular Ecology as:

Moore, J.A., H. C. Miller, C.H. Daugherty, and N.J. Nelson. In press. Fine-scale genetic structure of a long-lived reptile reflects recent habitat modification. Molecular Ecology.

Because this thesis is written as a series of standalone manuscripts, there may be some unavoidable repetition in the introduction sections. Each chapter includes an introduction of specific aims and hypotheses, as well as a discussion, which covers 
important aspects of the empirical data presented and places the results in the context of existing work. Lastly, Chapter Seven provides a synthesis of the main findings of the thesis, future directions for research, as well as broad implications for tuatara conservation. 


\section{Monitoring Over 54 Years Shows a Decline in Body Condition of a Long-lived Reptile (tuatara, Sphenodon punctatus)}

\subsection{Abstract}

Knowledge gained from monitoring has been the basis for many critical decisions in threatened and endangered species and ecosystem management. Long-term monitoring has been recognized as a necessity for elucidating population trends and community interactions, particularly for long-lived species or ecosystems with slow rates of change. We examine seasonal and annual cycles of morphological changes in a threatened, long-lived, insular reptile, the tuatara (Sphenodon punctatus), on Stephens Island, New Zealand. We used body condition indices as a surrogate measure of fitness, and examined seasonal fluctuations, using data from an intensive mark-recapture study, and long-term trends using a dataset that spans 54 years. In spite of seasonal and annual fluctuations, body condition of tuatara has declined significantly between 1949 and 2003; the decline was only evident after $>22$ years of monitoring. We hypothesize that increasing numbers of tuatara have resulted in a density-dependent population response driven by past habitat modification on Stephens Island. We emphasize the need for long-term monitoring and suggest that potentially costly management decisions, particularly for long-lived species or ecosystems with slow rates of change, should not be based solely on short-term monitoring.

\subsection{Introduction}

Many researchers have recognized the value of long-term ecosystem monitoring (Blossey 1999; Yoccoz et al. 2001), as only long-term data are sufficient to examine annual variation in population parameters and the influence of infrequent events or cyclic phenomena (Tinkle 1979, Wooller et al. 1992, Garza and Williamson 2001). Only long-term monitoring can provide the baseline data necessary to assess whether 
species declines are real or due to some natural phenomenon (Blaustein et al. 1994). Long-term datasets are especially important when the rates of change in a system are slow (e.g., long generation time). In the absence of these datasets, research is limited to short-term data that may only resolve fine-scale patterns without any indication of the underlying ecological mechanism (climate change, Dunn and Winkler 1999, Connell and Green 2000, Walther et al. 2002, Chamaille-Jammes et al. 2006).

Long-term monitoring has been recognized as a necessity, but it is often limited by feasibility and funding. Managers frequently need to make critical decisions based on the information that is available, and for minimizing cost and effort monitoring often needs to encompass the shortest time scale that is still biologically relevant (i.e., that accurately reflects the current biological state of the population or ecosystem, Chapman et al. 2000). Long-term trends may not be evident or may be misinterpreted if monitoring duration is insufficient (Madsen and Shine 2001, Thomas et al. 2002), which could result in inappropriate, costly management decisions. Initial monitoring may reveal population trends that are manifested as individual morphological changes (Adler and Levins 1994, for short-lived species), which would ultimately affect population dynamics.

So how long does a population need to be monitored before trends become evident and appropriate management decisions can be made? We address this question by investigating the seasonal and annual cycles of morphological changes in one population of a threatened, long-lived, insular reptile, the tuatara (Sphenodon punctatus). We use intensive mark-recapture data and a dataset spanning 54 years, to interpret body condition responses with respect to climate, reproduction, habitat modification, and monitoring duration.

Tuatara are medium-sized reptiles and the sole extant representatives of the Order Sphenodontia (Benton 2000). Endemic to New Zealand, they were once widespread throughout the main and outlying islands (Holdaway and Worthy 1997), but by the early $19^{\text {th }}$ Century, these long-lived reptiles (maximum recorded longevity is 91 years, N.J.N., personal communication) were extirpated on the two main islands, presumably as a result of habitat modification and introduction of rodents (Rattus exulans) by human settlers ( 750 ya; Anderson 1996). Much of the habitat on the 
approximately 30 offshore islands on which tuatara naturally remain has been heavily modified.

Over half of extant tuatara ( 30 - 50 000 individuals) inhabit Stephens Island (known also by its Māori name, Takapourewa; Marlborough Sounds, 4040'S, $174^{\circ}$ 00'E), which has been the focus of scientific research since 1949 (Dawbin 1962, Dawbin 1982b, Dawbin 1982a) and is the source island for two translocated populations (Nelson et al. 2002a; N.J.N. unpublished data). The 150 ha island supports a lighthouse and has a history of intensive habitat modification. By the mid-1920's, following constant human presence by permanent lighthouse keepers, an estimated $80 \%$ of the island's forested habitat had been cleared for farming and speculation was raised over the small number of tuatara remaining after intensive collection for museum specimens (Brown 2000). Cleared paddocks had been maintained on the island until removal of livestock in 2004, with little natural revegetation since the initial deforestation. Although reforestation efforts have been ongoing, remnant coastal forest now covers less than $15 \%$ of the island (Hare and Cree 2005), and in forest remnants, the average density of tuatara is ca. 2015 per hectare, which is five times greater than in the artificial paddocks (Carmichael et al. 1989), and at least 20 times greater than on any other island where tuatara naturally occur (Cree and Butler 1993).

In order to reveal demographic patterns and potential impacts to this biologically significant source population, we examine seasonal and long-term trends in body condition (a measure of mass relative to body size). Specifically, the following questions are addressed: (1) Are long-term trends or cycles in body condition evident, and do these vary between the sexes? (2) Does body condition of tuatara fluctuate seasonally, or with respect to sex or climate? (3) How many years of monitoring may be necessary to reveal significant long-term trends?

\subsection{Methods}

\subsubsection{Long term body condition trends}


Mark-recapture data were collected from Stephens Island tuatara from 25 separate years, spanning the period 1949-2003. In most sampling years, data were collected during multiple sampling trips, and the times of the sampling trips varied by year. Tuatara caught between 1949 and 1992 were given permanent individual marks by toe-clipping when first captured, and recaptures were recorded. After 1992 toeclipping was no longer used to permanently mark individuals. During the 2003 trip, a unique number was written on the side of each animal with a permanent marker pen, which was legible for the duration of the sampling period only.

From 1983-1985, only females were captured, as mark-recapture data are derived from a nesting study (Newman et al. 1994). Therefore we removed these years from intersexual analyses but retained them for subsequent female-only analyses.

Morphological measurements taken from captured tuatara included sex, snout to vent length (SVL; mm) and mass (g) (Table 1). The sex of each adult tuatara ( $\geq 170 \mathrm{~mm}$ SVL) was easily determined by examining secondary sexual characteristics, including crest development, spine shape, head size/shape, and shape of abdomen (Dawbin 1982b, Cree et al. 1991b)

We calculated body condition indices to assess trends in tuatara body condition. Body condition, which is often used as a surrogate measure of fitness, reflects an animal's storage and expenditure of energy, which can sometimes reveal the stresses or limitations affecting those individuals (Doughty and Shine 1998, Moore et al. 2000, Schulte-Hostedde et al. 2001). Recent debate has raised cautions about generating false relationships between condition and other parameters correlated with body size (Green 2001, Schulte-Hostedde et al. 2005). However, with proper testing of assumptions, body condition indices provide a powerful, non-destructive technique for examining body mass changes over time, while accounting for allometric growth (Bradshaw et al. 2000, Shine et al. 2001). We defined body condition as the residual values from a linear regression of $\log$ (mass) versus $\log (\mathrm{SVL})$, because it was the most appropriate for our dataset and meets the assumption of linearity $\left(r^{2}=0.95\right)$. 


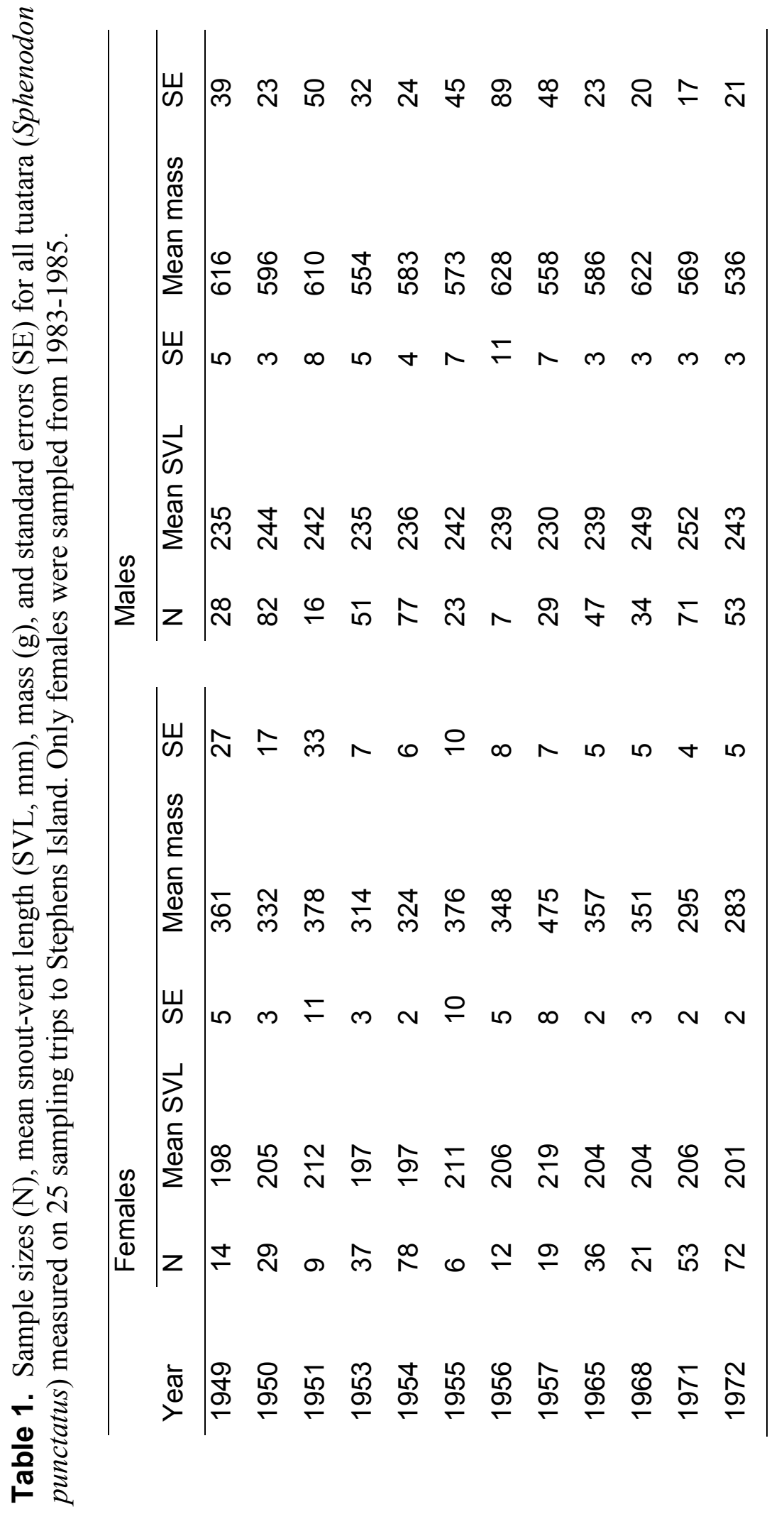




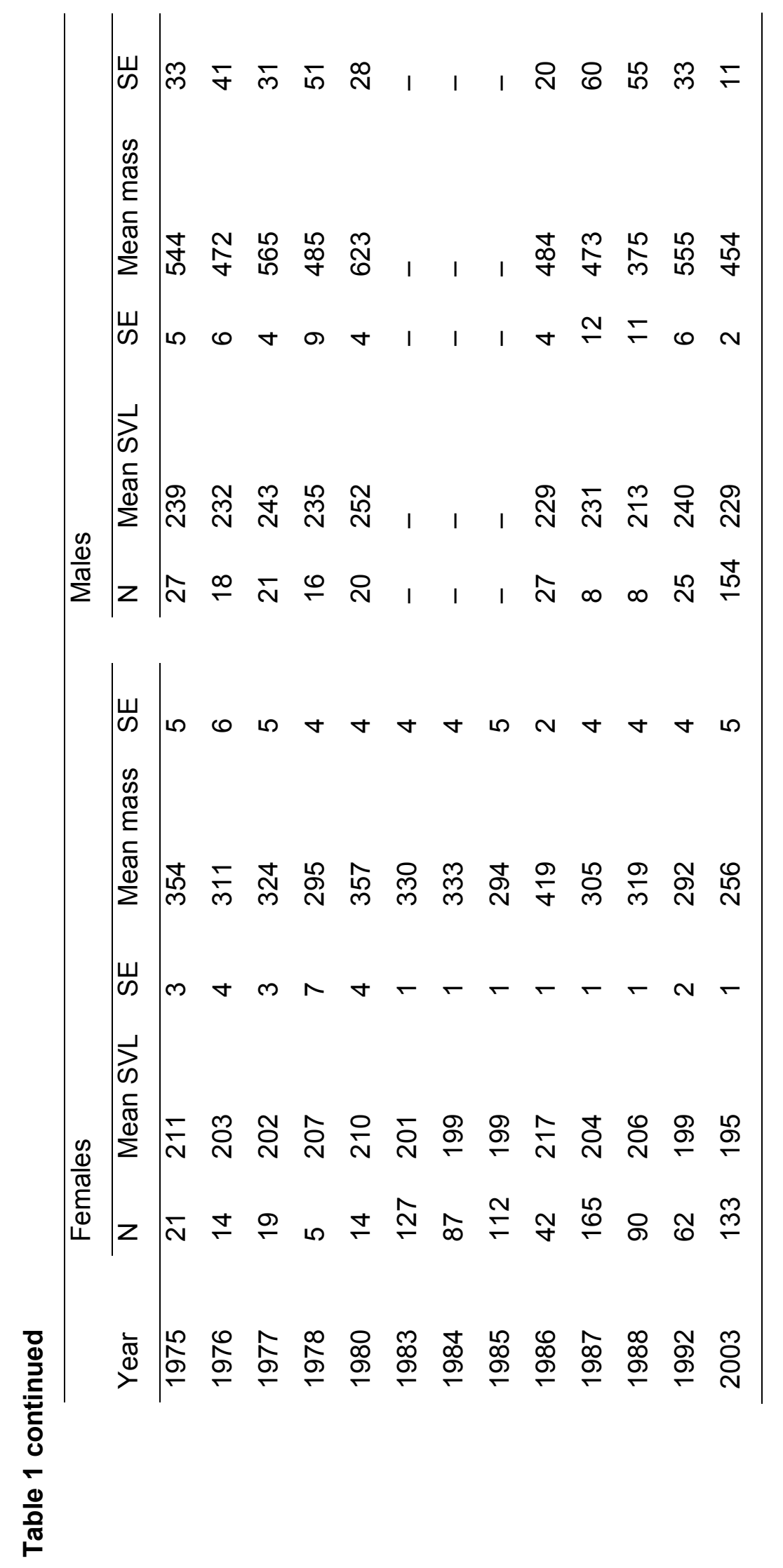


Body condition indices were used to assess long-term intersexual trends in tuatara body condition by carrying out a repeated measures analysis of variance (ANOVA) with a linear mixed effects model. The dependent variable was body condition of tuatara. We included sampling period (year) and sex as dependent fixed effects, and individual as an independent random effect. We used Akaike's Information Criterion (AIC; Akaike 1973; Burnham and Anderson 1998) for statistical model selection. For these analyses, we used data from all years in which both males and females were caught.

Upon finding a significant effect of sex and time on tuatara body condition, we explored temporal trends in body condition for each sex. We constructed models for adult females and males separately, including data from all sampling years, to assess trends using linear mixed effects models which accounted for individual variability. Models compared were those in which body condition (1) remained constant over time, (2) fluctuated through time, and (3) showed a linear increase or decrease over time.

We further explored the long-term dataset (for both males and females) using the same analysis as above, in the following ways (1) all data exclusive of 1949 and 2003 (as these appeared to have a potentially strong influence on the trend), (2) only data from years that were sampled in the same month (to test for a seasonal sampling effect), and (3) all data in 10 year, 30 year, and multiple-year additive blocks (to assess the monitoring duration necessary to reveal consistently significant trends).

We obtained maximum yearly rainfall data for Stephens Island over the last 150 years (C. Allen, unpublished data). These data were analyzed using an ANOVA with a linear mixed effects model to determine whether rainfall has fluctuated significantly through time, or whether any linear trends are evident that may help to explain any patterns in tuatara body condition.

\subsubsection{Seasonal body condition trends}

Upon finding significant fluctuations in the long-term dataset we investigated potential seasonal cycles in body condition by recording morphological data from 
Stephens Island tuatara on four trips (Nov 2004, Jan, Mar, May 2005) in three study plots in Keepers Bush (an original forest remnant). The centres of the study plots were randomly located from an accessible track running through the bush. All tuatara within two circular plots $10 \mathrm{~m}$ in radius, and one $14 \mathrm{~m}$ radius were captured, and their locations in the plot were recorded. Repeated captures of these individuals were made in November 2004 (over seven days, seven nights; austral spring), January 2005 (four days, four nights; austral summer), March 2005 (four days, four nights), and May 2005 (five days, five nights; austral autumn). We marked each individual using a passive integrated transponder (PIT) tag (AVID, Folsom, Louisiana, USA). At each capture, SVL (mm), mass (g), and sex were recorded. These data were not included in the long term analysis, as they were collected from a different sample of tuatara, and the body condition indices generated from this analysis are relative and not directly comparable to those generated from the long term analysis.

To assess seasonal trends in tuatara body condition, we carried out a repeated measures ANOVA with a linear mixed effects model. Body condition of tuatara was the dependent variable. Trip, plot, and sex were dependent fixed effects, and individual was included as an independent random effect. Because juveniles were not sampled in all trips, and were only caught in very low numbers, we did not include them in this analysis. Models were screened based on AICs (Akaike 1973; Burnham and Anderson 1998), and we then rescaled the values to the lowest AIC, to give relative AIC values ( $\triangle \mathrm{AIC}$ ). Those models with the lowest AIC values provide the best explanation of variance.

We used correlation tests with seasonal data to examine the relationship between body condition and (1) maximum monthly rainfall, (2) maximum monthly rainfall from one month prior to sampling month (to test whether there was a delayed response in condition), and (3) average monthly temperature. These climatic data were obtained for Stephens Island, and included maximum monthly rainfall (mm) and average monthly ambient temperature for the period Oct 04 - June 05 (C. Allen, unpublished data). 
All data sets satisfied the assumptions of normality and homogeneity of variances.

Means are reported as mean $\pm 1 \mathrm{SE}$, and significance is assumed at $p<0.05$. All analyses were carried out using the computer program $R$ (R Core Development Team 2006).

\subsection{Results}

\subsubsection{Long term body condition trends}

From 1949 to 2003, there was a $105 \mathrm{~g}$ decrease in average female mass, with only a $2 \mathrm{~mm}$ decrease in average SVL. Males showed a $162 \mathrm{~g}$ decrease in average mass, with only a $6 \mathrm{~mm}$ decrease in average SVL (Table 1). Between 1949 and 2003 a total of 2,508 captures were made of 1,888 adult tuatara. The heaviest tuatara was an adult male captured in 1950, weighing $1020 \mathrm{~g}(\mathrm{SVL}=285 \mathrm{~mm})$. Three other adult males weighing $1000 \mathrm{~g}$ were captured during this period (the same individual, in 1957, and two different individuals in 1954 and 1957; SVL $=270$ and $280 \mathrm{~mm}$ respectively). By 2003 maximum mass of adult male tuatara had declined to $770 \mathrm{~g}$ $(\mathrm{SVL}=267 \mathrm{~mm})$. The heaviest female tuatara was captured in 1953 and weighed $690 \mathrm{~g}(\mathrm{SVL}=267 \mathrm{~mm})$. A further 3 captures of females weighing $\geq 550 \mathrm{~g}$ have been made, all in the period 1950-1956. By 2003 maximum mass for female tuatara was $480 \mathrm{~g}(\mathrm{SVL}=240 \mathrm{~mm})$.

Both sex and year were significant main effects identified by AIC model selection $(\Delta \mathrm{AIC}=0.0$, compared with a null model of $\Delta \mathrm{AIC}=501.6 ;$ Table 2$)$. The next best model, where year is included as the single main effect, is a significantly poorer predictor of tuatara body condition $(\triangle \mathrm{AIC}=32.9)$. Adult male tuatara had higher body condition than adult females (males, mean $=0.02 \pm 0.004$; females, mean $=$ $0.02 \pm 0.004$; Fig. 1). The lack of a significant interaction between year and sex $(\triangle \mathrm{AIC}=115.9)$ demonstrates that temporal variation in body condition is not sexspecific.

Body condition fluctuated significantly through time, compared with a model treating body condition as constant with respect to time (males $\chi_{13}^{2}=250.1, p<$ 0.0001 ; females $\chi_{13}^{2}=490.5, p=0.0001$; Fig. 1). Furthermore, from $1949-2003$ 


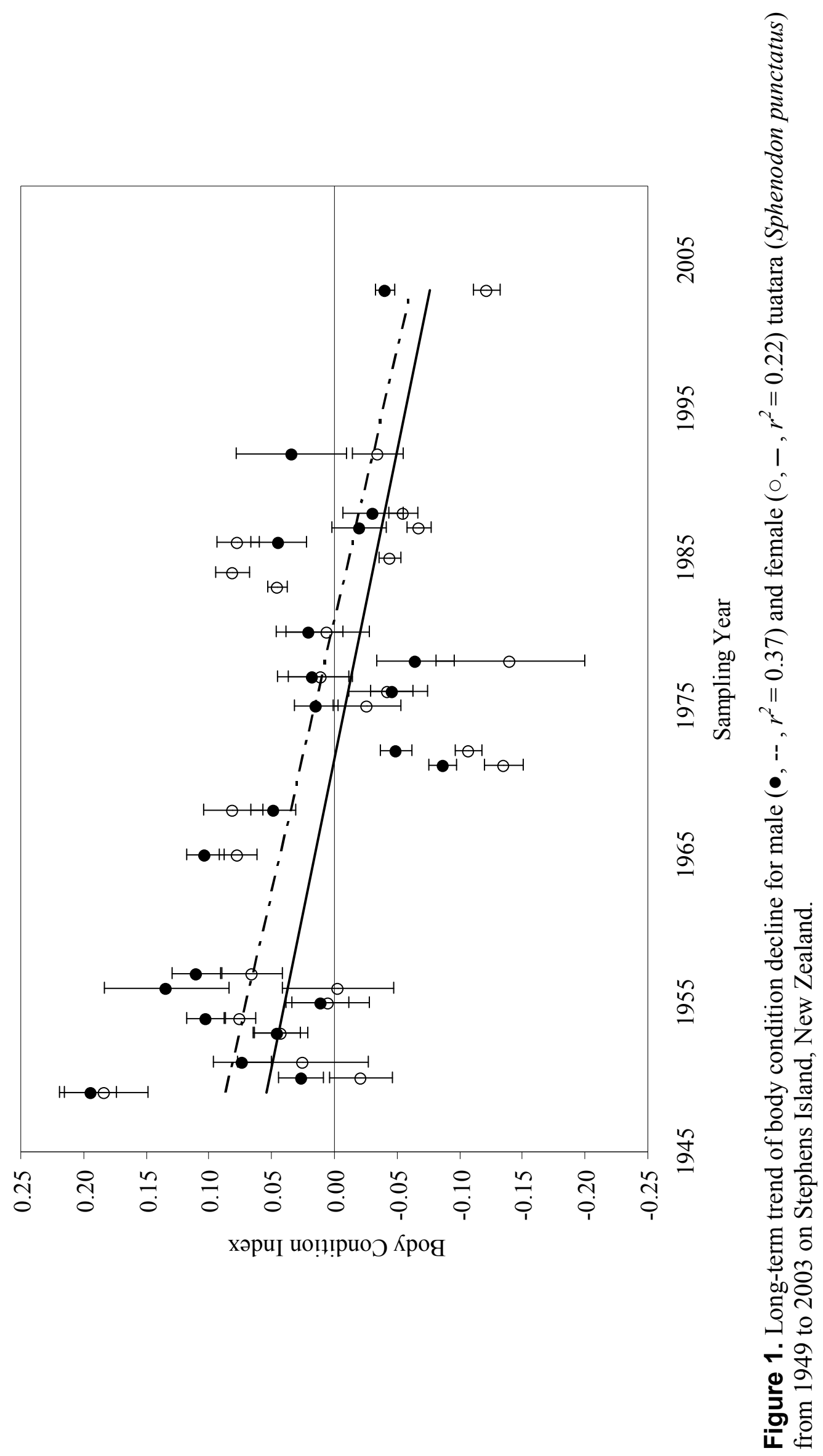


Table 2. Results of linear mixed effects models of body condition index of tuatara (Sphenodon punctatus) from Stephens Island, including rescaled AIC ( $\triangle \mathrm{AIC}$ ) and degrees of freedom (DF). The model with the lowest $\triangle \mathrm{AIC}$ best explains the variance in the seasonal and long-term dataset.

\begin{tabular}{lcc}
\hline \multicolumn{1}{c}{ Seasonal Models } & $\Delta \mathrm{AIC}$ & $\mathrm{DF}$ \\
\hline trip & 0.00 & 6 \\
trip + sex & 4.77 & 7 \\
trip + plot & 14.65 & 8 \\
trip + plot + sex & 19.13 & 9 \\
trip + sex + (trip * sex) & 25.43 & 10 \\
trip + plot + (trip * plot) & 39.62 & 12 \\
null & 127.83 & 3 \\
sex & 131.52 & 4 \\
plot & 142.09 & 5 \\
\hline & & \\
\hline sex + year & 0.00 & 25 \\
year & 32.87 & 24 \\
sex + year + (sex * year) & 115.85 & 46 \\
null & 501.56 & 3 \\
sex & 504.83 & 4
\end{tabular}

body condition of both adult male and adult female tuatara declined significantly. A linear decline in condition fits the data better than a model where condition is constant over time in adult tuatara of both sexes (males $\chi^{2}{ }_{7}=79.6, p<0.0001$; females $\chi^{2}{ }_{7}=67.8, p<0.0001$; Fig. 1). The decline remained significant even when the analyzed dataset did not include data from 1949 and 2003 (indicating that these years did not disproportionately skew the results), and when the dataset only included years that were sampled in the same month (indicating no effect of sampling season).

A consistently significant decline in body condition only became evident after including $>22$ years of data (starting in 1949). When each decade of data was analyzed separately, no clear patterns were evident and results varied from significant linear increases (e.g., females $1970-1980, \mathrm{t}=5.2, p<0.001$ ) to periods 
with constant body condition indices (e.g., females $1950-1960, \mathrm{t}=-0.6, p=0.58$; males $1980-1990, \mathrm{t}=-0.6, p=0.7$ ) to significant linear declines (e.g., females 1980 $-1990, \mathrm{t}=-7.4, p<0.0001$; males $1960-1970, \mathrm{t}=-3.5, p<0.01)$. Regardless of the starting date, datasets that included at least 30 years of data all revealed significant declines in body condition, with the exception of males from $1970-2000$ (Table 3). Annual rainfall has remained relatively constant over time, and did not exhibit any significant linear trends $\left(\mathrm{F}_{1,52}=1.7, p=0.2\right)$.

\subsubsection{Seasonal body condition trends}

From the three study plots, we recorded 461 captures, from 201 individual tuatara (107 males, 87 females, 7 juveniles), over four trips between Nov 2004 and May 2005. Individual recaptures increased with time, and new captures decreased with time until they approached zero (Table 4). We found a significant positive relationship between body mass and SVL (linear regression, $r^{2}=0.95, \mathrm{P}<0.001$ ). Snout-vent length averaged $196.6 \pm 0.9 \mathrm{~mm}$ (female) and $261.7 \pm 3.7 \mathrm{~mm}$ (male), and mass averaged $231.8 \pm 1.5 \mathrm{~g}$ (female) and 473.8 $\pm 9.0 \mathrm{~g}$ (male). Body condition was significantly higher in males (mean $=0.02 \pm 0.009)$ than in females (mean = $0.03 \pm 0.006$ ) or juveniles (mean $=-0.08 \pm 0.006$ ), although this is not surprising considering sexually dimorphic morphologies of males and females.

The univariate model including trip explained the greatest amount of variance in body condition $(\mathrm{AIC}=-929.1, \Delta \mathrm{AIC}=0.0)$, followed by trip $+\operatorname{sex}(\Delta \mathrm{AIC}=4.8$; Table 2). However, because the trip + sex model is not within two AIC units of the best model, we did not consider it to be competitive with the top model (Burnham and Anderson 1998). Body condition was significantly lower in March (mean = $0.06 \pm 0.01 ; p<0.001)$ and higher in May (mean $=0.06 \pm 0.006)$ than at other times of the year (Fig. 2).

The warmest months during the sampling period were February 05 (mean temp $=$ $\left.18.0^{\circ} \mathrm{C}\right)$, followed by March $05\left(\right.$ mean temp $\left.=16.0^{\circ} \mathrm{C}\right)$. There was no significant correlation between mean body condition and mean monthly temperature $(r=-0.6$, $p=0.3$ ). The maximum rainfall was highest in May 05 with $136.1 \mathrm{~mm}$, and lowest in 
Table 3. Results of linear mixed effects models of body condition of male and female tuatara of varying sampling periods using reduced datasets collected from Stephens Island over the period $1949-2003$. Direction of t-values (positive or negative) indicates the direction of the linear trend over time, and asterisks indicate significance $(p<$ $0.05)$.

\begin{tabular}{lllll}
\hline Time span & \multicolumn{2}{l}{ Females } & \multicolumn{3}{l}{ Males } \\
\hline 10-year blocks & $\mathrm{t}$ value & $\mathrm{p}$ value & $\mathrm{t}$ value & $\mathrm{p}$ value \\
\hline $1950-1960$ & -0.6 & 0.6 & 0.002 & 1.0 \\
$1960-1970$ & 0.1 & 0.9 & -3.5 & $0.004^{*}$ \\
$1970-1980$ & 5.2 & $<0.0001^{*}$ & 3.0 & $0.02^{*}$ \\
$1980-1990$ & -7.4 & $<0.0001^{*}$ & -0.6 & 0.7 \\
$1990-2000$ & -4.5 & $0.0026^{*}$ & -3.0 & 0.1 \\
\hline $30-$ year blocks & & & & \\
\hline $1950-1980$ & -8.2 & $<0.0001^{*}$ & -7.8 & $<0.0001^{*}$ \\
$1960-1990$ & -3.0 & $0.006^{*}$ & -2.7 & $0.01^{*}$ \\
$1970-2000$ & -4.7 & $<0.0001^{*}$ & 1.0 & 0.3 \\
\hline
\end{tabular}

Table 4. Frequency of new captures and recaptures, and mean body condition index of all tuatara (Sphenodon punctatus) sampled on four trips to Stephens Island ( $\mathrm{M}=$ males, $\mathrm{F}=$ females, and $\mathrm{J}=$ juveniles).

\begin{tabular}{|c|c|c|c|c|c|c|c|}
\hline \multirow[b]{2}{*}{ Trip } & \multicolumn{3}{|c|}{ New captures } & \multicolumn{3}{|c|}{ Recaptures } & \multirow{2}{*}{$\begin{array}{l}\text { Mean body } \\
\text { condition } \\
\text { index }\end{array}$} \\
\hline & $\mathrm{M}$ & $\mathrm{F}$ & $J$ & $\mathrm{M}$ & $\mathrm{F}$ & $J$ & \\
\hline November 04 & 62 & 38 & 2 & 0 & 0 & 0 & 0.009 \\
\hline January 05 & 34 & 39 & 0 & 41 & 34 & 0 & 0.002 \\
\hline March 05 & 7 & 7 & 3 & 48 & 48 & 1 & -0.070 \\
\hline May 05 & 4 & 3 & 2 & 50 & 37 & 1 & 0.052 \\
\hline
\end{tabular}




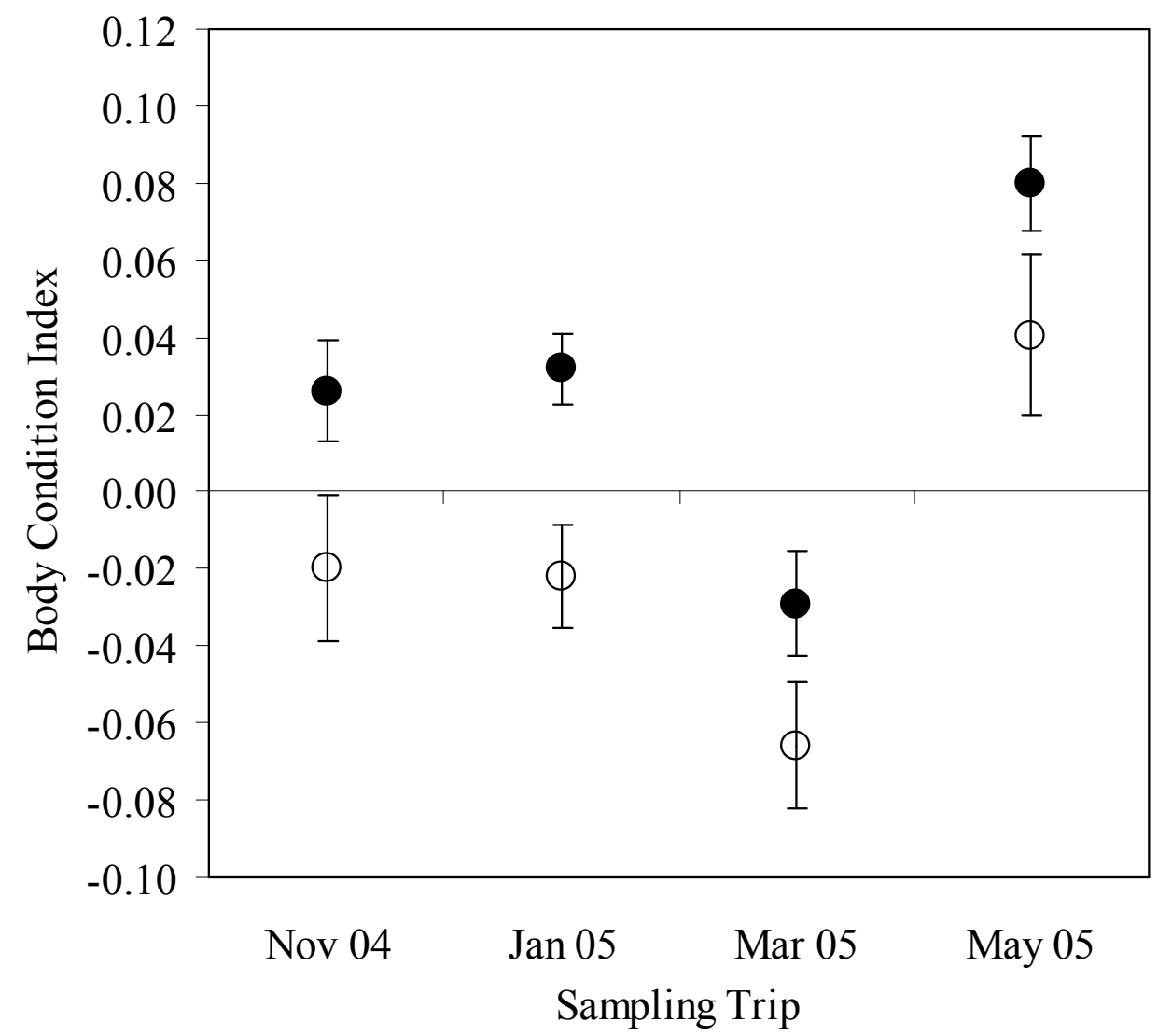

Figure 2. Mean seasonal body condition $( \pm 1 \mathrm{SE})$ of male $(\bullet)$ and female ( $($ ) tuatara (Sphenodon punctatus) sampled from four trips to Stephens Island.

April 05 with $4.1 \mathrm{~mm}$. There was also no significant correlation between body condition and maximum monthly rainfall $(r=0.4, p=0.6)$, or maximum monthly rainfall one month prior to the sampling month $(r=-0.2,0.8)$.

\subsection{Discussion}

Over the past 54 years, tuatara body condition has decreased significantly over time, with adult male tuatara having consistently higher body condition than adult females, although both sexes have declined at a similar rate. Body condition of both sexes of tuatara appears to fluctuate seasonally and is lowest in March (austral autumn).

The most obvious cause of a seasonal decline in body condition during the mating season (March) is from increased energetic costs of reproductive activity. Plasma levels of oestradiol in female tuatara from Stephens Island are highest in February - 
March, which is indicative of vitellogenesis (Cree et al. 1992). Furthermore, Cree et al. (1992) found a peak in testosterone of female and male tuatara, and a peak in corticosterone in males (Tyrrell and Cree 1998) at this time. High testosterone levels are known to increase mobility and social contact of reptiles during mating (Wada 1982, Ketterson and Nolan 1992, Denardo and Sinervo 1994). In tuatara, mite infestation (Neotrombicula sphenodonti and N. naultini, Acari: Trombiculidae, Goff et al. 1987) also peaks during the breeding season, and is evident by obvious orange patches on the skin that are absent at other times of the year (S. Godfrey, unpublished data; J.A.M., personal observation). Testosterone, in addition to increased physical contact, could therefore have a similar effect of lowered body condition and increased ectoparasite intensity of tuatara. Further research is needed to confirm this hypothesis and because our seasonal dataset is somewhat limited, our conclusions remain speculative.

Despite monthly and annual fluctuations, rainfall levels on Stephens Island have remained constant over the past 150 years, with no significant increases or decreases. A long-term decline in body condition was also found for neighboring North Brother Island tuatara, $S$. guntheri (an island which is very similar to Stephens in habitat modification history and geographic locale). After fully exploring potential climatic influences (including long-term cyclic events), Hoare et al. (2006) found no significant correlations between climate and body condition. Although there is no source of fresh water on Stephens Island, and the animals are highly dependent upon rainfall, because rainfall levels have remained steady over time it does not appear that climate changes are responsible for the body condition decline.

A more likely hypothesis is that the decline may be a density dependent response to resource competition from a steadily increasing number of tuatara. There is anecdotal evidence of intensive collection pressure on Stephens Island tuatara in the late $19^{\text {th }}$ to early $20^{\text {th }}$ centuries. This, coupled with the clearing of over $80 \%$ of the forest for farming (likely their preferred habitat, as evidenced by the much higher densities in the forest than in cleared areas; Carmichael et al. 1989) could have caused a temporary bottleneck in this population (Brown 2000). With time, female tuatara took advantage of the clearings and moved into these areas to nest (females on forested islands nest in open areas such as cliff edges and rocky outcrops with 
temperatures appropriate to support full egg development; Nelson et al. 2004b). The resultant steady increase in nesting activity would have increased recruitment. With a population increasing and the existing adults potentially being displaced to forest remnants, where food is more abundant (Carmichael et al. 1989), food resources (including threatened invertebrates, e.g., Cook Strait giant weta, Deinacrida rugosa; Cook Strait click beetle, Amychus granulatus) may have been limited.

Tuatara, like many reptiles, may have high phenotypic plasticity (Dufty et al. 2002), allowing them to survive in conditions that other animals may not. Whereas densitydependence can cause decreased survivorship and population declines in, for instance, some mammals (Brown et al. 2001), long-lived reptiles may respond phenotypically (Sumner et al. 1999). In species of reptile that are long-lived, and have slow generation times (like tuatara) these changes may take years to manifest themselves in a population. We speculate that this population rebound is having negative morphological impacts on the individuals.

Adding further evidence to this hypothesis are the morphological responses that accompany newly translocated tuatara individuals (Nelson et al. 2002a). Animals used for translocations have been sourced from Stephens Island, or neighboring North Brother Island. In all cases where tuatara have been moved to a new island, the translocated individuals show massive weight gain even after years of stable mass on the source island (averaging 41\% mass increase for tuatara translocated from North Brother to Titi Island in 1993, Nelson et al. 2002a; N.J.N., unpublished data). This provides strong evidence for competitive release, which, in addition to the very high densities, suggests that resources are limited on source islands. However, because pre-habitat modification morphological data are lacking, this hypothesis remains speculative.

When analyzing our dataset, the significant decline was only apparent after including at least 22 years of data. Ten year datasets revealed conflicting results, and in this species, these short-term datasets are most likely only encompassing natural fluctuations that may reflect food abundance or reproductive activity (e.g., female tuatara only nest on average, once every four years (Cree et al. 1992) and if there is any nesting synchrony there may be an associated population increase following a 
productive year). Significant body condition increases in earlier decades (e.g., 1970 -1980) were apparently not sufficient to reverse the overall declining trend. The reverse may also be true for other populations or species. If a short term decline is severe enough, it may bring a population below the recovery point, thus having a major impact on the viability of that population.

Many studies are conducted within the span of a normal research grant (3-5 years), but this may only represent a minor blip on the evolutionary radar of a long-lived species (Likens 1989, Madsen and Shine 2001). Although in some cases short-term datasets are appropriate (e.g., to detect annual or seasonal fluctuations, or when declines are abrupt), it may be inappropriate to make drastic population level management decisions for long-lived species based on a five, 10 or even 15 year dataset. At least thirty years of sampling seems sufficient to reveal consistent trends in our dataset, and the results become more consistent with increasing monitoring. One anomaly, however, is the non-significant linear decline for male tuatara from 1970 - 2000. This could indicate that the decline in body condition of males in this population is stabilizing, and with current reforestation of Stephens Island, it is possible that this trend is beginning to reverse itself.

Numerous ecological studies revealing significant population trends have been based on 20 - 30 year datasets (Likens 1989). This monitoring time span seems especially effective at detecting changes in (1) long-lived species with slow rates of change (generation times and/or recruitment events; Wooller et al. 1992, Connell and Green 2000, Walther et al. 2002), (2) ecosystems subject to long-term or infrequent climatic events (Elliott et al. 1997, Visser et al. 1998, Dunn and Winkler 1999, Hughes and Connell 1999, Walther et al. 2002, Connell et al. 2004), (3) species or ecosystems that are slow to respond to disturbance (Westemeier et al. 1998, Chapman et al. 2000), and (4) newly created or restored ecosystems (Mitsch and Wilson 1996).

In addition to detecting declines, a 25 year monitoring period has been sufficient to reveal population rebounds, even in long-lived species where it had been suggested that such rebounds would not be evident for 100+ years (Chaloupka 2002). Balazs and Chaloupka (2004), Troeng and Rankin (2005), and most recently Antworth et al. (2006) have all been able to conclude with relative certainty that sea turtle nesting 
activity is increasing significantly, and that these once depleted populations are responding positively to conservation efforts that began in the 1970's. Likewise, Iverson et al. (2006) have detected a rapid recovery, from near extirpation, of Allen Cays Rock Iguana (Cyclura cychlura inornata) populations over the past 25 years, further concluding that these long-lived, insular lizards may now be nearing their carrying capacity.

In conclusion, our results, which reveal a long-term decline in morphological characteristics in spite of seasonal and annual fluctuations for the largest extant tuatara population, further emphasize the need for long-term monitoring (30+ years) when considering threatened and endangered species management of species with slow life histories. This decline may be a density dependent response to increases in tuatara numbers due to past habitat modification for this long-lived, insular species. At present, this biologically significant population is undoubtedly stable in numbers, albeit representing over half of the world's remaining tuatara. With ongoing reforestation of Stephens Island, we expect that with continued monitoring, a reversal of this decline will become evident in the future. We suggest that conservation management decisions, for this and other long-lived reptiles, should be based on the longest datasets possible, and caution should be used when prescribing conservation solutions based on short-term datasets ( $<15$ years) alone. 


\section{Large Male Advantage: Phenotypic and Genetic Correlates of Territoriality and Female Access in an Ancient Reptile (tuatara, Sphenodon punctatus)}

\subsection{Abstract}

In reptiles, phenotypic measures such as body size usually predict a male's success in territorial interactions. Recent evidence from fish, birds and mammals has shown that genetic heterozygosity can have a strong influence on competitive ability and territory quality as well. Here we provide a comprehensive assessment of the social structure and factors affecting male territory quality and aggressive behaviour in a dense population of tuatara, a long-lived reptile that maintains long-term territories, on Stephens Island, New Zealand. Male body size and individual heterozygosity significantly predicted the number of females to which a male had access, but there was no relationship between male body size and heterozygosity and only a weak relationship between male competitive ability and heterozygosity. Body size, body condition and heterozygosity did not predict core home range size. Large, more heterozygous males were more effective at 1) monopolizing areas where females were most dense and 2) guarding females by consistently winning aggressive encounters with other males. In this system, we found no spatial or social evidence for alternative male reproductive strategies. A stronger association between aggression and heterozygosity may be evident in a more inbred population. Further research is needed to understand territory establishment and assess whether female access equates to increased reproductive success in this species.

\subsection{Introduction}

Knowing the factors that affect individual success in territorial interactions is a critical first step in understanding the evolution of mating systems and reproductive strategies. Territoriality is common many reptiles (particularly lizards, reviewed in Stamps 1983), but most studies cite the distribution of ecological attributes, such as 
habitat characteristics and food quantity, as the driving force behind the observed spatial structure (Maher and Lott 2000). Food resources in many territorial reptile systems are evenly distributed, many females nest outside of breeding territories, and paternal care is absent. Territory structure and quality may depend more on the distribution of mates and competitors than on other ecological attributes (Stamps 1983). However, few studies consider the distribution of potential mates as the driving force because conspecific interactions are often difficult to observe and quantify in cryptic species (but see Mcloskey et al. 1987, Wikelski et al. 1996).

For many vertebrates, including reptiles, male phenotypic measures, such as body size or condition, predict territory size and access to females (Shine et al. 2000, Candolin and Voigt 2001, Morrison et al. 2002, Calsbeek and Sinervo 2004, Whiteman and Parker 2004, Välimäki et al. 2007). These characteristics consequently bias reproduction toward large males (Abell 1997, Lewis et al. 2000, Lebas 2001). Further, many male reptiles guard the females within their territories, or defend an exclusive area around their mate that may differ by season (Stamps 1983, Olsson et al. 1996). Where dominance hierarchies are formed, it is the smaller males that assume subordinate roles or adopt alternative reproductive strategies (e.g., 'satellites' or 'floaters', Andersson 1994, Maher and Lott 1995).

Male phenotypic measures are not the only predictors of territory quality. Genetic heterozygosity, a measure of inbreeding, affects standard fitness measures such as survival, hatching success, and disease resistance (Madsen et al. 1996, Hansson and Westerberg 2002, Keller and Waller 2002, Reed and Frankham 2003, Hansson 2004, Calleri et al. 2006). Growing evidence shows that genetic heterozygosity can also be reflected in competitive behaviour and territoriality (Höglund et al. 2002, Tiira et al. 2003, Hoffman et al. 2004, Lieutenant-Gosselin and Bernatchez 2006). Seddon et al. (2004) found that heterozygosity was the best predictor of territory quality in a group living bird (Monias benschi). Likewise, individual competitive ability is affected more by heterozygosity than body size or learning in common shrews (Sorex araneus; Välimäki et al. 2007). In many fish, birds, and mammals, acquisition of seasonal breeding territories is critical for individual survival and fitness. These examples provide strength for the argument that aggressiveness and territoriality are reliable fitness correlates, and should be honest signals of individual genetic quality. 
So, what influences individual differences in competitiveness, territoriality, and female access in reptiles that maintain long-term territories? In this study, we investigate the social structure and individual male territoriality in relation to conspecific distribution of a long-lived ( $>85$ years) reptile (tuatara, Sphenodon punctatus). Tuatara maintain stable home ranges throughout the year that vary in size depending on population density and habitat type (Gillingham et al. 1995). Although mating occurs in defended areas within male home ranges (=territories), female tuatara migrate outside home ranges to nest as temperatures in the forest are too low to support egg development (Thompson 1990). Females do not ovulate every year, and only reproduce every two to four years (Cree et al. 1992). Anecdotal evidence indicates that large male tuatara have long term territory fidelity (i.e., males that were toe-clipped 40-50 years ago have been recaptured near their original capture locations, N. Nelson, pers. obs., Dawbin 1949, Dawbin 1962). Previous chance observations of tuatara mating suggest that reproduction is dominated by large males (Gillingham and Miller 1991, Cree et al. 1992), although small males have the physiological capacity to mate (Cree et al. 1992). Here we aim to 1) understand the role of conspecific (inter- and intrasexual) interactions in overall territoriality and social structure, and 2) investigate the phenotypic and genetic traits that affect male aggressiveness and physical access to females.

Because the social structure and the extent of territoriality may depend on population density and the local adult sex ratio (Emlen and Oring 1977), we first quantify these population parameters. Our study site, Stephens Island, New Zealand, holds over half of extant tuatara (the largest and most dense population by orders of magnitude, Gaze 2001). Theory predicts that at extremely high population densities, the energetic costs of site defence outweigh the reproductive benefits associated with territoriality (Brown 1969, Emlen and Oring 1977). Thus, alternative mating strategies should evolve to maximize reproductive success of small or subordinate males (Maher and Lott 2000), and if present, alternative strategies should be evident in the spatial patterns of males.

\subsection{Methods}




\subsubsection{Study animals and study site}

Tuatara represent an ancient order of reptiles, the Sphenodontia (Benton 2000). Endemic to the main and outlying islands of New Zealand, they are now restricted to approximately 30 small, offshore islands due to predation by introduced mammals (Gaze 2001). The mating season of tuatara peaks in March (austral summer) and nesting occurs approximately $8-10$ months later (Cree et al. 1992). On average, females reproduce once every four years (Cree et al. 1992), while adult males are capable of reproducing every year. Tuatara occupy burrows that can be shared with other individuals and/or nesting seabirds, and underground burrow systems are dynamic and can be extensive (Newman 1987).

Stephens Island (known also by its Māori name, Takapourewa; Marlborough Sounds, $40^{\circ} 40^{\prime} S, 174^{\circ} 00^{\prime} \mathrm{E}$ ) has a total area of 150 ha, supports a lighthouse, and has a history of intensive habitat modification. Although coastal forest would have covered most of the island before the arrival of humans, currently two habitat types dominate; regenerating coastal forest and grassland pastures (which were originally cleared for farming and livestock grazing in the early 1900s; Brown 2000). We estimate population densities for both habitat types, but focus the behavioural and genetic components of this study on the forest tuatara as this represents a more natural state.

\subsubsection{Density and sex ratio estimation}

From 8 - 16 March 2003, two survey areas in the pastures (3470 and $4005 \mathrm{~m}^{2}$ ) and four accessible survey strips (tracks with $3 \mathrm{~m}$ borders on either side, from 107 - 443 $\mathrm{m}^{2}$ ) in a section of remnant forest (Keeper's Bush) were surveyed using capturemark-recapture methods (Table 1). Areas were systematically surveyed each night and all tuatara were captured by hand. Individual capture locations were recorded, the capture site marked, and all individuals returned to the capture location. Sex of adults was determined by sexually dimorphic characters (e.g., larger head and spines of males vs. smaller spines and pear shaped abdomen of females; Cree et al. 1991a). 


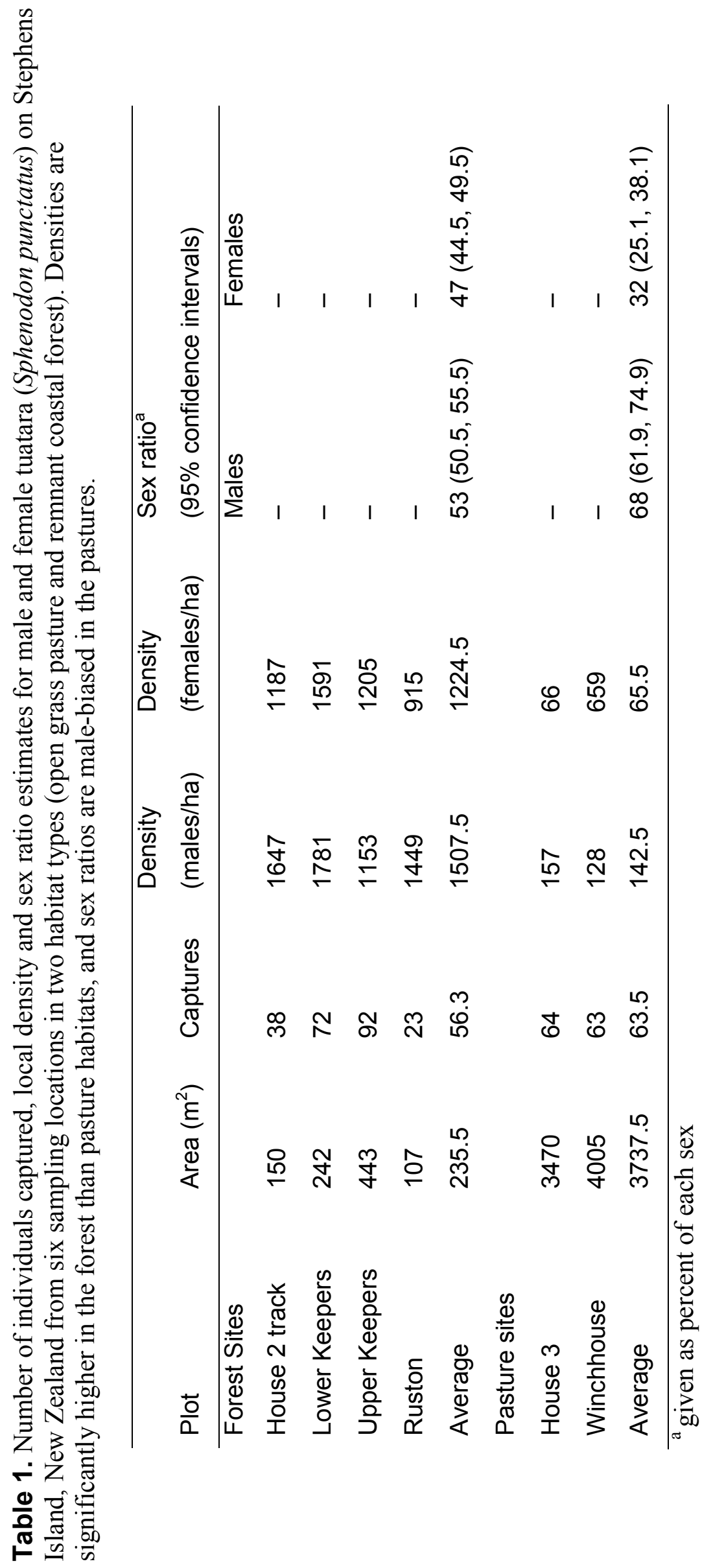


Each animal was marked with a unique number written on their sides (with a nontoxic marker) that was legible throughout the duration of the trip.

Capture data for adults were analyzed using closed population models in the program MARK (v3.0 (Win32) Sep 2002; White and Burnham 1999). Juveniles were excluded from analyses as only 10 individuals were captured in the pastures and none were recaptured. Data were grouped according to the following parameters: habitat (forest, pasture), plot (four forest and two pasture), sex (male, female), and combinations of sex and habitat, and sex and plot, over eight capture occasions (a time model), with allowance for variation in population number. Other models available in MARK, for example open population models, or those allowing for behaviour (when previous capture affects subsequent capture probability) and heterogeneity (individual variation in capture probabilities), may have provided a better fit but could not provide estimates of population number due to small sample sizes (e.g., Nelson et al. 2002b). The small sample version of Akaike's Information Criterion ( $\mathrm{AIC}_{\mathrm{c}}$; Burnham and Anderson 1998) was used to assess the fit of models. Estimates of population size, including 95\% confidence intervals, are presented using the model with the best fit for our data that allowed for capture probabilities to vary with capture occasion and habitat, and by sex within the pasture habitat $\left(\mathrm{AIC}_{\mathrm{c}}\right.$ four points greater than the next model; $K=36$ ). Sex ratios were estimated for each plot using population estimates from the MARK analysis, and are reported with upper and lower $95 \%$ confidence intervals.

\subsubsection{Spatial structure}

\subsubsection{Field data collection}

In November 2004, three circular study plots (from $314-615 \mathrm{~m}^{2}$ ) were randomly located from an accessible track running through Keeper's Bush. Plot centres were marked with a GPS and post-processed to increase accuracy. All tuatara in the study plots were captured by hand, and location, snout-vent length (SVL, mm), mass (g), and sex were recorded. A blood sample $(0.5-1.0 \mathrm{ml})$ was drawn from the caudal vein/artery and stored in 95\% ethanol. A passive integrated transponder (PIT) tag (11mm length x 2mm width, AVID Identification Systems, Inc., Norco, CA, USA) 
was inserted subcutaneously just anterior to the left rear leg for individual identification. A subset $(\mathrm{n}=100)$ of these animals were marked using a unique colour bead tag inserted through the nuchal crests (Fisher and Muth 1989) to enable individual recognition from a distance. Predation on tuatara in the forest on Stephens Island is extremely low. Thus, there was little potential for increased predation of bead tagged animals. There were no apparent long-term effects of bleeding, PIT tagging, or bead tagging and animals were inspected during recaptures to ensure proper healing. Tuatara that were not bead tagged were recaptured prior to the mating season and marked by writing a unique number on their sides with a nontoxic marker, or were recognized by individual idiosyncrasies in tail, head or spine morphology.

Spatial and behavioural data were collected during two mating seasons ( $28 \mathrm{Feb}-28$ March 2006, and 27 Feb - 27 March 2007) and one nesting season (16 - 28 November, 2005). Study plots were surveyed twice daily and locations of all visible animals were recorded (as a distance and azimuth from plot centres). Mating partners of individuals in the study plots were also known from a concurrent study of the mating system. All aggressive interactions between marked males were recorded. 'Losers' were defined as males that were chased, bitten, or interrupted in the middle of courtship, and fled $>1 \mathrm{~m}$ from the 'winner', subsequently adopting a submissive posture or running down a burrow. All animals were re-weighed and measured following each monitoring period. We did not perform focal animal observations because tuatara spend the majority of the day sitting motionless (Saint Girons et al. 1980), so infrequent activity would have gone undetected using this method.

\subsubsection{Core home range estimation}

Tuatara locations were entered into a geographic information system (GIS). Because agonistic encounters between males only occur infrequently (J. Moore, per. obs.), specific territory boundaries were not always clearly definable. Thus, in this study, we use the term 'core home range' which we defined as 95\% minimum convex polygons (MCPs). These areas include defended areas (when male-male agonistic encounters were observed) and exclude foraging excursions (that occur at night) and nesting migrations (Burt 1943, Brown and Orians 1970). MCPs were estimated using 
Home Range Tools (Rogers et al. 2005) and Hawth's tools (Beyer 2004) in ArcGIS 9.1 (ESRI, Redlands, California). We chose not to implement commonly used kernel density estimators because they are known to be problematic for herpetofauna (Row and Blouin-Demers 2006). Core home ranges were estimated for each individual, using 1) all locations (2005 - 2007 inclusive), 2) only locations from 2006, and 3) only locations from 2007, with the latter two representing consecutive mating seasons (i.e., seasonal ranges). An asymptote analysis (ABODE extension, Laver 2005 ) found that at least 20 relocations were necessary to accurately estimate core range size, thus we only included animals with $\geq 20$ relocations in analyses.

We calculated the percent male-male core home range overlap, and for each male, we summed the percent core home range overlap of all other males to determine cumulative percent overlap (as some males overlapped multiple males). We also calculated the percent core home range overlap for male-female pairs, and summed the number of females that each male's core home range overlapped (= female access).

\subsubsection{Activity centres}

Using point data, activity centres (highest use areas within territories, as defined by Hayne 1949) were determined for all individuals using the mean centre tool in ArcGIS 9.1. Using activity centres, we calculated average nearest neighbour statistics for males and females to assess the extent of territoriality. Nearest neighbour indices show whether significant clustering or dispersion exists by comparing the observed spatial distribution to a random expected distribution. Activity centres should be significantly dispersed in highly territorial systems (Brown and Orians 1970).

\subsubsection{Genetic analyses}

DNA extraction and PCR amplification of polymorphic microsatellites for all marked tuatara followed Moore et al. (2008b) and Hay and Lambert (2008). Eight tuatara-specific loci $(C 2 F, C 11 P, E 11 N, H 5 H, B 8 P, A 12 N, C 12 F, H 4 H$, Aitken et al. 2001, Hay and Lambert 2008) were amplified. Common measures used to determine 
individual heterozygosity include 1) mean $d^{2}$, a measure reflecting the evolutionary similarity of alleles (Coulson et al. 1998), 2) standardized heterozygosity (SH), that allows for incomplete genotyping (Coltman et al. 1998), and 3) internal relatedness (IR), that weights allele sharing by the frequencies of the alleles involved (Amos et al. 2001). We calculated IR for each individual using an Excel macro (available at http://www.zoo.cam.ac.uk/zoostaff/amos/\#ComputerPrograms, Amos et al. 2001).

\subsubsection{Statistical analyses}

Intersexual differences in mean core home range sizes were compared with analyses of variance (ANOVAs). To test whether large males are more effective at maintaining exclusive core home ranges, we compared the cumulative percent core home range overlap to male SVL using a Pearson's correlation. If mate guarding occurs via spatial proximity, within a season, we expect that a male will overlap a greater proportion of his mate's core home range than the average female. Thus, we compared the mean percent overlap of mates to non-mated male-female pairs using an ANOVA.

We used a general linear model (glm) to test the effects of male SVL, body condition (defined as the residual values from a linear regression of log mass over log SVL), IR, and core home range size on female access (response variable). A glm was also used to model the effects of SVL, body condition, and IR on core home range size (response variable). We also explored the relationship between IR and SVL using a correlation test. Lastly, we used a multinomial logistic regression to test the effects of SVL, body condition, and IR on percent wins (number of wins in male-male encounters/total number of encounters). Models were evaluated based on their AIC values, were rescaled to the lowest model ( $\triangle \mathrm{AIC})$ and Akaike weights $\left(w_{i}\right)$ were calculated to assess the proportion of variance explained by each model in the set (Burnham and Anderson 2004). ANOVAs were used to assess the significance of each variable in the top models.

Statistical analyses that were not performed in ArcGIS 9.1 or MARK (as described above) were carried out in R (R Core Development Team 2006). Means are reported as \pm 1 standard error (SE) and statistical significance is inferred at $\mathrm{p}<0.05$. All 
statistical tests were two-tailed and datasets satisfied the assumptions of normality and homogeneity of variances or were appropriately transformed.

\subsection{Results}

\subsubsection{Density and sex ratio}

In total, 352 adult tuatara was captured in the mark-recapture survey, including 138 females and 214 males (Table 1). Almost twice as many tuatara were captured in the forest $(\mathrm{N}=225)$ than in the pastures $(\mathrm{N}=127)$. Density estimates were significantly higher for the forest $($ mean $=2732$ tuatara $/$ ha) than the pastures $($ mean $=208$ tuatara / ha) (Table 1). Sex ratio estimates were approximately $1 \mathrm{M}: 1 \mathrm{~F}$ in the forest, whereas in the pastures they were approximately $2 \mathrm{M}: 1 \mathrm{~F}$ (Table 1).

\subsubsection{Social structure and female access}

From November 2005 to March 2007 we recorded 1,711 locations from 89 marked tuatara (40 females, 49 males) in the three study plots on Stephens Island. The average number of relocations was 22.7 (range $=1-67$ ) per male, and 16.1 (range = $1-56)$ per female. Male core home ranges $\left(95 \% \mathrm{MCP}\right.$ area $\left.=30.6 \pm 3.9 \mathrm{~m}^{2}\right)$ were significantly larger than female core home ranges $\left(95 \% \mathrm{MCP}\right.$ area $=13.9 \pm 2.8 \mathrm{~m}^{2}$; $\left.\mathrm{F}_{1,33}=9.9, \mathrm{p}<0.01\right)$. On average, male core home ranges overlapped $3.9 \pm 0.6$ females (range $=0-7$ ), while female core home ranges overlapped $1.8 \pm 0.2$ males (range $=0-6)$.

Of male-female pairs that overlapped, male core home ranges overlapped $44.0 \pm 3.8$ $\%$ of the female's core home range (range $=1.2-100 \%$ ). Within a season, mated males overlapped a significantly greater proportion of their mate's core home ranges than the average unmated pair (mated pairs $=76.5 \pm 7.1 \%$ female overlap vs. unmated pairs $=38.3 \pm 3.9 \%$ female overlap; $\left.F_{1,73}=14.7, p<0.001\right)$. In 2006, $29.6 \%$ of males maintained core home ranges completely exclusive of other males, and in $2007,8.0 \%$ of males had exclusive core home ranges. On average, male core home ranges overlapped by $24.9 \pm 4.2 \%(n=38)$ (Fig 1$)$. Controlling for home range size, there was a significant inverse relationship between male SVL and 

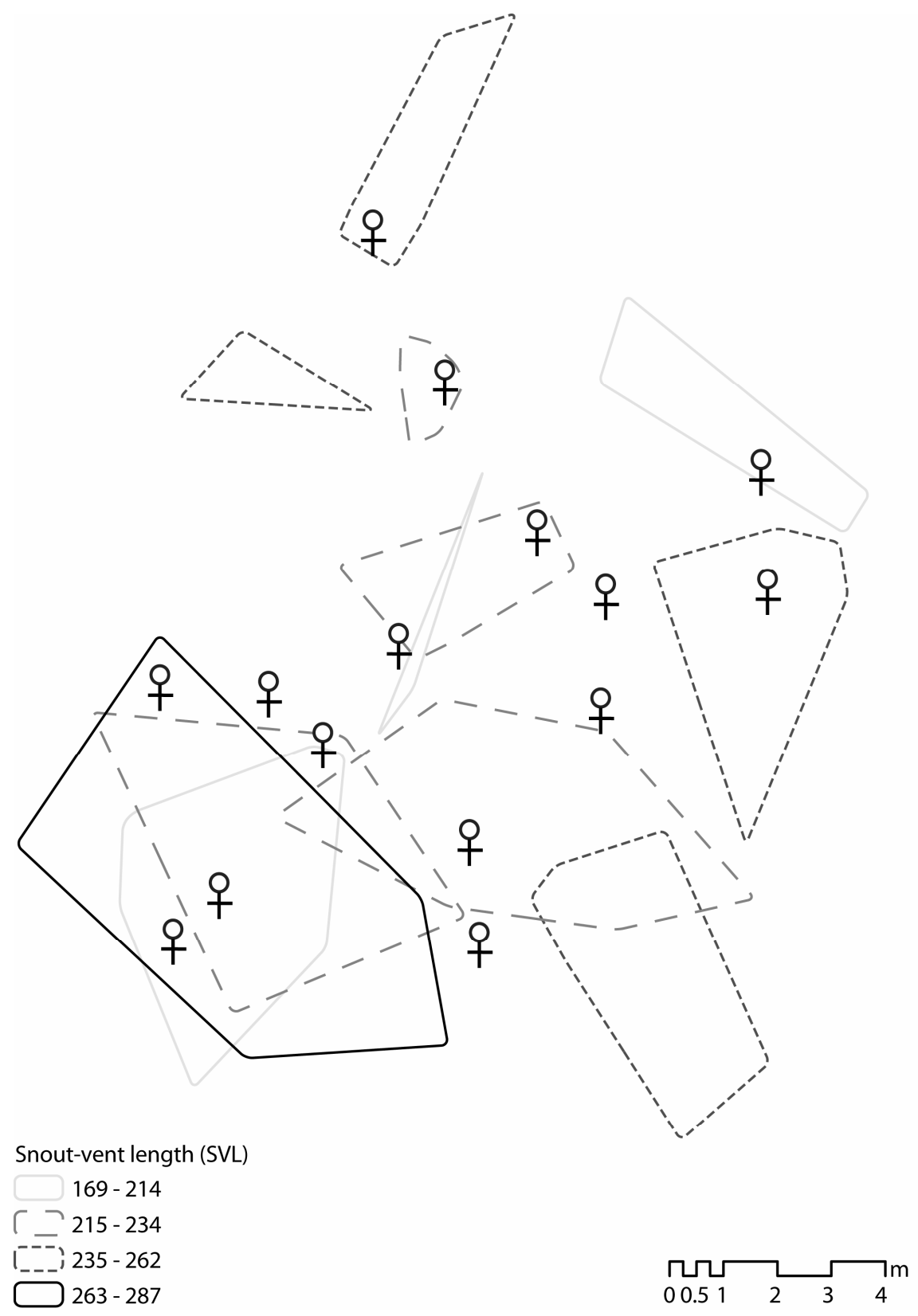

Figure 1. Core home ranges of all male tuatara (categorized by snout-vent length, SVL) in one study plot from one mating season (March 2006) on Stephens Island. Female symbols represent activity centres of females. 
cumulative percent overlap by other males $(\mathrm{r}=-0.36, \mathrm{p}=0.017)$, indicating that body size increases a male's ability to maintain an exclusive core home range.

The top model predicting female access included male SVL, IR and core home range size (Table 2), with the second best model including only SVL and IR. Only SVL (F $=8.51, \mathrm{p}=0.02)$ and $\mathrm{IR}(\mathrm{F}=6.73, \mathrm{p}=0.03)$ were significant in the top model. Thus, larger, more heterozygous males with slightly larger core home ranges had greater access to females (Figure 2). There was no relationship between core home range size and any of our explanatory variables as the top models were not different from the null model (with no explanatory variables). We found no significant correlation between male SVL and IR $(n=20, R=0.32, p=0.16)$.

\subsubsection{Activity centres / spatial proximity}

Spatial distribution was significantly structured for males, but not females. We were only able to calculate nearest neighbour statistics for plots one and three because we were lacking sufficient data for some animals in plot two. Male activity centres were significantly structured in both plots in both years, with the exception of plot three in 2007 (Table 3). Conversely, female activity centres were not significantly dispersed or clustered (Table 3).

\subsubsection{Male-male agonistic interactions}

We recorded 28 agonistic interactions involving 22 marked males. The number of contests per male ranged from $0-9$, and $100 \%$ of contests (that were not 'draws', $\mathrm{n}$ =1) were won by the larger of the two males (Figure 3). Approximately $18 \%$ of contests were the result of larger males interrupting courtships. The top model predicting percent wins in male-male agonistic interactions included SVL (AIC = $\left.31.0, w_{i}=0.59\right)$ and the second best model included SVL and IR (AIC $=32.1, w_{i}=$ 0.34 ) (Table 2). 
Table 2. Results from general linear models of male tuatara variables including female access, core home range size, and percent wins in male-male agonistic encounters. The best models have $\Delta \mathrm{AIC}=0.00$. Explanatory variables include snout-vent length (svl), internal relatedness (ir), core home range size (CHR) and body condition (bc). K is the number of parameters in the models, $\triangle \mathrm{AIC}$ is the re-scaled AIC values, and $w_{i}$ is the Akaike weights, or the proportion of variance in the response that is explained by each model in the set.

\begin{tabular}{|c|c|c|c|}
\hline \multicolumn{4}{|c|}{ Response variable $=$ female overlap, $n=22$} \\
\hline Models & $\mathrm{k}$ & $\triangle \mathrm{AIC}$ & $w_{i}$ \\
\hline$s v l+i r+C H R$ & 4 & 0.00 & 0.41 \\
\hline$s v l+i r$ & 3 & 0.55 & 0.31 \\
\hline$s v l+b c+i r+C H R$ & 5 & 1.13 & 0.23 \\
\hline svl & 2 & 4.78 & 0.04 \\
\hline \multicolumn{4}{|c|}{ Response variable $=$ male $\mathrm{CHR}$ size, $\mathrm{n}=22$} \\
\hline Models & $\mathrm{k}$ & $\triangle \mathrm{AIC}$ & $w_{i}$ \\
\hline ir & 2 & 0.00 & 0.27 \\
\hline svl & 2 & 0.10 & 0.26 \\
\hline null & 1 & 0.27 & 0.24 \\
\hline$s v l+i r$ & 3 & 0.99 & 0.16 \\
\hline \multicolumn{4}{|c|}{ Response variable $=$ percent wins, $n=21$} \\
\hline Models & $\mathrm{k}$ & $\triangle \mathrm{AIC}$ & $w_{i}$ \\
\hline$s v l$ & 2 & 0.00 & 0.59 \\
\hline$s v l+i r$ & 3 & 1.11 & 0.34 \\
\hline$s v l+b c+i r$ & 4 & 4.44 & 0.06 \\
\hline
\end{tabular}




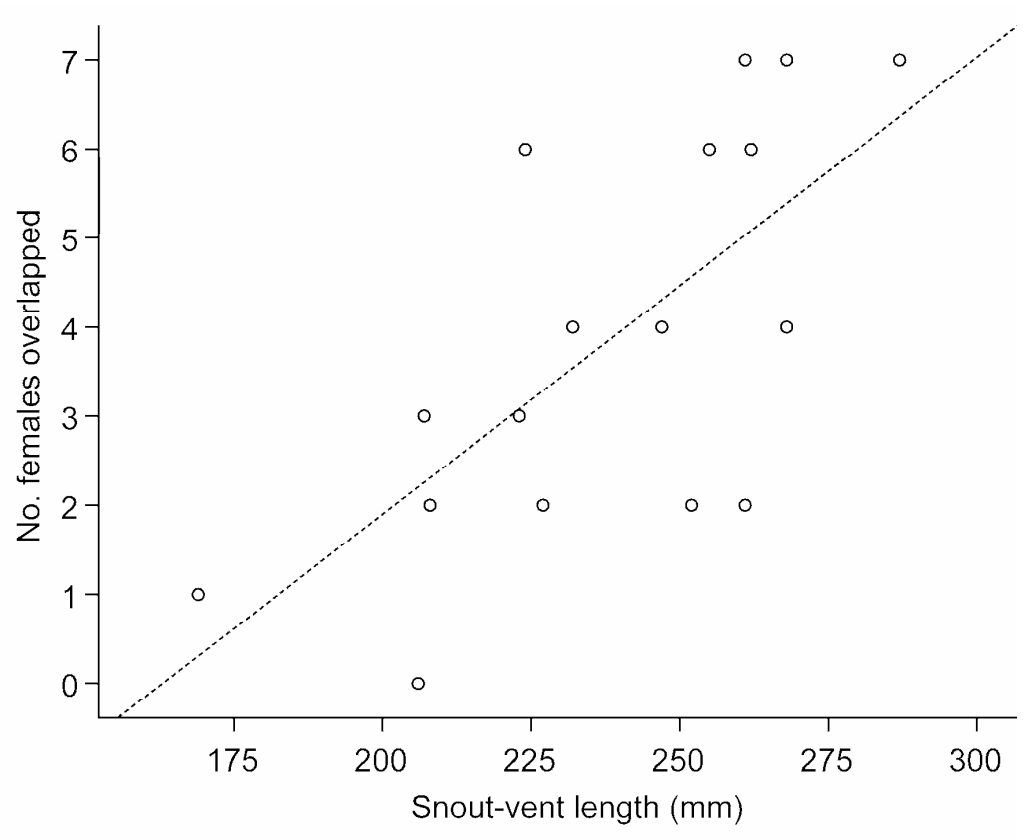

Figure 2. Body size of male tuatara predicts access to females, as represented by the significant linear regression of male body size (snoutvent length, SVL) over the number of females each male's core home range overlaps.

Table 3. Results of the nearest neighbour test for complete spatial randomness of tuatara activity centres on Stephens Island by sex, including year and study plot. Z scores are measures of standard deviations from a randomly distributed spatial pattern. Significant structuring of male tuatara activity centres, and not female activity centres, indicate that males are significantly more territorial than females. Mean nearest neighbour distance (NND) is the mean observed distance (in metres) between activity centres. A nearest neighbour ratio (NNR) above one indicates dispersion, while a NNR below one indicates clumping. significant dispersion at $\mathrm{p}<0.01$.

\begin{tabular}{lllll}
\hline Sex & Year (study plot) & Mean NND & NNR & $Z$ \\
\hline Males & & & & \\
& $2006(1)$ & 2.03 & 1.53 & $3.83^{*}$ \\
& $2006(3)$ & 2.27 & 1.45 & $3.40^{*}$ \\
& $2007(1)$ & 3.50 & 1.44 & $3.39^{*}$ \\
& $2007(3)$ & 1.66 & 1.15 & 1.04 \\
Females & & & & \\
& $2006(1)$ & 2.16 & 1.24 & 1.91 \\
& $2006(3)$ & 1.94 & 1.25 & 1.85 \\
& $2007(1)$ & 3.62 & 1.06 & 0.35 \\
& $2007(3)$ & 2.41 & 1.23 & 1.78 \\
\hline
\end{tabular}




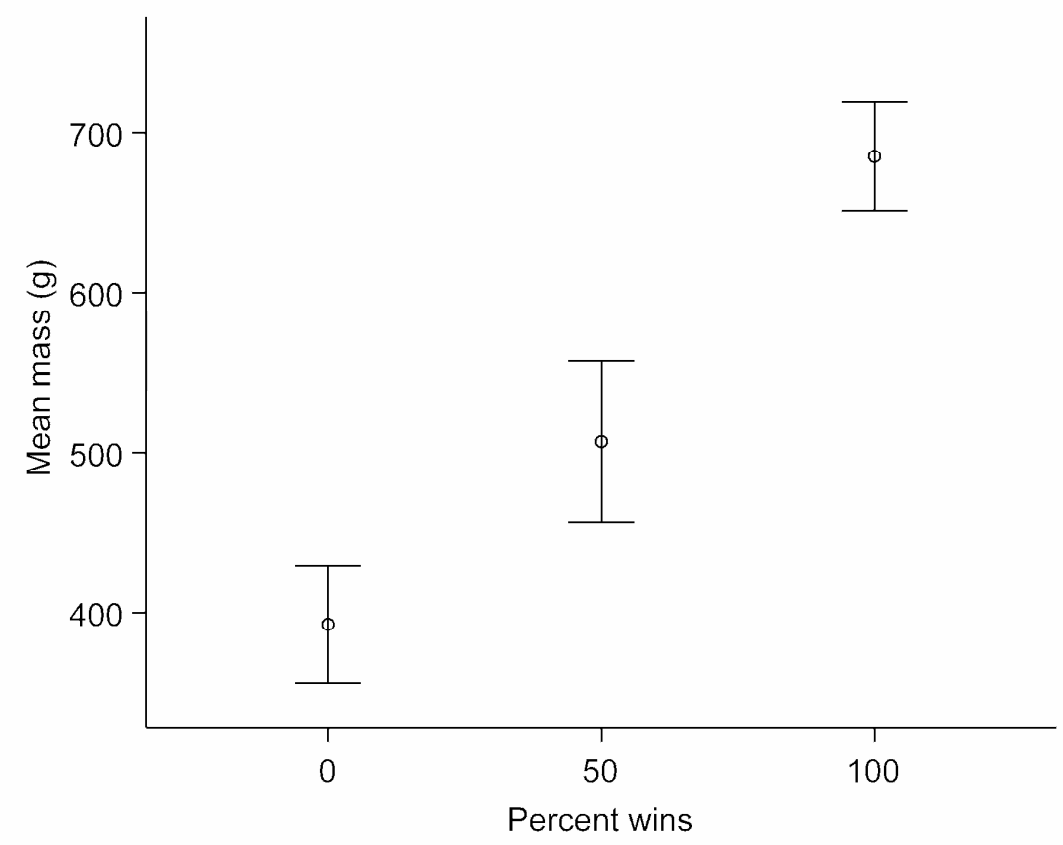

Figure 3. Mean mass of male tuatara $( \pm 1 \mathrm{SE})$ and the percent of wins in male-male contests (as a function of total male-male contests per male) indicate that larger males are more likely to win agonistic encounters.

\subsection{Discussion}

To our knowledge, our results provide the first comprehensive assessment of genetic and morphological traits affecting individual social structure and competitiveness in a wild reptile population. In this very dense population $(<2,700$ tuatara / ha), tuatara home ranges are small and inter- and intrasexual overlap is common. Large, more heterozygous males have greater access to females, and are more successful in intrasexual interactions, although there was no relationship between body size and heterozygosity. Male core home range sizes, although highly variable, are not dependent on body size, and large home range size does not increase access to females. However, large body size does confer definite advantages in terms of exclusive access to potential mates. Large males are able to monopolize areas where females are most dense, which is facilitated by the uneven dispersion of females. Large males are not only able to secure territories with a greater number of females overlapping, but they are also better able to maintain those territories and guard 
mates by consistently outcompeting smaller males. The phenomenon of large male advantage is common among many taxa, so this result is not surprising.

More surprising is the weak relationship between female access and male heterozygosity. Although body size explains the majority of variation in female access, internal relatedness was included in the top three models. Based on this result, we would have also expected to find a relationship between male heterozygosity and a phenotypic measure like body size or competitive ability. While we did not find a relationship between internal relatedness and male body size, the second best model predicting the results of male-male aggressive interactions did include internal relatedness. Thus, increased heterozygosity may slightly improve a male's competitive ability, and with larger sample sizes (Coltman and Slate 2003), this relationship may have been stronger. Aggressive encounters are energetically costly for tuatara, and reptiles in general. Thus, a male may be more prone to engage in male-male combat if he is more heterozygous and thus more fit and vigorous (e.g., for salmon, Salmo salar, Tiira et al. 2003). Also, we currently know very little about territory establishment and the potential role of female choice. Females may be establishing themselves near heterozygous males, and assessing them based on a fitness-related trait that we did not measure (e.g., head size, Lappin and Husak 2005; parasite resistance, Folstad and Karter 1992). The ability to detect heterozygosityfitness correlations depends strongly on the underlying genetic background of the population (Slate et al. 2004). Stephens Island has a very high level of genetic diversity (MacAvoy et al. 2007), so genetic effects may be more evident in inbred populations (Tiira et al. 2006).

Population density on Stephens Island $(\sim 2,700$ individuals / ha) is extreme for tuatara populations, and is high for insular populations of reptiles in general (which average $1920 \pm 574$ individuals / ha, Buckley and Jetz 2007), especially considering the moderate size of tuatara. The social structure of tuatara may be radically different on less dense islands. Gillingham et al. (1995) found that home range sizes in the considerably less dense pastures ( 200 individuals / ha) on Stephens Island are 3-4 times larger than in the forests. Therefore, spatial patterns on less dense islands could follow a similar pattern, with male home ranges overlapping little. Although 
logistically challenging, comparable research on less dense islands would help to elucidate these patterns.

Although Stephens Island represents a highly dense population, our spatial data provide little concrete evidence for alternative reproductive strategies (e.g., 'floaters' or 'satellites', roving males with inflated, non-defended home ranges that overlap multiple territories, Brown 1969, Maher and Lott 1995). However, it appears that dominance hierarchies may form where male core home ranges overlap extensively (e.g., lower left corner of Fig. 1). Dominant males are always considerably larger than subordinates, which are restricted from mating by aggressive encounters with larger males. It may prove advantageous for a smaller, subordinate male to associate with a larger, dominant male (similar to the "hotshot" phenomenon of lekking marine iguanas, Amblyrhynchus cristatus; Wikelski et al. 1996, Partecke et al. 2002), as he could potentially sneak matings while the larger male is otherwise occupied, or overtake the territory once he reaches an appropriate size.

Home range size generally increases with body size among species from many taxa, including lizards (Perry and Garland 2002). When comparing tuatara home ranges to ecologically similar lizard species (representing four families) with similar body sizes (drawn from Perry and Garland 2002, who reviewed home ranges of 222 lizard species), tuatara core home ranges fall well below the regression lines for lizards and are at least an order of magnitude smaller than the lizard home ranges (see Fig. 4). Why do tuatara have such small home ranges compared to other similar sized reptiles? While home range sizes can reflect phylogenetic differences, it is more likely that the small core home ranges of tuatara reflect their energetics, resource availability and population density. Tuatara are cold-adapted and have very low activity levels and energetic requirements (Saint Girons et al. 1980). Furthermore, nutrient input from extremely high seabird densities on Stephens Island increases primary productivity and has flow-through effects to invertebrate herbivores (i.e., tuatara prey; Mulder and Keall 2001). Population density can also affect home range or territory size within a species (e.g., Kwiatkowski and Sullivan 2002). On Stephens Island, tuatara appear to be able to acquire all necessary metabolic and reproductive 


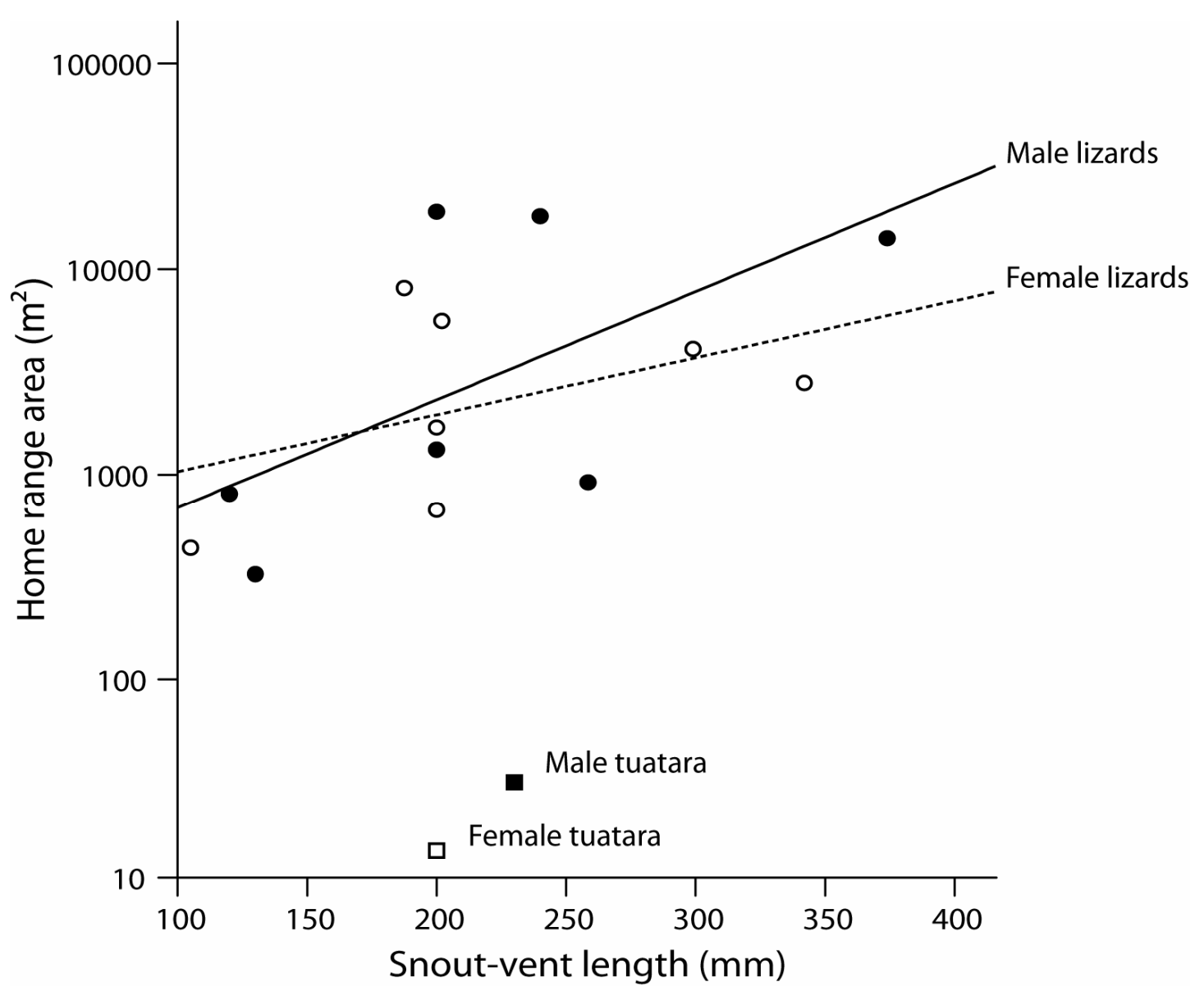

Figure 4. Home range area as a function of snout-vent length (SVL) for lizard species $(\mathrm{n}=7$, males $=$ closed circles, females $=$ open circles) with body sizes similar to tuatara (Sphenodon punctatus). Male and female tuatara fall well below the regression lines for male $\left(\mathrm{r}^{2}=\right.$ $0.37)$ and female $\left(r^{2}=0.21\right)$ lizard home range area versus SVL. Note log scale for home range area. Lizard home range and body size data drawn from appendix A in Perry and Garland 2002. Lizard species and original data sources include; Anolis cuvieri, A. frenatus, Schoener and Schoener 1982; Chlamydosaurus kingii, Griffiths 1999; Cyclura carinata, Iverson 1979; Iguana iguana, Rand et al. 1989; Lacerta lepida, Castilla 1989; Sauromalus obesus, Johnson 1965.

resources in an unpredictably small space; a size that is contrary to patterns seen in lizards, yet consistent with a highly dense population of a cold-adapted reptile with low energetic requirements and/or high nutrient availability.

By investigating the social structure of these ancient reptiles, our findings shed new light on patterns of territoriality and aggression in vertebrates. Body size had the strongest effect on female access and competitive ability, although there was a weak effect of individual heterozygosity. We suspect that future research may reveal similar patterns in genetically diverse, large, outbred populations of other territorial 
taxa. Genetic effects may also be more apparent in short-lived species (that only experience one or two breeding seasons in a lifetime), where the variance in male body size is small and traits affecting competitive ability are tightly linked to individual heterozygosity. In this dense, territorial system, intrasexual competition and female access are highly skewed toward large, heterozygous males. Future research should address whether heterozygosity and female access actually equates to realised increases in reproductive success, and whether female choice plays a role in territory establishment. 


\section{High Reproductive Skew, Size-Assortative Mating, and Seasonal Monogamy in a Territorial Reptile (tuatara)}

\subsection{Abstract}

Variation in traits that affect success in competition and mate choice often equates to high variance in reproductive success. Reproductive skew (the extent to which breeding is monopolized by dominant individuals) can be high in reptiles, often resulting in polygynous systems dominated by large males. Here, we use behavioral data and genetic paternity analyses to characterize the poorly known mating system of a long-lived, archaic reptile (tuatara, Sphenodon punctatus) at high and low densities (on Stephens Island, New Zealand). We further investigate the phenotypic traits (including body size, body condition, tail length, and ectoparasite load) that affect male reproductive success. Our behavioral data reflect a seasonally monogamous system with low levels of polyandry and polygyny that are consistent with a male mate guarding hypothesis. Male reproduction is highly skewed (only 25$30 \%$ of males are successful), and body size was the primary predictor of male reproductive success. We found weak positive size-assortative mating at high densities, but not at low densities where small males were more likely to be successful. This is indicative of a male preference for large females that breaks down when intrasexual competition is reduced. Although our sample sizes were small, we did not find multiple paternity in any clutch, including that of a polyandrous female. This warrants further investigation into the mechanisms underlying tuatara fertilization and the frequency of genetic polyandry in the wild.

\subsection{Introduction}

Sexual selection (Darwin 1871) is still unequivocally acknowledged as one of the most powerful evolutionary forces shaping populations and species. A complex reciprocal relationship exists between sexually selected traits and mating system 
evolution, so understanding one should shed light on the other (Andersson 1994). Considerable variation in traits that improve success in intrasexual contests and/or mate attraction equates to high variance in male mating success and high reproductive skew in a population (i.e., only a small proportion of males dominate mating, Keller and Reeve 1994, Johnstone 2000). In species where fights over mates are frequent, selection often favors strength, which can be attained with large body size or weaponry (Clutton-Brock et al. 1979, Hews 1990). Few reptiles have exaggerated weaponry or ornaments, so body size is often cited as the sole predictor of male mating success (reviewed in Olsson and Madsen 1998) because it not only improves competitive ability, but should be an honest signal of a male's quality (Cooper and Vitt 1993, Abell 1997, Shine et al. 2000, Calsbeek and Sinervo 2004).

Two major routes exist for males to increase their fitness under strong sexual selection. First, a male can increase the number of mates he secures, which depends on mate handling time and his investment in each reproductive event (Moller 1998). Male investment is small in reptiles, as male parental care is virtually non-existent (Shine 1988), thus many reptile mating systems are characterized as polygynous with high reproductive skew. The second way that a male can increase his fitness is by increasing fecundity per mate. Fecundity is generally correlated with body size in female reptiles, which can result in a male preference for larger females (Cooper and Vitt 1997, Cuadrado 1998). Taken together, increased competitive ability of large males and a preference for larger females can result in positive size-assortative mating. This form of non-random mating depends on a number of factors, including population density and the operational sex ratio, and can be highly variable among populations of a species (e.g., Otronen 1993).

In territorial tuatara (Sphenodon punctatus), there is opportunity for strong sexual selection by choice and competition. Tuatara are sexually dimorphic; adult males are considerably larger than females. Male-male contests are common, including sexual interference in the form of courtship interruptions. In reptiles, fights often result in physical damage including tail loss (via autotomy) that can be extremely costly both energetically and socially (Dial and Fitzpatrick 1981, Martin and Salvador 1993, Martin 1996, Chapple and Swain 2002). Adult male size in tuatara is highly variable, and female fecundity increases with body size (Newman et al. 1994). Female tuatara 
often reject courtship attempts by males (J. Moore, pers. obs.), although it is unknown whether this is due to receptivity or female choice. Polyandry and multiple paternity have been confirmed in a captive population (Moore et al. 2008b, Chapter Five) but have yet to be found in wild tuatara (Hay and Lambert 2008).

Here we characterize the mating system and reproductive skew in a natural population of tuatara, and investigate the phenotypic factors affecting male mating success. Stephens Island is a 150 ha island composed of two distinct habitat types with markedly different densities of tuatara: remnant native coastal forest $(\sim 2500$ tuatara / ha) and grassland pasture ( 200 tuatara / ha, Moore et al. in review, Chapter Three) that was cleared in the early 1900's for grazing livestock. Population density affects many aspects of mating systems (Kokko and Rankin 2006). Additionally, the operational sex ratio may be highly skewed toward males because female tuatara average reproduction every four years (Cree et al. 1992), while males are capable of annual reproduction. Thus, this system presents an excellent opportunity to evaluate the effects of density and intense competition on the natural mating patterns of these long-lived reptiles. Furthermore, because of the high population density and visually unobstructed habitat, Stephens Island is ideal for conducting behavioral studies. Specifically, we (1) document the extent of polyandry, polygyny and reproductive skew, (2) determine what phenotypic traits (body size, tail length, body condition and ectoparasite load) affect male mating success, and (3) assess whether sizeassortative mating occurs and if it is density-dependent. We also provide preliminary data on genetic paternity to determine how reliable mating observations are as a proxy for realized reproductive success and whether multiple paternity exists in the wild.

We predict a high variance in male reproductive success that is biased toward males with traits that are indicative of high quality (e.g., large body size or long/complete tails). The spatial structure of tuatara on Stephens Island reflects a seasonally monogamous system, as male home ranges only overlap an average of four females, not all of which are receptive in a season (Moore et al. in review, Chapter Three). If males can only economically monopolize one mate per season, size-assortative mating could result because larger males succeed in mating with larger (i.e., more fecund) females. Furthermore, according to the armament-ornament model, females 
benefit from choosing mates based on the same traits that are selected for via malemale competition (Mateos and Carranza 1999) which could further this effect.

Testing for female choice in tuatara requires challenging behavioral experiments and an underlying knowledge of the mating system and sexual selection in this species. Thus, in this study we focus on the male perspective and lay the groundwork for future studies which could differentiate between male-male competition and female choice.

\subsection{Methods}

Tuatara are medium-sized, long-lived (80+ years, N. Nelson, pers. comm.) reptiles that are the sole representatives of the ancient reptilian order Sphenodontia. The tuatara mating season peaks in March (austral summer) and nesting occurs $8-10$ months later (Cree et al. 1992). Mating is a long process (taking anywhere from $60-$ 90 mins, J. Moore, unpubl. data) that involves a lengthy, conspicuous courtship followed by copulation (via cloacal apposition, as tuatara lack an intromittent organ), with males remaining mounted on top of females, shuddering periodically, for up to an hour until the female moves away (Gillingham et al. 1995). Tuatara occupy home ranges/territories year-round, except when females migrate to nesting rookeries. Territory size is not related to male body size or the number of females a male has access to (Moore et al. in review, Chapter Three). Large males dominate areas where females are most dense, and the spatial structure provides no evidence for alternative reproductive strategies (Moore et al. in review, Chapter Three).

\subsubsection{Focal animal marking}

In November 2004, three circular study plots (from $314-615 \mathrm{~m}^{2}$ ) were located from an accessible track running through a section of remnant forest on Stephens Island. All tuatara in the study plots were captured by hand for marking and measuring, and capture location, snout-vent length (SVL), tail length (VT), regenerated tail length (R), mass, and sex were recorded. Blood samples $(0.1-1.0 \mathrm{ml})$ were taken from the caudal vein/artery of all captured tuatara and stored at $-80^{\circ} \mathrm{C}$. Tuatara have two types of ectoparasite (mites, Neotrombicula spp., Acari:Trombiculidae, Goff et al. 1987; and ticks, Amblyomma sphenodonti; Barker and Murrell 2004). We counted mites 
and ticks for each individual because parasites may be indicators of poor health (mites are bright orange and heavy infestations are visually conspicuous) or reflect immunocompetence from high testosterone levels (Folstad and Karter 1992, Salvador et al. 1996). When more than 100 mites were present, we counted the number of mites within a defined area, and estimated mite loads based on the total infected area of the animal. A passive integrated transponder (PIT) tag (AVID Identification Systems, Inc., Norco, CA, USA) was inserted subcutaneously anterior to the left rear leg for future identification of individuals. A subset $(n=100)$ of these animals were marked using a unique colored bead tag inserted through the nuchal crests (Fisher and Muth 1989) to allow for individual distance recognition without disturbing behavior.

\subsubsection{Field data collection}

Mating activity was monitored during the peak of three mating seasons $(5-30$ March 2005, 28 Feb - 28 March 2006, and 27 Feb - 27 March 2007). Daily, all tuatara visible along accessible tracks in the forest were monitored continuously from 13:00 h until dark (approximately 21:00 h), by slowly walking along tracks and visually surveying for courtship or mating activity. All courtships were observed until there was an outcome (i.e., mating occurred or they were interrupted by the female or a rival male). Unmarked pairs of tuatara that were opportunistically observed mating were captured by hand, PIT-tagged, measured, weighed, and blood samples and ectoparasite counts were taken after mating concluded. In 2005 and 2006, mated pairs were marked with bead tags to aid in future identification and recapture to obtain eggs from females for paternity analyses. Pairs were returned immediately after processing to their capture locations. Handling and processing did not appear to affect behavioral interactions as some pairs were observed re-mating less than 30 minutes after release. In order to compare patterns of mating at high density (forest) and low density (pastures), in 2007, an approximately $500 \mathrm{~m}$ long road running through the pasture was surveyed each night after dark until approximately 00:00 h. Activity of pasture and forest tuatara differs. Pasture tuatara do not emerge from their burrows during daylight hours (due to increased predation risk). Forest tuatara are active during the day and night, but activity in the forest 
shifts to foraging after dark. Thus, forest and pasture surveys were conducted during peak mating activity for each habitat type.

\subsubsection{Data analysis}

To examine the effects of individual phenotypic differences on male mating success, we performed a binary logistic regression analysis in $\mathrm{R}$ ( $\mathrm{R}$ Core Development Team, 2006) with mating success as the dependent variable. Males were categorized as successful if they were ever observed mating. For males that were observed mating more than once, only the first record was used in the analysis. Males were categorized as unsuccessful if they were monitored for $\geq 2$ mating seasons, in our focal study plots, and they were never observed mating. Predictor variables included SVL, body condition (defined as the residuals from a regression of log-transformed mass / log-transformed SVL), tail length ratio (defined as VT / VT+SVL), mite load, and tick load. To control for body size, mite load was defined as the residuals from a linear regression of mite number / $(\mathrm{SVL}+\mathrm{VT})$. A comparable statistic was calculated for tick load. Mite load and tick load were not related to SVL and mass. We did not include mass in this analysis because it is highly correlated with SVL $(r=$ 0.94, $\mathrm{p}<0.001)$. Models were built in a backward stepwise manner, starting with the full model, with variables removed in an iterative process based on their relative Akaike's Information Criterion (AIC) values. The best model was selected based on having the lowest AIC, and terms were analyzed for significance within the models using analyses of variance (ANOVAs).

To assess whether mating was assortative with respect to body size, we regressed the log-transformed SVL of successful males on the log-transformed SVL of their mates. Individuals were included more than once in this analysis if they had multiple partners. We performed separate analyses for pasture (low density) pairs, and forest (high density) pairs, and data were pooled across years.

To examine whether successful males differed with respect to density, we compared mean log-transformed SVL and mass, body condition, tail length ratio, and mite and tick loads, of successful males in the pastures to successful males in the forest using an ANOVA. We also compared log-transformed SVL and mass of mated females in 
the forest versus the pasture (using an ANOVA) to determine whether successful females differed by habitat type. Although the mean size of forest males is slightly smaller than pasture males (N. Nelson, unpublished data), this is driven primarily by the larger range of sizes at the lower end of forest males (because of their higher density). Data were pooled across years. Means are reported as $\pm 1 \mathrm{SE}$ and all data were checked for normality and homogeneity of variances, or were appropriately transformed. Significance is inferred at $p<0.05$.

\subsubsection{Paternity analysis}

To examine whether behavioral observations reflect realized fertilization success, eggs were collected from females that had been observed mating. In November 2005 (nesting season), 10 gravid females with known mating histories were fitted with backpack radio transmitters and tracked to their nests. Females were allowed to lay eggs naturally and nests were then excavated to collect eggs. Many nest sites proved inaccessible and complex, and locating eggs was difficult, therefore we were only able to collect partial clutches from three females in 2005. One of these clutches failed, probably because they had been disturbed by another female prior to collection. In October 2006, we were able to locate four more females in their home ranges, prior to their nesting migrations, and induced oviposition by injecting oxytocin (concentration $10 \mathrm{IU} / \mathrm{ml}, 10 \mathrm{IU} / \mathrm{kg}$ body mass) intraperitoneally. We held females overnight in cardboard boxes and collected eggs as they were laid throughout the night. Females were then returned to their capture locations. All eggs were incubated at Victoria University of Wellington (VUW), and toe-clips were collected from all hatchlings the following year and stored at $-80^{\circ} \mathrm{C}$ until processing.

Genomic DNA was extracted from toe-clips of hatchlings (one per individual) and blood from parents $(5-10 \mu \mathrm{l})$ using a proteinase $\mathrm{K}$ phenol-chloroform protocol (Sambrook et al. 1989). DNA was quantified using a Nanodrop ND-1000 spectrophotometer, and all samples contained sufficient DNA for PCR amplification. Seven highly polymorphic microsatellite loci were amplified using PCR ( $C 2 F$, C11P, E11N, H5H, A12N, C12F, H4H; Aitken et al. 2001, Hay and Lambert 2008) in $15 \mu \mathrm{l}$ reactions. Reactions and PCR conditions followed Moore et al. (2008b; Chapter Five) and Hay and Lambert (2008). Amplified products were combined for 
genotyping and were run on an ABI 3730 Genetic Analyzer (Applied Biosystems, Inc., Foster City, CA, USA). Alleles were visualized using Genemapper software (Applied Biosystems, Inc., Foster City, CA, USA) and sizes were manually scored by the same observer (JAM).

We checked offspring genotypes manually to confirm maternity. Paternity was assigned for all offspring based on seven locus genotypes, with males that were observed mating with each female considered as the candidate fathers, using the computer program Cervus 3.0 (Marshall et al. 1998, Kalinowski et al. 2007).

Clutches were determined to have multiple paternity if more than one offspring per clutch was assigned to a different father with $>95 \%$ confidence, and that this assignment was based on two or more loci.

\subsection{Results}

From three consecutive mating seasons, we recorded a total of 97 mating events from 75 pairs ( $n=62$ males, 69 females) in the forest $(n=54$ pairs $)$ and pasture $(n=$ 21 pairs) on Stephens Island. Using data from the forest only, where animals were intensively monitored, the average frequency of within-season polyandry and polygyny was low (7\% of mated females were polyandrous and $9 \%$ of mated males were polygynous; Table 1).

No individuals (male or female) had more than two mates per season. On average, $24 \%$ of pairs re-mated at least once and up to five times throughout the season. Only one female was observed mating in multiple seasons (in 2005 and again in 2007, in a similar location but with a different partner). Six successful males (14\%) mated in two of the three seasons, with different partners. We did not observe any males mating in all three seasons. All mating within focal study plots was dominated by a small number of males (29\%), leaving the majority of males unsuccessful in all three seasons.

The best logistic regression model of successful $(n=62)$ versus unsuccessful $(n=$ 52) males included SVL and tail length ratio (AIC $=66.77)$. The next best model included SVL, tail length ratio, and body condition (AIC $=67.70)$. The only 
Table 1. Mating patterns of tuatara (Sphenodon punctatus) in focal study plots in remnant forest (Keepers Bush), on Stephens Island from $2005-2007$. Percent polyandry/polygyny is the percent of successful females/males that had more than one mate per season (total number of successful males/females in parentheses). Re-mating is the percent of mated pairs that were observed re-mating more than once (total number of mated pairs in parentheses). Male reproductive skew is the percent of males that were successful (number of successful males in parentheses). Overall reproductive skew indicates the total number of males that mated in any season over the total number of successful and unsuccessful focal males (not the sum of skew per season as some males mated in multiple seasons). Means are $\pm 1 \mathrm{SE}$.

\begin{tabular}{|c|c|c|c|c|c|}
\hline Season & $\begin{array}{l}\text { Percent } \\
\text { polyandry }\end{array}$ & $\begin{array}{l}\text { Percent } \\
\text { polygyny }\end{array}$ & Re-mating & \multicolumn{2}{|c|}{$\begin{array}{l}\text { Male reproductive } \\
\text { skew }\end{array}$} \\
\hline 2005 & $11.1(18)$ & $4.8(21)$ & $14.0(22)$ & & $10.9(6)$ \\
\hline 2006 & $0.0(8)$ & $14.3(7)$ & $40.0(10)$ & & $11.9(5)$ \\
\hline 2007 & $9.1(22)$ & $9.1(22)$ & $19.0(43)$ & & $9.1(5)$ \\
\hline Average & $6.7 \pm 3.4$ & $9.4 \pm 2.8$ & $0.24 \pm 0.08$ & Overall & $29.1(14)$ \\
\hline
\end{tabular}

predictor that was significant in the model was $\operatorname{SVL}(\beta=0.10, \mathrm{z}=4.4, \mathrm{p}<0.0001)$. Mean SVL for successful males was $258.0 \pm 2.7 \mathrm{~mm}($ range $=213-292$ $\mathrm{mm})$ and $221.0 \pm 3.5 \mathrm{~mm}$ (range $=165-263 \mathrm{~mm}$ ) for unsuccessful males. Successful males had significantly shorter tails relative to their body length than unsuccessful males (mean tail length ratio, successful males $=0.45 \pm 0.008$, unsuccessful males $\left.=0.48 \pm 0.006 ; \mathrm{F}_{1,112}=4.7, \mathrm{p}=0.03\right)$. Only $14 \%$ of males $(\mathrm{n}=$ 10 unsuccessful, 6 successful) had complete tails (i.e., had never autotomized a portion of their tail).

The regression analysis testing for size assortative mating found a weak but significant positive relationship between male SVL and female SVL of mated pairs in the high density forest $\left(r^{2}=0.08, p=0.038\right)$, but not in the low density pasture $\left(r^{2}\right.$ $=0.001, \mathrm{p}=0.87)($ Fig 1$)$. There were no significant differences in $\operatorname{SVL}\left(\mathrm{F}_{1,60}=3.6\right.$, $\mathrm{p}=0.06)$, body condition $\left(\mathrm{F}_{1,60}=0.6, \mathrm{p}=0.4\right)$, mite load $\left(\mathrm{F}_{1,41}=1.9, \mathrm{p}=0.2\right)$, or tick load $\left(\mathrm{F}_{1,41}=0.9, \mathrm{p}=0.3\right)$ between successful males in the forest and the pasture. On 


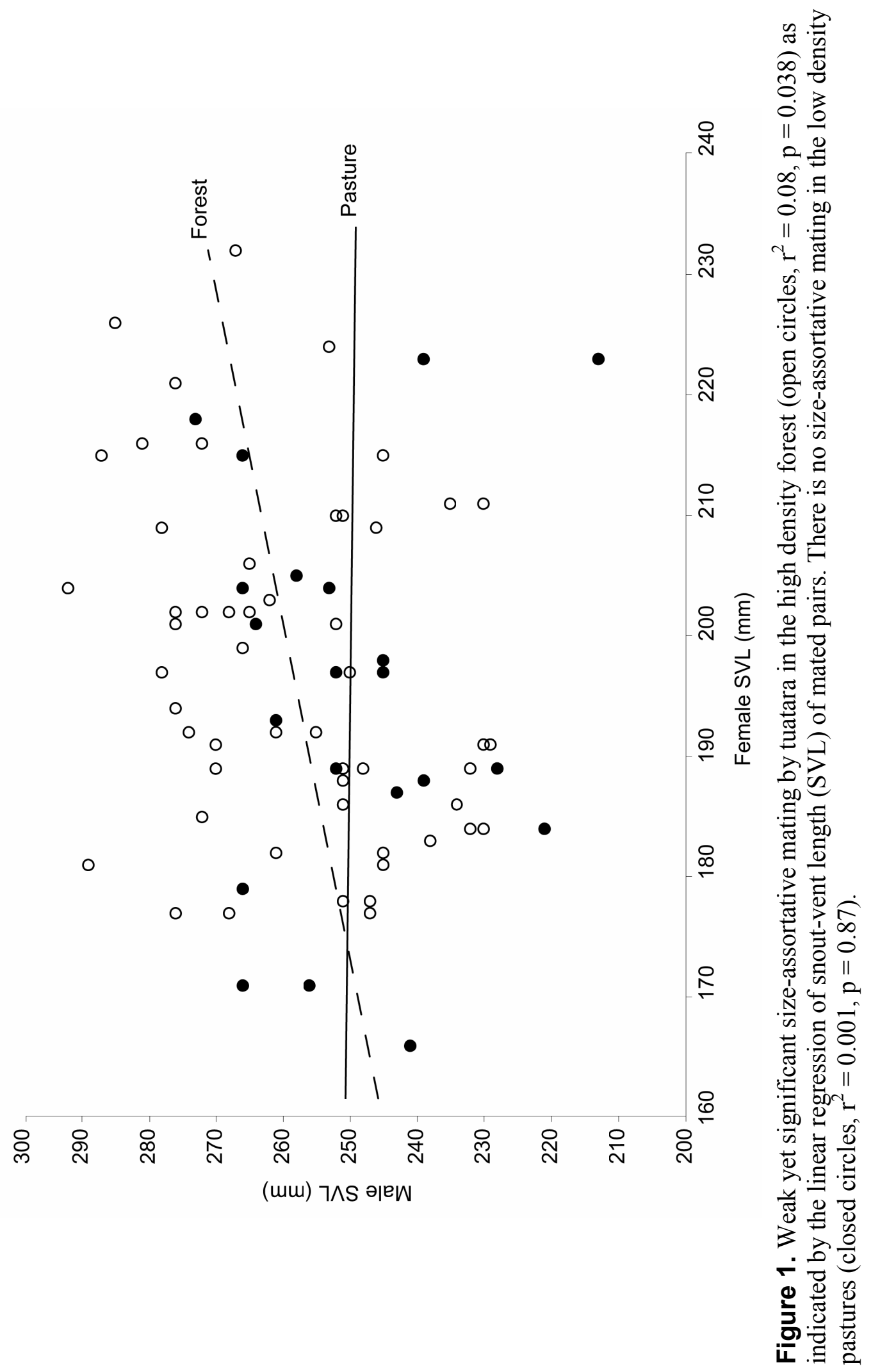


average, successful males in the forest were significantly heavier (mean mass, pasture males $=559.6 \pm 25.2$, forest males $\left.=628.3 \pm 14.2, \mathrm{~F}_{1,60}=6.8, \mathrm{p}=0.01\right)$ and had longer tails (mean tail length ratio, pasture males $=0.42 \pm 0.02$, forest males $=$ $0.47 \pm 0.009, \mathrm{~F}_{1,60}=5.9, \mathrm{p}<0.02$ ) than successful males in the pasture (Table 2). There was no difference in SVL $\left(\mathrm{F}_{1,72}=0.3, \mathrm{p}=0.6\right)$ or mass $\left(\mathrm{F}_{1,72}=0.04, \mathrm{p}=0.8\right)$ of mated females in the forest versus the pasture.

Seven-locus genotypes were successfully assigned to 12 adults (six known mothers, and six candidate fathers) and their 39 offspring (comprising 6 clutches, 4 complete and 2 incomplete). Paternity was assigned to candidate sires for 35 offspring ( 5 clutches) with $>95 \%$ confidence, and alleles were checked manually to confirm assignment. The likelihood (LOD) scores (the sum of the log-likelihood ratios of each locus) from these 35 offspring were all positive and ranged from 0.9 to 7.1. One clutch ( $n=4$ offspring) had negative LOD scores (range $=-2.5$ to -15.0 ) and the genotype of the candidate father from behavioral observations did not match the offspring at $2-4$ loci per individual. This clutch was from a female that we opportunistically observed mating once in 2006 (outside of our focal and

Table 2. Successful male tuatara (Sphenodon punctatus) in the low density pasture habitat are smaller and have shorter tails relative to their body length, than in the high density forest habitat on Stephens Island

\begin{tabular}{|c|c|c|c|c|c|c|}
\hline & \multicolumn{3}{|c|}{ Pasture $(n=18)$} & \multicolumn{3}{|c|}{ Forest $(n=44)$} \\
\hline & mean & SE & range & mean & SE & range \\
\hline $\operatorname{Mass}(g) * *$ & 552.8 & 49.2 & $300-707$ & 635.4 & 16.6 & $470-830$ \\
\hline $\begin{array}{l}\text { Snout-vent } \\
\text { length (mm) }\end{array}$ & 251.5 & 7.3 & $213-273$ & 259.5 & 2.9 & $229-292$ \\
\hline $\begin{array}{l}\text { Body } \\
\text { condition }\end{array}$ & -0.5 & 0.2 & $-1.4-0.4$ & 0.05 & 0.2 & $-2.1-1.5$ \\
\hline Tick load & 0.06 & 0.01 & $0.002-0.1$ & 0.04 & 0.01 & $0.004-0.3$ \\
\hline Mite load & 0.6 & 0.3 & $0-2.6$ & 1.3 & 0.2 & $0-4.5$ \\
\hline $\begin{array}{l}\text { Tail length } \\
\text { ratio ** }\end{array}$ & 0.4 & 0.03 & $0.3-0.5$ & 0.5 & 0.01 & $0.2-0.5$ \\
\hline
\end{tabular}


regularly monitored areas) and she was not seen again during that season. We did not observe or sample her other partner. Thus the candidate fathers, from behavioural observations, matched the assignment from the genetic data for $83.3 \%$ of clutches $(95 \% \mathrm{CI}=42.1$ to $96.3 \%)$. Multiple paternity was not detected in any clutch.

\subsection{Discussion}

Results from this study support three main findings. First, seasonal monogamy is the predominant mating system for tuatara on Stephens Island, although there is a low frequency of within-season polyandry and polygyny. Second, all mating activity is dominated by a small proportion of males ( $25-30 \%)$, and mating success depends largely upon body size. Lastly, positive size-assortative mating is evident at high densities, but appears to break down at lower densities. Although the number of clutches we sampled is small, our paternity assignments largely match our mating observations, which indicates that mating success often equates to realized fertilization success in this population.

\subsubsection{Mating system}

Very few reptiles show within-season monogamy, and even fewer have long-term pair fidelity (reviewed in Bull 2000). Most species are polygynous, and there is strong genetic evidence to support high rates of polyandry as well (Blouin-Demers et al. 2005, Oppliger et al. 2007, Zbinden et al. 2007). Monogamy in vertebrates is usually assumed to be maintained through parental care (Emlen and Oring 1977), mate guarding (Stamps 1983), or because unattended females are somehow disadvantaged. Tuatara parental care is negligible, aside from the occasional short period of nest guarding by females (Refsnider et al. in review). Also, unattended females do not appear to be disadvantaged in any way (J. Moore, pers. obs.). Stamps (1983) suggested that monogamy in lizards should be more common in larger species, because they have larger home ranges and it is more economical for a large male to defend a single female from rivals, rather than the entire area encompassing multiple females. Thus, social monogamy for male lizards and tuatara may be facultative because they are unable to defend multiple females (Bull et al. 1998, Bull 2000). For tuatara, facultative monogamy is further strengthened by the 
asynchronous breeding of females, and the long intervals (2-5 years, Cree et al. 1992) between successive female breeding events. This means that highly successful males (whose home ranges overlap multiple females) vary in the number of partners they have per year, and may have years where they do not mate at all simply because none of the females with which they have regular access are receptive.

Although most tuatara exhibit within-season monogamy, we currently have no reason to suspect long-term pair fidelity. Pairs live in close spatial proximity throughout the year. However, when females leave the forest to lay eggs they do not always return to the same home burrow (Moore et al. in review, Chapter Three), meaning they could end up in a new male's territory. The female we recorded mating in two seasons had different partners, even though successive mating locations were in close proximity. Females returning from nesting migrations might have the opportunity to assess many different males at once and be choosy about the males they end up near, especially because male spatial structure is relatively static in this system (Moore et al. in review, Chapter Three).

\subsubsection{Variance in male reproductive success}

Reproduction is highly skewed toward a small proportion of large male tuatara, so the majority of adult males provide no genetic contribution at any given point in time. This can have negative implications for the effective population size (Sugg and Chesser 1994). However, successful individuals and their genetic contributions will likely change with time even though reproductive skew may still remain high. The timescale for turnover of successful males may be very long for tuatara due to their extreme longevity and slow growth rates. In a paternity study of a group of captive tuatara, one adult male (of four) dominated reproduction for the length of time they were in captivity ( $\sim 12$ years, Moore et al. 2008b, Chapter Five).

The adult census sex ratio in the forest on Stephens Island is $1 \mathrm{M}: 1 \mathrm{~F}$ (Moore et al. in review, Chapter Three). However, because female tuatara only reproduce, on average, every four years (Cree et al. 1992), the operational sex ratio could be as high as $4 \mathrm{M}: 1 \mathrm{~F}$. The low percent of females that are fertile ( $25 \%$ per year) coupled with the high skew in male reproductive success ( $\sim 30 \%$ of males) renders the 
breeding sex ratio back to approximately $1 \mathrm{M}: 1 \mathrm{~F}$. This functional sex ratio should be evolutionarily stable and probably either indirectly causes, or is a result of, the high proportion of seasonal monogamy in this system.

It is not surprising that large body size is a major determinant of reproductive success for male tuatara, as this is the case in many taxa, particularly reptiles (Cooper and Vitt 1993, Shine et al. 2000, Lebas 2001, Salvador et al. 2008). A more intriguing finding is that successful males had shorter tails, relative to their body size, than unsuccessful males. This is contrary to previous findings of tail autotomy having negative consequences for reptile energy stores (Dial and Fitzpatrick 1981, Doughty and Shine 1998), survival (Fox and McCoy 2000), locomotor performance (Chapple and Swain 2002), social status (Martin and Salvador 1993), and reproductive success (Martin and Salvador 1993, Hofmann and Henle 2006, Salvador et al. 2008). The consequences of tail loss are poorly understood for tuatara. If the costs of tail autotomy are outweighed by the benefits of large body size, losing a tail may have a negligible effect on social status and reproductive success. Furthermore, greater tail losses in successful males could simply be a byproduct of age (i.e., the longer a male competes in this system, the greater the likelihood of losing a significant proportion of his tail). Successful males may also be more aggressive and/or more prone to fighting (e.g., for fallow deer, Dama dama; McElligott and Hayden 2000) which would probably increase the frequency of tail loss.

\subsubsection{Size-assortative mating}

Weak positive size-assortative mating in forest tuatara is indicative of a male preference for larger females. A facultatively monogamous male tuatara should increase his fitness by competing more intensely for a large, more fecund (i.e.,g higher quality) female (Clutton-Brock and Parker 1992). Size-assortative mating of tuatara appears to be density dependent, a phenomenon which is supported theoretically and empirically in other taxa (Crespi 1989, Otronen 1993, Kissner et al. 2005). Smaller male tuatara are more successful at lower densities, even though there is no difference in the average size of mated females. This indicates that sizeassortative mating is more a result of males competing for larger females, than large 
females resisting smaller males. At lower densities, smaller males may fare better because competition is reduced, and courtship interference by rival males is probably lessened. Forest is probably the preferred habitat on Stephens Island as resources may be more abundant, and predation risk is lower (raptors methodically search the pastures during the daytime, limiting tuatara activity to the night-time, J. Moore, pers. obs.). However, smaller, unsuccessful forest males may move into the pastures to increase their chances of mating success, especially if they are continually outcompeted in the forest. The current adult sex ratios on Stephens Island (1M : 1F in the forest, 2M : 1F in the pastures; Moore et al. in review, Chapter Three) support this speculation. Further research is needed to determine whether this tactic may function as a successful alternative reproductive strategy for smaller, subordinate males.

\subsubsection{Fertilization success}

Our observations of mating success equate to realised fertilization success for most male tuatara we sampled. In one clutch, our observed mate did not match the paternity assignment. This female was from outside our heavily monitored study plots. Although she was polyandrous, her entire clutch was fertilized by one male. Unfortunately, we have no information on the order of mating or the second male she mated with, therefore we cannot speculate on patterns of fertilization success in polyandrous females. This supports the potential for sperm competition, cryptic female choice, or first/last-male precedence, but further experimental data are needed to fully understand postcopulatory phenomena in tuatara.

Our study is the second to find only single-paternity clutches in wild populations of tuatara (Hay and Lambert 2008), even though multiple paternity has been confirmed in a captive population (Moore et al. 2008b, Chapter Five). Single paternity clutches reflect the high level of seasonal monogamy, but we cannot confidently rule out multiple paternity with our limited sample sizes and two incomplete clutches. The long interval between mating and oviposition presents challenges for sampling hatchlings from wild females, as evidenced by the small number of clutches sampled in our study, in spite of a considerable amount of effort. The polyandrous female that we sampled had a clutch that was sired entirely by one male. Some of the hypotheses 
regarding why polyandry should be adaptive for females include transfer of nutrients in seminal fluid, genetic benefits to offspring quality (via multiple paternity, enhanced sperm competition, or increased opportunity for cryptic female choice; reviewed in Jennions and Petrie 2000), or fertilization insurance (Uller and Olsson 2005). Polyandry is probably limited to a small proportion of female tuatara because they are strongly guarded by their mates, opportunities for multiple mating are limited, and it might not benefit a female to abandon her home range to solicit additional pairing. Once a male has a receptive female in his territory, he re-mates with her throughout the season, which may function as a paternity assurance mechanism. For a female, re-mating with the same partner may be just as effective at ensuring fertilization as mating with multiple males (Hunter et al. 1993, Bull et al. 1998). Furthermore, the odds of a female mating repeatedly with an infertile male are probably very low, as natural rates of infertility are very low among male reptiles (Olsson and Shine 1997).

In conclusion, seasonal monogamy in tuatara is consistent with the mate guarding hypothesis and there is no evidence for long-term pair bonding. Male tuatara exhibit highly skewed reproduction dominated by large males, which is indicative of male quality and competitive ability. The apparent density-dependent size-assortative mating of tuatara reflects a male preference for large females that breaks down when male-male competition is reduced. Our finding of single paternity clutches, even from a socially polyandrous female, warrants further investigation into the mechanism behind tuatara fertilization. Although tuatara are phylogenetically distinct from lizards, our results are consistent with theoretical predictions for mating systems of large lizards.

\subsubsection{Conservation and management implications}

A solid knowledge of the mating system of a threatened species can significantly aid recovery and restoration efforts, particularly in terms of genetic diversity and population demography (Berger 1996, Legendre et al. 1999). Translocating animals is a key recovery tool for tuatara conservation (Gaze 2001) and Stephens Island is the primary source for translocations because it is the largest, most accessible population. The results of our study not only provide insight into the dynamics of the 
main source population, but can aid managers in founder selection for future translocations. Because population density appears to affect the mating system of tuatara, new populations should be established at high enough densities to avoid Allee effects (Stephens and Sutherland 1999), but low enough densities to minimize intrasexual competition and reproductive skew. This may help to equalize founder representation, which should maximize genetic diversity in the new population.

Other potential ways of decreasing competition and equalizing founder representation for tuatara include: 1) only translocating males of similar body size (i.e., minimizing the size variance among male founders), 2) biasing the sex ratio of the founders toward females (possibly as much as 4F:1M), which could also increase the population growth rate, 3 ) releasing founders in the same spatial organization as they existed on the source island, which could also help to reduce settling time. Future translocations could thus be used as experiments to test whether these techniques improve the immediate and long-term success of the newly established populations. 


\section{Implications of Social Dominance and Multiple Paternity for the Genetic Diversity of a Captive-Bred Reptile Population (tuatara)}

\subsection{Abstract}

Captive breeding is an integral part of many species recovery plans. Knowledge of the genetic mating system is essential for effective management of captive stocks and release groups, and can help to predict patterns of genetic diversity in reintroduced populations. Here we investigate the poorly understood mating system of a threatened, ancient reptile (tuatara) on Little Barrier Island, New Zealand and discuss the impact on its genetic diversity. This biologically significant population was thought to be extinct, due to introduced predators, until 8 adults ( 4 males, 4 females) were rediscovered in 1991/92. We genotyped these adults and their 121 captively-bred offspring, hatched between 1994 to 2005, at five microsatellite loci. Multiple paternity was found in $18.8 \%$ of clutches. Male variance in reproductive success was high with one male dominating mating (77.5\% of offspring sired) and one male completely restricted from mating. Little Barrier Island tuatara, although clearly having undergone a demographic bottleneck, are retaining relatively high levels of remnant genetic diversity which may be complemented by the presence of multiple paternity. High variance in reproductive success has decreased the effective size of this population to approximately 4 individuals. Manipulation to equalize founder representation was not successful, and the mating system has thus had a large impact on the genetic diversity of this recovering population. Although population growth has been successful, in the absence of migrants this population is likely at risk of future inbreeding and genetic bottleneck.

\subsection{Introduction}

Captive breeding is an essential tool for conservation of many threatened and endangered species, but establishing a successful program is often challenging 
(Snyder et al. 1996). Apart from simply increasing numbers of individuals, a primary goal in captive breeding for species recovery is to maintain the genetic diversity of a population (Ralls and Ballou 1986) to ultimately create a selfsustaining wild population (Ebenhard 1995). Captive breeding programs that are aimed at restoring severely declining populations are often limited to only a small number of founders (Ralls and Ballou 1986), thus furthering the loss of genetic diversity and imposing imminent and/or long-term consequences for fitness and adaptability of the new population (Allendorf and Luikart 2007). Isolated, insular populations may be particularly at risk of losing genetic diversity. Ideally, genetic change in a captive population should be minimized by equalizing founder representation. However, in instances where founders 1) do not breed readily in captivity, or 2) do not accept manipulation (e.g., artificial insemination, isolating mating pairs), retaining remnant diversity in the captive population is challenging (Snyder et al. 1996).

The mating system plays an important role in determining levels of genetic diversity in captive and wild populations (Anthony and Blumstein 2000). For instance, disassortative mate choice can result in balancing selection on functional genes (Penn and Potts 1999, Roberts and Gosling 2003), and multiple paternity increases the effective population size $\left(N_{e}\right.$; Sugg and Chesser 1994). Alternatively, social dominance may limit all reproduction to a few successful males, thereby heavily biasing paternity and greatly decreasing genetic diversity and $N_{e}$ (Hoelzel et al. 1999).

Among reptiles, mating systems are poorly understood. Most reptiles are believed to be polygynous (e.g., Zamudio and Sinervo 2000), but cases of monogamy in lizards do exist (in the genus Egernia, Bull 2000, Chapple and Keogh 2005). Because parental care is limited or non-existent, reptile mating systems are usually characterized by social dominance and/or spatial structure. Recent discoveries of genetic polyandry in many reptiles is broadening the understanding of the female's role in the mating system (e.g., Lee and Hays 2004). Furthermore, because females of many long-lived reptiles are capable of storing sperm, multiple paternity has been found at high frequencies in some species (Pearse and Avise 2001). In order to begin to understand the mating system of an ancient reptile species and its impact on 
the genetic diversity of a small population, we investigate patterns of paternity in a captively bred, insular population (on Little Barrier Island, New Zealand) where manipulation to equalize founder representation was not successful.

Little Barrier Island (LBI; known also by its Māori name, Hauturu) is a 3083 ha volcanic Nature Reserve located in the Hauraki Gulf off the east coast of North Island, New Zealand ( $\left.36^{\circ} 12^{\prime} \mathrm{S}, 175^{\circ} 07^{\prime} \mathrm{E}\right)$. Despite a history of habitat modification, human presence, and introduced predators, the island is currently largely forested (Girardet et al. 2001), providing suitable habitat for a number of native species which have been extirpated from the mainland. One such species is the tuatara, a mediumsized, long-lived reptile that is endemic to New Zealand. Tuatara are the sole extant representatives of the ancient reptilian order Sphenodontia (Benton 2000). Although once widespread throughout the mainland, natural populations are now restricted to small offshore islands, primarily due to predation from introduced mammalian predators.

The tuatara on LBI were initially described as morphologically unique (Reischek 1886), and this island population was subsequently elevated to subspecific status in 1943 making it the rarest of the tuatara populations. Allozyme and mitochondrial DNA analyses have since revealed that LBI tuatara are not genetically distinct from other northern island populations of tuatara (Daugherty et al. 1990, Whitaker and Daugherty 1991, Hay et al. 2003). However, as the largest island (by at least an order of magnitude) supporting one of the 32 natural island populations of this threatened reptile, the importance of conserving the LBI population of tuatara is not diminished. Little Barrier is also the only island where tuatara occur in a habitat that may be similar to what they once inhabited on mainland New Zealand.

By the late 1900's, tuatara were thought to be extinct on LBI (due primarily to predation by introduced cats and rats or kiore, Rattus exulans) until systematic surveys rediscovered eight adults (4 males, 4 females) in 1991 - 1992 (Whitaker and Daugherty 1991, Whitaker 1993). These adults were brought into captivity on the island and housed under semi-natural conditions behind a predator proof fence, with the goal of establishing a captive breeding colony to repopulate LBI. Tuatara and rats rarely coexist because the rats limit recruitment (Cree et al. 1995), so the 
recovered adults likely represented relicts of a population that was headed for extinction (Whitaker and Daugherty 1991). Although extinction threats are often difficult to determine and quantify (Sarrazin and Barbault 1996), in this case there was strong evidence to suggest that rats posed the primary threat to the persistence of tuatara on LBI. As such, the New Zealand Department of Conservation undertook an eradication program in 2004 and in 2006 LBI was declared rat free.

Since their rediscovery in 1991/92, the eight LBI tuatara have bred in captivity and have successfully produced over 120 offspring. Eggs were laid in naturally constructed nests in the tuatara enclosure, recovered by the island caretakers, and artificially incubated at Victoria University of Wellington (VUW), after which the hatchlings were returned to LBI and held in captivity until rats were eradicated and they reached an appropriate size (120 mm snout-vent length, SVL) for release onto the island. Because tuatara exhibit temperature dependent sex determination (TSD; Nelson et al. 2004a), clutches were split and incubated at two different temperatures to give the offspring group a slightly female biased sex ratio. In an effort to equalize founder representation, the eight adults were initially housed separately as malefemale pairs, but after two years of no reproductive activity, they were released into the enclosure as a group. Within this group enclosure, the suspected mothers of each clutch were identified (although not confirmed genetically). However, the fathers (of which there are four candidate males) of each clutch were not identified because mating, which occurs $\sim 8$ months earlier, was not observed. Because captive breeding on LBI could not be manipulated, this new population could hypothetically have been fathered by one individual.

Currently, little is known about the mating system of tuatara. Although presumed to be polygynous due to their highly territorial social system (Gillingham et al. 1995), genetic paternity and the female's contribution to the mating system are unknown. To better understand the genetic mating system of tuatara and its potential impacts on genetic diversity of reintroduced populations, we assign paternity to captively bred offspring and their potential parents, and discuss the implications for the future of this highly valued population of a biologically significant reptile.

\subsection{Methods}




\subsubsection{Sample collection and genotyping}

Tissue samples were collected from all LBI tuatara from the period $1991-2005$. These included $\sim 0.5-1.0 \mathrm{~mL}$ whole blood taken from the caudal vein/artery of adults, and toe-clips taken from hatchlings that had been incubated at VUW. All samples were stored at $-80^{\circ} \mathrm{C}$. DNA was extracted from $10 \mu \mathrm{l}$ of blood, and/or toeclips (one per individual) using a proteinase $\mathrm{K}$ phenol-chloroform protocol (Sambrook et al. 1989). DNA was quantified using a Nanodrop ND-1000 spectrophotometer, and all samples contained sufficient DNA for PCR amplification.

Seven microsatellite loci were amplified using PCR (Table 1; Aitken et al. 2001; Hay and Lambert 2008) in $15 \mu 1$ reactions. Reactions included approximately $10-50$ ng of template DNA, and followed the general thermal cycle of $94^{\circ} \mathrm{C}$ for $1 \mathrm{~min}$, $\left(94^{\circ} \mathrm{C}\right.$ for $30 \mathrm{~s}, 58-63^{\circ} \mathrm{C}$ for $20 \mathrm{~s}, 72^{\circ} \mathrm{C}$ for $\left.30 \mathrm{~s}\right)$ for $35-40 \mathrm{cycles}, 72^{\circ} \mathrm{C}$ for $30 \mathrm{~min}$ (see Table 1 for locus-specific details). These loci were previously recognized as the most variable for tuatara on LBI and Stephens Island (Hay and Lambert 2008). Amplified products were multiplexed for genotyping and were run on an ABI 3730 Genetic Analyzer (Applied Biosystems, Inc.). Alleles were visualized using Genemapper software (Applied Biosystems, Inc.) and sizes were manually scored by the same observer.

\subsubsection{Data analysis}

Offspring maternity was assumed based on nesting behavior and gravidity of females at the time of egg collection. We checked offspring genotypes manually to confirm maternity. Paternity was assigned for all offspring based on 5 locus genotypes, with all four males considered as candidate parents using the computer program Cervus 2.0 (Marshall et al. 1998). Prior to paternity analysis, we checked loci for null alleles (in Cervus 2.0), and found that one locus $(C 2 F)$ had a high frequency of null alleles (null allele frequency $=0.73$ ). Null alleles (i.e., true alleles that fail to amplify) can cause false exclusion of potential parents by incorrectly typing true heterozygotes as homozygotes (Dakin and Avise 2004). As this locus was not highly variable and had a high probability of null alleles, it was removed from the analysis. Another 
Table 1. Tuatara (Sphenodon) microsatellite primer sequences $(\mathrm{F}=$ forward, $\mathrm{R}=$ fluorescently labeled reverse), optimal annealing temperatures $\left(T_{A}\right)$, number of cycles, and optimal $\mathrm{MgCl}_{2}$ concentrations used for PCR reactions in this study.

\begin{tabular}{|c|c|c|c|c|}
\hline Locus & Primer sequence $\left(5^{\prime}-3^{\prime}\right)$ & $T_{A}\left({ }^{\circ} \mathrm{C}\right)$ & $\begin{array}{l}\text { No. } \\
\text { cycles }\end{array}$ & $\begin{array}{c}\mathrm{MgCl}_{2} \\
(\mathrm{mM})\end{array}$ \\
\hline \multirow[t]{2}{*}{$\mathrm{C} 1 \mathrm{H}^{\mathrm{a}}$} & F: gtttctttgtctcattgctttcccag & 60 & 35 & 2.5 \\
\hline & R: cctcttctccgccttacact & & & \\
\hline \multirow[t]{2}{*}{$C 2 F^{a}$} & F: tcactgtcagcaggctcttc & 60 & 35 & 2.5 \\
\hline & R: gaatgcggggaatgtgagg & & & \\
\hline \multirow[t]{2}{*}{$A 12 N^{a}$} & $\mathrm{~F}:$ gtttgttggagaagggaggagaataatc & 60 & 38 & 2.5 \\
\hline & $\mathrm{R}$ : atcactgctcatttcagcc & & & \\
\hline \multirow[t]{2}{*}{$B 8 P^{b}$} & F: gtttcttagatggatgattgggggagt & 58 & 38 & 2.5 \\
\hline & R: agaatgggccaacaagacag & & & \\
\hline \multirow[t]{2}{*}{$C 11 P^{b}$} & F: gtttcttaagtgaaatgggaagctgga & 60 & 40 & 2.0 \\
\hline & R: gcaataagttccacccgtca & & & \\
\hline \multirow[t]{2}{*}{$E 11 N^{b}$} & F: gtttcttttgtgtgaagaacgcatcc & 63 & 40 & 2.5 \\
\hline & R: cactcccccattactggaca & & & \\
\hline \multirow[t]{2}{*}{$H 5 H^{b}$} & F: gtttcttactaaacccccactttggag & 60 & 40 & 2.5 \\
\hline & R: gtgtcacctgcttcccagtt & & & \\
\hline
\end{tabular}

\footnotetext{
${ }^{a}$ sequences from Aitken et al. 2001

${ }^{\mathrm{b}}$ sequences from Hay and Lambert 2008
}

locus $(E 11 N)$ proved difficult to score (due to non-specific amplification), and was likewise removed from further analysis. Clutches were determined to have multiple paternity if more than one offspring per clutch was assigned to a different father with $>95 \%$ confidence, and that this assignment was based on two or more loci.

To determine relative genetic diversity in the LBI adults, we compared their number of alleles and observed heterozygosity to the average of three random samples of eight individuals each, from the largest extant population of tuatara (Stephens Island, $30-50,000$ individuals). We collected blood samples from 300 tuatara on Stephens Island (for a concurrent genetic study), and genotyped them at the same five loci as the LBI samples. From the Stephens Island samples, three groups of eight samples were randomly selected for comparison to LBI adults. We then determined the mean 
coefficient of relatedness (r; Queller and Goodnight 1989) of the LBI adults and the three random samples of Stephens individuals, and compared them for significant differences using the computer program GenAlEx (Peakall and Smouse 2006). We compared the parental and offspring generations for significant differences in allele frequencies using the computer program Genepop (Raymond and Rousset 1995), and calculated observed and expected heterozygosities in GenAlEx (Peakall and Smouse 2006).

We also used the program ENDOG v4.0 (Gutierrez and Goyache 2005) to calculate the average relatedness coefficient (AR) of each of the founders based on pedigree data. Average relatedness values (Gutierrez et al. 2003) can be used to indicate the relative genetic contribution of the founders to the population and have been used directly in genetic management of small populations (e.g., Goyache et al. 2003).

We calculated the effective population size $\left(N_{e}\right)$, as a surrogate for the effective number of breeders ( $N_{e b}$; e.g., Fiumera et al. 2002) based on the variance in male and female reproductive success. First, the effective number of males $\left(N_{e m}\right.$; Kimura and Crow 1963) was calculated using the formula

$$
N_{e m}=\frac{N_{m} \bar{k}_{m}-1}{k_{m}-1+\frac{V_{k m}}{\bar{k}_{m}}}
$$

where $N_{m}$ is the census number of breeding males, ${ }^{{ }^{m}}$ is the mean number of offspring produced per male, and $V_{k m}$ is the variance in male reproductive success. A similar formula was used to calculate the effective number of females $\left(N_{e f}\right) . N_{e}$ was then determined based on the formula $N_{e}=\frac{4 N_{e m} N_{e f}}{N_{e m}+N_{e f}}$

Heterozygote excess can also be used to calculate the effective number of breeders, based on the theory that when the number of breeders is small, allele frequencies in males and females will be different due to binomial sampling error resulting in heterozygote excess in the offspring (Pudovkin et al. 1996). Likewise, the temporal change in allele frequencies between generations can also be used to calculate $N_{e}$ 
(Waples 1989). These methods do have limitations (Luikart and Cornuet 1999), and because (1) heterozygote excess was not consistent across all loci in the offspring (we found it in four of five loci), and (2) we can assign maternity and paternity with great confidence in this small population, we relied on variance in reproductive success for directly determining $N_{e}$ as it is the most accurate estimator in this case.

\subsection{Results}

Five locus genotypes were successfully assigned to all adults $(\mathrm{n}=8)$ and 16 clutches (121 offspring) hatched from 1994 to 2005 . All loci were polymorphic, and the number of alleles per locus averaged 7.2 for the parents $(n=8)$ and 7.0 for the offspring $(\mathrm{n}=121)$. All four founding mothers successfully reproduced, and clutch sizes varied per year and by female (mean size $=9.3 \pm 3.8$, range $=2-12$ eggs). Hatching success averaged $76.4 \%$ and was not significantly different between mothers $\left(\mathrm{F}_{(3,13)}=1.5, \mathrm{p}=0.2\right)$ or fathers $\left(\mathrm{F}_{(3,13)}=1.2, \mathrm{p}=0.4\right)$. Because the number of clutches differed between females, the maternal contribution was unequal among release offspring (total number of eggs, proportion; $\mathrm{Mrs} \mathrm{O}=23,14.6 \%$; Kowhai $=$ $39,24.7 \%$; Greta $=40,25.3 \%$; Whero $=56,35.4 \%$ ). From the pedigree data, the genetic contribution of the founding females to the population was as follows; Mrs O $=6.6 \%$, Kowhai $=11.3 \%$, Greta $=11.72 \%$, Whero $=20.31 \%$. On average, LBI females reproduced every two years, which is more frequent than the four year average seen in the wild (Cree et al. 1991a, Cree et al. 1992). However, two females produced clutches in consecutive years, indicating that female tuatara are capable of producing clutches every year when in good condition. One of these clutches failed to hatch, and only 2 of the 3 hatchlings survived from the other.

Paternity was assigned to all offspring with $>95 \%$ confidence, and alleles were manually checked to confirm assignment. All offspring likelihood (LOD) scores (the sum of the log-likelihood ratios of each locus) were positive and ranged from 1.05 to 8.99. Multiple paternity was found in $18.8 \%$ of clutches $(n=3$; Fig 1$)$. No more than two sires were represented in any clutch, and in multiply sired clutches, the percentage of paternity by the second sire ranged from $33-50 \%$ (Fig 1). Paternity was not equal among all males, with one male (Punga) siring $77.5 \%$ of offspring $(\mathrm{n}=$ 93). Spike sired 16.7\%, Arnie sired 5.8\%, and one male (Rudolph) sired no 


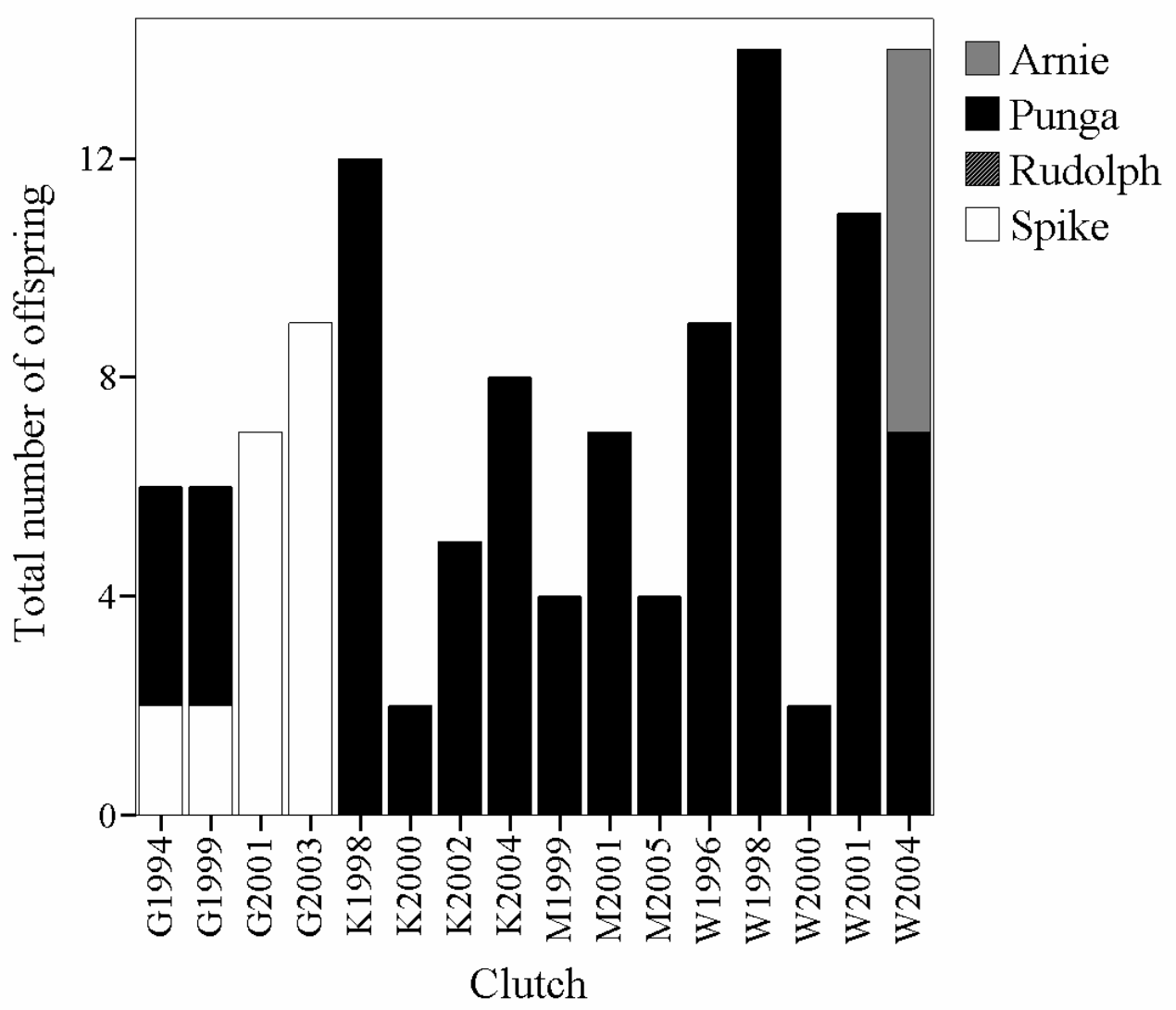

Figure 1. Relative reproductive success of the four founding male tuatara. Bars represent total number of offspring per clutch (by female $\mathrm{W}=$ Whero, $\mathrm{M}=\mathrm{Mrs} \mathrm{O}, \mathrm{G}=\mathrm{Greta}, \mathrm{K}=$ Kowhai, and year) as a proportion of each of the four sires.

offspring. Punga sired offspring in all but two of the clutches. From the pedigree data, the genetic contribution of each of the founding males to the population was as follows; Punga $=37.11 \%$, Spike $=8.59 \%$, Arnie $=3.52 \%$ and Rudolph $=0.78 \%$.

Body mass of the founding males generally increased between 1991 and 2006, with Punga eventually outweighing the other males (Fig 2). Mean observed heterozygosity decreased by $14 \%$ from the parent to the offspring generation, which is consistent with a loss of genetic diversity due to unequal male contribution (Table $2)$. One allele was lost from the parent to the offspring generation, yet allele frequencies were not significantly different $\chi^{2}(10,129)=16.15, p=0.095$.

The average number of alleles per locus and the mean observed heterozygosity for the LBI adults did not differ significantly from Stephens Island tuatara $\left(\mathrm{F}_{(3,16)}=0.16\right.$, $\mathrm{p}>0.9$ ), when sample sizes were equal. Compared to a large sample of tuatara 


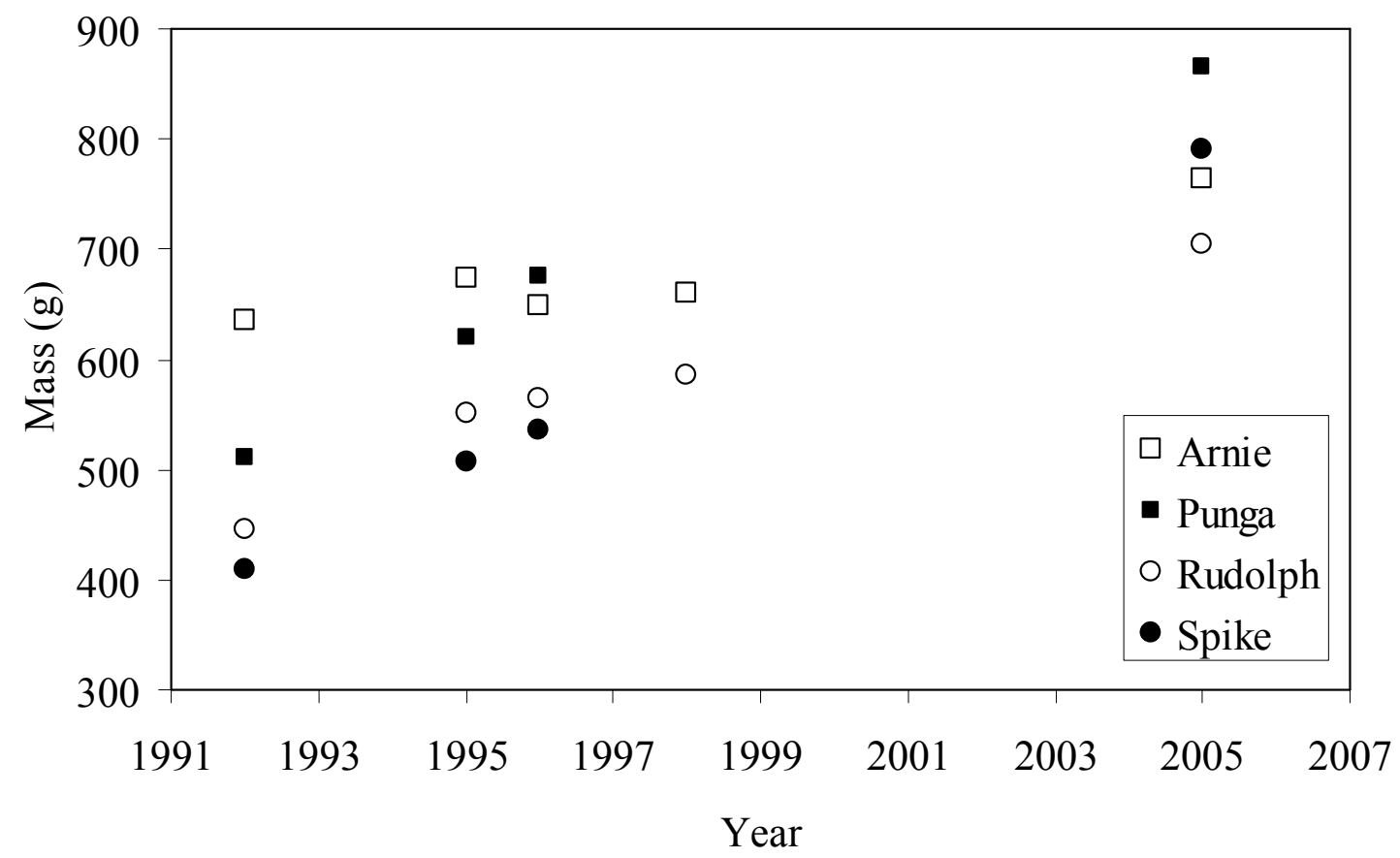

Figure 2. Body mass of founding male tuatara over time. Punga is the heaviest male and sired $78.8 \%$ of the offspring (closed squares $=$ Punga, closed circles $=$ Spike, open squares $=$ Arnie, open circles $=$ Rudolph). Snout-vent length follows a similar pattern of growth.

from Stephens Island that we genotyped at the same five loci $(\mathrm{n}=50)$, private alleles were found in LBI tuatara at 2 of 5 loci $(C 11 P$ and $B 8 P)$. The mean relatedness of LBI adults $(r=0.065)$ did not differ significantly from Stephens Island tuatara (mean $r=0.033$ ), indicating that the LBI adults are no more inbred than those of a large, highly dense population (2000 tuatara / ha; Carmichael et al. 1989). Furthermore, the effective number of LBI breeders was lower than the census number of breeders $(\mathrm{N}=8)$. Based on the variance in reproductive success, $N_{e}=3.77$ $\left(N_{e m}=1.32\right.$ and $\left.N_{e f}=3.30\right)$.

\subsection{Discussion}

This is the first study to document the occurrence of within-season multiple paternity in tuatara. Multiple paternity is common in many taxa including mammals (Eberle and Kappeler 2004), birds, (Gibbs et al. 1990, Jamieson et al. 1994), insects (Bretman and Tregenza 2005), fish (Avise et al. 2002), amphibians (Gopurenko et al. 2006), and in other reptiles (e.g., Zamudio and Sinervo 2000, Davis et al. 2001, 
Table 2. Number of alleles (Na) and observed heterozygosity (Ho) of offspring and adult Little Barrier Island tuatara by locus.

\begin{tabular}{lllll}
\hline Locus & $\begin{array}{l}\mathrm{Na} \\
\text { parents }\end{array}$ & $\begin{array}{l}\mathrm{Na} \\
\text { offspring }\end{array}$ & $\begin{array}{l}\mathrm{Ho} \\
\text { parents }\end{array}$ & $\begin{array}{l}\mathrm{Ho} \\
\text { offspring }\end{array}$ \\
\hline$A 12 \mathrm{~N}$ & 7 & 7 & 0.63 & 0.42 \\
$\mathrm{C} 1 \mathrm{H}$ & 4 & 4 & 0.63 & 0.53 \\
$\mathrm{C} 11 P$ & 10 & 9 & 0.88 & 0.89 \\
$B 8 P$ & 10 & 10 & 0.88 & 0.91 \\
H5H & 5 & 5 & 0.88 & 0.60 \\
Average & 7.2 & 7.0 & 0.78 & 0.67 \\
\hline
\end{tabular}

Morrison et al. 2002, Lee and Hays 2004, Xu et al. 2005). Our results thus confirm the presence of multiple paternity, and also genetic polygyny in tuatara.

Numerous hypotheses have been presented to explain the benefits conferred to females that exhibit polyandry (see Reynolds 1996, Jennions and Petrie 2000 for review). These include, but are not limited to, 1) improved genetic quality of offspring (via enhanced offspring diversity, genetic compatibility, increased sperm competition, cryptic female choice; Madsen et al. 1992, Calsbeek and Sinervo 2004), 2) transfer of nutrients in seminal fluid, and 3) insurance against male infertility (Levitan and Petersen 1995). In populations or species where the odds of encountering a mate are low, females are expected to exhibit high levels of multiple paternity as a consequence of sperm storage. Although there is no evidence of longterm sperm storage in tuatara (Saint Girons 1983), ovulation occurs $\sim 1-2$ months after mating (Cree et al. 1992) thus providing a window for sperm competition or cryptic female choice to occur. The mechanism underlying fertilization success in tuatara remains unknown, but cryptic female choice and/or sperm competition could play a role in paternity determination.

Polyandry, polygyny and social dominance are clearly reflected in paternity of the LBI tuatara population. Social dominance may be based on large body size, as the smallest male was completely restricted from mating. Male-male competition appears to be an important determinant of male reproductive success. Females may also exhibit a preference for larger, more dominant males, a phenomenon which has 
been shown in other taxa (e.g., Ambystoma tigrinum tigrinum, Howard et al. 1997; Psammodromus algirus, Salvador and Veiga 2001; Uta stansburiana, Calsbeek and Sinervo 2004). Although it is possible that Rudolph, who sired no offspring, was simply infertile, it is unlikely as the rates of infertility in reptile populations are generally very low (Olsson and Shine 1997).

At the population level, social dominance of mating by one or a few males decreases genetic diversity (e.g., Hoelzel et al. 1999). The loss of heterozygosity from the parent to the offspring generation $(14 \%)$ in the LBI tuatara population is not surprising considering the unequal representation of the founding males. Although there are eight potential breeders in the LBI captive breeding program, based on the variance in male and female reproductive success, the effective size of this population is approximately 4 . This small $N_{e}$ is cause for concern as this growing population is likely to lose diversity at a rapid rate. The presence of multiply sired clutches may help to offset the potential loss of diversity from social dominance by increasing the diversity of offspring within individual clutches and ultimately increasing $N_{e}$ (Sugg and Chesser 1994).

Because we have included every known individual in the LBI population in our analyses, it is impossible to under- or overestimate current levels of genetic diversity. However, our data span the first 12 years of this breeding program (only a portion of the reproductive lifespan of a tuatara), and it is possible that as male size and condition changes with time, and management options are explored (see below) the dominance structure will be altered significantly. Aside from obvious correlates like body size (i.e., competitive ability), it is currently unknown why some males are consistently more successful than others. Reproductive dominance by these individuals could be beneficial if, for instance, they have greater variation at functional genes, such as the major histocompatibility complex (MHC) (Miller et al. 2007). If this were the case, allowing the natural mating system to play a role, rather than manipulating captive breeding, could actually enhance offspring fitness.

While the small number of remnant LBI tuatara indicates a recent demographic bottleneck, the remaining tuatara still retain relatively high levels of genetic diversity. In a survey of genetic diversity of tuatara populations, MacAvoy et al. 
(2007) found similar results. Based on a different set of microsatellite markers than we used in our study, MacAvoy et al. (2007) found an intermediate level of genetic diversity in the LBI tuatara $(n=7)$ when compared to 13 other tuatara populations. Tuatara populations exhibit strong genetic structuring across their range, which further emphasizes the need to conserve every remnant population via threat removal and/or successful captive breeding (Aitken et al. 2001, MacAvoy et al. 2007). MacAvoy et al. (2007) concluded that a loss of rare alleles, resulting in a mode shift in allele frequency classes, was indicative of a genetic bottleneck that puts LBI tuatara at risk.

\subsubsection{Conservation / management implications}

Conservation breeding programs are common in New Zealand species recovery plans. In some instances, human intervention and manipulation of founder representation are possible (Clout and Craig 1995). However, in cases such as the LBI tuatara, the best managers can do to retain the genetic diversity of a particular population is to repopulate the island with the genetic stock that remains, and any breeding in captivity by these individuals is thus considered a success. Although conservation efforts for tuatara have been extremely successful (Nelson et al. 2002a), from a genetic standpoint it would be useful for managers to consider the genetic effects of potentially highly polygynous captive colonies. Many captive-bred populations scheduled for reintroduction are already suffering from genetic bottlenecks, and unequal founder representation would only further this, thus putting these populations at even greater risk. In a captive setting, rotating resident males with a group of females may help to alleviate the effects of dominance and equalize male representation. However, managing on a very fine scale (e.g., isolating specific breeding pairs) has not proven successful in the past, so it is unknown whether breeding would even occur under highly managed circumstances.

Although the remaining LBI tuatara appear to be retaining some remnant diversity, the release group that will repopulate this island is composed of all half and full siblings, which may hinder the future success of this population by reduced reproduction, survival and hatching success resulting from inbreeding depression. Releasing the offspring at geographically distinct sites may help to slow the rate of 
inbreeding by decreasing the probability of full-sibling mating. Furthermore, removing Punga from the captive colony may help to even out the distribution of founder alleles, although this does not guarantee that all males will be represented in the future. Since rats have been removed from LBI, one new wild tuatara has been sighted on the island. The admixture of new genetic stock, from remnant tuatara still living on LBI outside of captivity, could improve the genetic health of this new population.

In future captive breeding efforts, manipulation of hatchling sex ratios could be beneficial for population growth. Because tuatara exhibit TSD, manipulating sex ratios of release groups (via artificial incubation temperatures) is easily accomplished. Theoretically, an equal sex ratio should maximize $N_{e}$ (Allendorf and Luikart 2007). However, the adult sex ratio also has an impact on the degree and frequency of polyandry and/or polygyny (e.g., Anthony and Blumstein 2000, Fitze et al. 2005). In small populations where females are the reproductively limiting sex, a female-biased sex ratio can amplify population growth. Lenz et al. (2007) found that female-biased sex ratios (of as much as 0.3 males : 1 female) in captive bred Lesser Kestrels, could not only increase $N_{e}$, but lead to recovery of the wild population. Because reproductive success is so variable in male tuatara and females have an infrequent, low reproductive output (Cree 1994), a female biased sex ratio (of possibly as much as 0.25 males : 1 female) may help to offset the variance in male reproductive success by decreasing intrasexual competition, while maximizing population growth and maintaining genetic diversity.

The concept of translocating individuals or eggs from one population to another (i.e., introducing migrants) has been suggested as a potential means to increase genetic diversity and population demography of some tuatara populations (Allendorf 2001). This could be a way of increasing $N_{e}$ for the LBI population. Because tuatara exhibit strong phylogenetic structuring across their range, source islands should be the most genetically similar populations that would not be harmed by removal of a small portion of their population. However, it is currently unknown whether this could have negative impacts (e.g., outbreeding depression), so future research and management should aim to explore this direction. 


\section{Fine-scale Genetic Structure of a Long-lived Reptile Reflects Recent Habitat Modification}

\subsection{Abstract}

Anthropogenic habitat fragmentation - ubiquitous in modern ecosystems - has strong impacts on gene flow and genetic population structure. Reptiles may be particularly susceptible to the effects of fragmentation because of their extreme sensitivity to environmental conditions and limited dispersal. We investigate finescale spatial genetic structure, individual relatedness, and sex-biased dispersal in a large population of a long-lived reptile (tuatara, Sphenodon punctatus) on a recently fragmented island. We genotyped individuals from remnant forest, regenerating forest, and grassland pasture sites at seven microsatellite loci and found significant genetic structuring $\left(R_{\mathrm{ST}}=0.012\right)$ across small distances $(<500 \mathrm{~m})$. Isolation by distance was not evident, but rather, genetic distance was weakly correlated with habitat similarity. Only individuals in forest fragments were correctly assignable to their site of origin, and individual pairwise relatedness in one fragment was significantly higher than expected. We did not detect sex-biased dispersal, but natural dispersal patterns may be confounded by fragmentation. Assignment tests showed that reforestation appears to have provided refuges for tuatara from disturbed areas. Our results suggest that fine-scale genetic structuring is driven by recent habitat modification and compounded by the sedentary lifestyle of these long-lived reptiles. Extreme longevity, large population size, simple social structure and random dispersal are not strong enough to counteract the genetic structure caused by a sedentary lifestyle. We suspect that fine-scale spatial genetic structuring could occur in any sedentary species with limited dispersal, making them more susceptible to the effects of fragmentation.

\subsection{Introduction}


Habitat fragmentation is ubiquitous in modern ecosystems (Saunders et al. 1991). In addition to natural forces like dispersal, demography, and the mating system (Wright 1931, Crow and Kimura 1970, Wright 1978, Bohonak 1999), anthropogenic habitat fragmentation and disturbance have strong effects on gene flow and genetic population structure (Manel et al. 2003, Lawton-Rauh 2008, Walker et al. 2008). Animals living in fragmented habitats often show decreased dispersal because of unwillingness or inability to move between fragments (Saunders et al. 1991, Debinski and Holt 2000, Couvet 2002). Fragmentation increases the likelihood of inbreeding by causing an accumulation of related individuals within fragments, and increases the rate of population differentiation due to genetic drift (Saunders et al. 1991, Couvet 2002, Allendorf and Luikart 2007). Thus, genetic studies of dispersal, relatedness and population structure can inform conservation management by elucidating the potential impact of habitat fragmentation and disturbance. Because the two primary effects of habitat fragmentation are isolation and alteration of the microclimate (Saunders et al. 1991), reptiles, with their naturally limited dispersal (Gibbons et al. 2000) and extreme sensitivity to environmental conditions (Janzen 1994a, Janzen 1994b, Gibbons et al. 2000), may be more susceptible to the effects of fragmentation than other taxa.

Genetic analyses based on individual genotypes have enabled detection of fine-scale genetic structuring, individual migration, and cryptic behavior (Knutsen et al. 2003, Vignieri 2007, Clark et al. 2008). For instance, assignment tests can recognize probable migrants by identifying the population to which an individual's genotype has the highest likelihood of belonging. Likewise, patterns of dispersal and mating between relatives can be inferred by examining pairwise coefficients of relatedness among subpopulations or sexes. Molecular methods can be applied to systems where behavioral and dispersal patterns are difficult to observe or too low to detect by traditional ecological methods (e.g., radio-telemetry, capture-mark-recapture), and often enhance or provide results contrary to those obtained using traditional methods (Hughes 1998 and references therein).

Many fine-scale genetic techniques now incorporate detailed spatial information that goes beyond simple linear distances between populations. Incorporating advanced spatial analyses has enabled quantification of the effects of habitat and/or geographic 
barriers to explain genetic patterns (Manel et al. 2003, Spear et al. 2005, Storfer et al. 2007, Telles et al. 2007). For example, interpolation, a procedure that is commonly used in spatial analyses to calculate new data points to fit the range of known data points, is now being used to present novel graphical representations of spatial genetic structure (Miller 2005, Vignieri 2007). Interpolation enables population geneticists to model continuous genetic distances across a patchily sampled landscape without $a$ priori grouping samples into subpopulations. When applied in the context of landscape-scale processes like habitat fragmentation, novel molecular methods are a powerful way of revealing genetic impacts to populations.

In this study, we use a large island population of tuatara (Sphenodon punctatus) to investigate the potential effects of recent habitat fragmentation on spatial genetic structure, dispersal, and relatedness. Endemic to New Zealand, tuatara are mediumsized (approximately $200 \mathrm{~mm}$ snout-vent length), territorial reptiles that are extremely long-lived (80+ years, Dawbin 1982b), and have a long generation time (40 - 50 years, Allendorf and Luikart 2007). Although once distributed throughout the main and outlying islands of New Zealand, tuatara are now restricted to approximately 35 small offshore islands. Over half of extant tuatara (estimated at 30 - 50,000 individuals, Newman 1987) inhabit Stephens Island, a 150 ha island in the Marlborough Sounds (4040’S, $\left.174^{\circ} 00^{\prime} \mathrm{E}\right)$.

Coastal forest covered Stephens Island until the early 1900's when over $80 \%$ had been cleared or severely degraded for livestock grazing (Dieffenbach 1843, Brown 2000; see Figure 1A). Tuatara appear to have altered their behavior and movement patterns significantly in only two or three generations since fragmentation. In both habitats, tuatara exhibit high territory fidelity and the adult spatial structure is relatively static over time (Moore et al. in review). Tuatara are nocturnal in the pastures, but they are active throughout the day and night in the forest (Gillingham et al. 1995). Further, population density is currently ten times higher in the forest than the pastures ( $\sim 2700$ tuatara/ha in the forest vs. $\sim 250$ tuatara/ha in the pasture; Moore et al. in review). Pastures do not appear to pose significant barriers to tuatara movement (e.g., many females traverse this habitat for nesting), and because tuatara are so long-lived, this population was assumed to be panmictic. However, although 
habitat fragmentation has affected the demography and behavior of Stephens Island tuatara, any unrecognized genetic effects have yet to be revealed.

Genetic structuring and gene flow are well understood for long-lived plants (see Vekemans and Hardy 2004 for a review), but few studies have investigated finescale genetic structuring and dispersal of long-lived animals. Further, most studies of fine-scale genetic structuring and individual dispersal and relatedness patterns are conducted in taxa with well-developed social systems (e.g., insects - Ross 2001, Schrey et al. 2008; mammals - Coltman et al. 2003, Nussey et al. 2005, Frantz et al. 2008). Few reptiles have complex social systems (but see Bull and Cooper 1999, Stow et al. 2001, Chapple and Keogh 2005), and because of ecological and thermal constraints, many reptiles have extremely limited dispersal capabilities. Specifically, we ask:

1) Can dispersal or migration be sex-biased in a species with a simple territorial social structure?

2) Could fine-scale spatial genetic structuring (i.e., between subpopulations $<$ $750 \mathrm{~m}$ apart) occur in a long-lived reptile, and what is the effect of recent habitat fragmentation?

\subsection{Materials and Methods}

\subsubsection{Sample collection}

We collected blood samples from 272 tuatara from eight sampling sites distributed around Stephens Island (Figure 1). In a remnant forest patch on Stephens Island (Keeper's Bush, F1 from now) three study plots (F1a, F1b, and F1c) were established and all individuals within the study plots $(\mathrm{n}=142)$ were captured by hand on six separate sampling trips between November 2004 and March 2007. Four other sites (one regenerating forest, R1; three pasture, P1, P2 and P3) were sampled around the island and were chosen based on accessibility and permission from the New Zealand Department of Conservation (as researcher access is restricted to certain parts of the island). Individuals were located by opportunistic encounters, at night, between 28 Feb and 16 Mar 2006. Thirty tuatara were sampled in Mar 2003 from a forest remnant (the Frog Bank, F2) that is normally inaccessible to tuatara 
A)

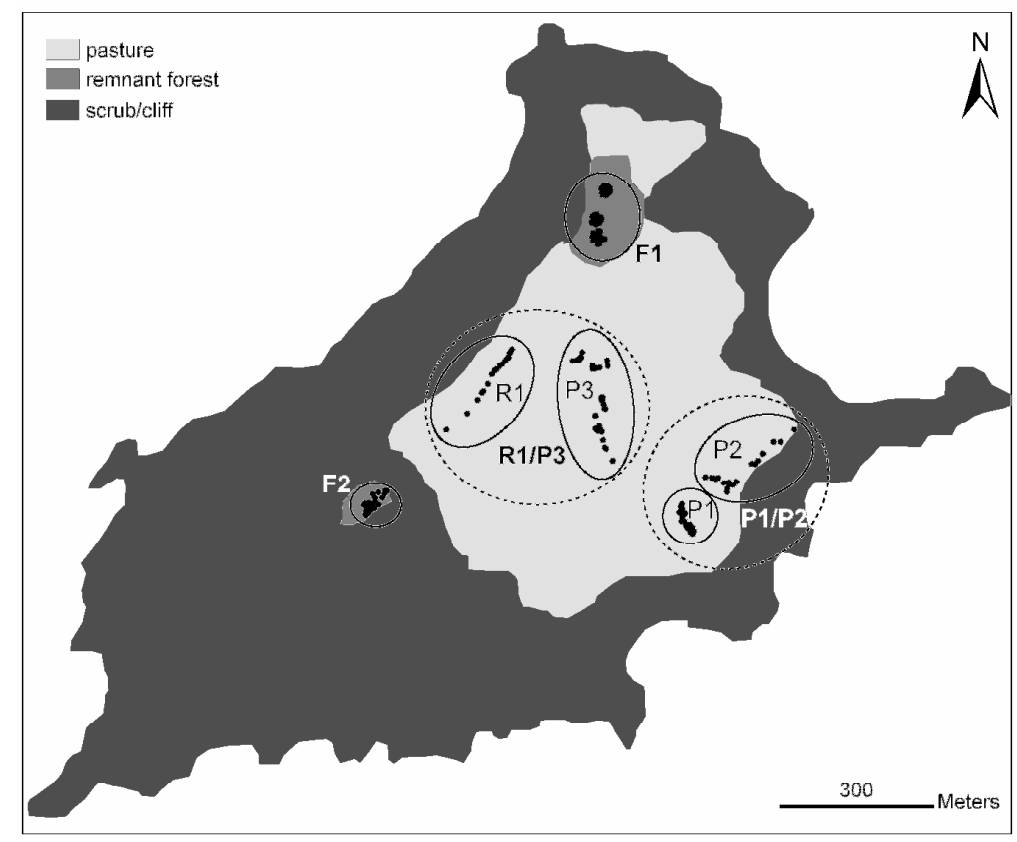

B)

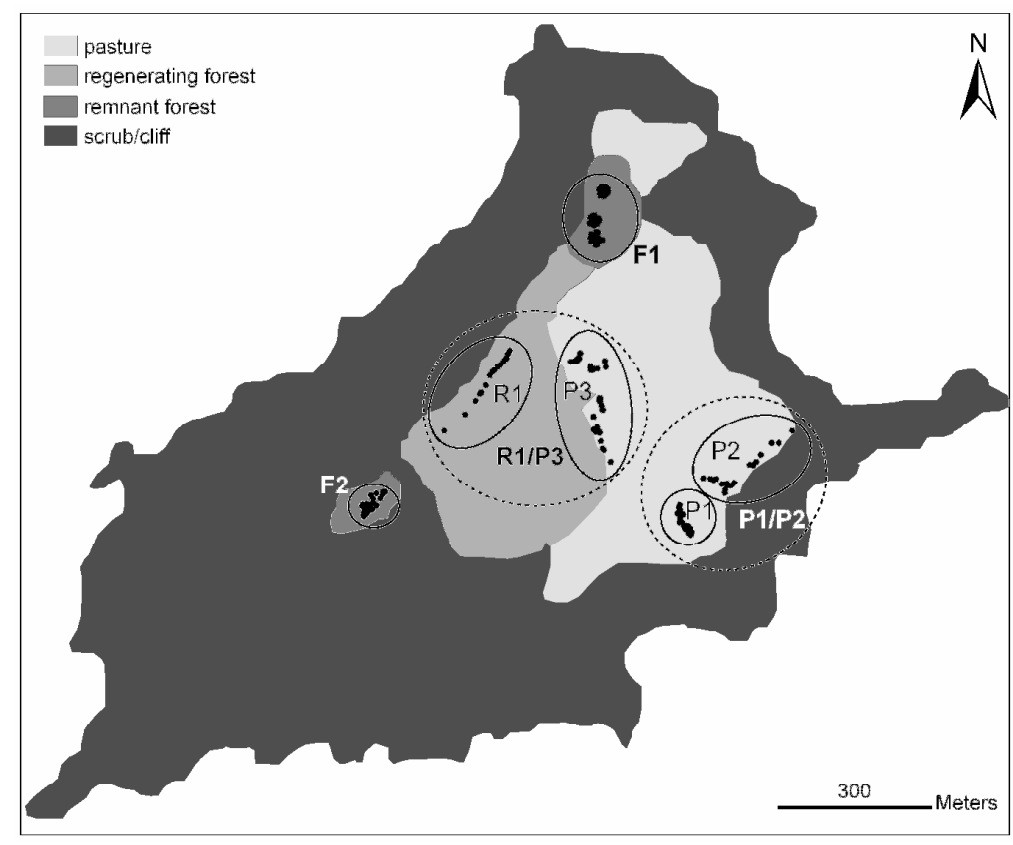

Figure 1. Aerial view of Stephens Island with eight tuatara sampling locations (black dots are individual locations) by habitat type in A) 1943 and B) 1994. Data were grouped for some analyses into four subpopulations (indicated by dashed lines and bold lettering). Significant topography exists, with the island rising to near $300 \mathrm{~m}$ above sea level at the summit (near R1). Landcover layers were digitized based on high resolution aerial photographs and ground-truthed for accuracy. 
researchers. Aside from the F1 site which was repeatedly sampled, no samples were collected during nesting season (Nov - Dec) when females would have been away from their home burrows. All individual capture locations were marked with a handheld GPS (Trimble GeoXT) and locations were post-processed to increase accuracy using Pathfinder Office software (Trimble Navigation Ltd.) and base files from Wellington, NZ. Data were then entered as a point coverage in a geographic information system (GIS).

Upon capture, all tuatara were weighed, measured, sexed, and $0.2-1.0 \mathrm{~mL}$ of blood was drawn from the caudal vein/artery. Sex of adults was determined by sexually dimorphic characters (e.g., larger head and spines of males vs. smaller spines and pear shaped abdomen of females; Cree et al. 1991a) and individuals that were too young to be sexed were classified as juveniles. Blood samples were stored in cryotubes in either $70 \%$ ethanol at room temperature or snap frozen in liquid nitrogen until they could be placed in long-term storage at $-80^{\circ} \mathrm{C}$. Individuals in the F1 plots were marked with a subcutaneous passive integrated transponder (PIT) tag (AVIDC Identification Systems, Inc.), and all others were marked by writing a unique number code on the side of the animal with a non-toxic marker that was visible throughout the duration of the sampling trip, to ensure individuals were not resampled.

\subsubsection{Genotyping and genetic analyses}

Genomic DNA was extracted from 5 - $10 \mu \mathrm{l}$ of whole blood using a proteinase $\mathrm{K}$ phenol-chloroform protocol (Sambrook et al. 1989) or with a DNeasy tissue kit (QIAGEN) following the manufacturer's protocol. We genotyped all individuals using seven reliable and polymorphic loci $(C 2 F, C 11 P, E 11 N, H 5 H, A 12 N, C 12 F$ and $H 4 H$ ) in $15 \mu$ reaction volumes, following PCR conditions outlined in Hay and Lambert (2008). Amplified products were multiplexed for genotyping and were run on an ABI 3730 Genetic Analyzer (Applied Biosystems) with the internal size standard GeneScan 500 LIZ (Applied Biosystems). Fragments were analyzed and visualized using Genemapper software (version 3.0, Applied Biosystems) and sizes were manually scored by the same observer. 
We calculated observed and expected heterozygosities and number of alleles per locus in GENALEX 6 (Peakall and Smouse 2006), and tested for significant deviations from Hardy-Weinberg equilibrium (HWE) and for linkage disequilibrium at each locus for each sampling locality in GENEPOP 4.0 (Raymond and Rousset 1995). We used a Monte Carlo chain method (1000 dememorizations, 100 batches, 1000 iterations) following the algorithm of Guo and Thompson (1992) and applied a Bonferroni correction for a tablewide significance level of 0.05 (adjusted $p$-value $=$ 0.0008). We calculated allelic richness per locus for each sampling site using FSTAT 2.9 (Goudet 1995), and used MICRO-CHECKER 2.0 (Van Oosterhout et al. 2004) to estimate the frequency of null alleles.

\subsubsection{Population patterns of genetic diversity}

We first examined subpopulation structuring in the Stephens Island tuatara using an analysis of molecular variance (AMOVA) framework in GENALEX 6 following methods of Excoffier et al. (1992). AMOVA provides estimates of traditional Fstatistics (Weir and Cockerham 1984), as well as their analogues ( $R_{\mathrm{ST}}$ and $\left.\Phi_{\mathrm{PT}}\right)$. We also calculated pairwise $F_{\mathrm{ST}}$ and $R_{\mathrm{ST}}$. A limitation to the AMOVA framework is that it requires a priori clustering of samples into subpopulations. Thus, we first explored pairwise $F_{\mathrm{ST}}$ and $R_{\mathrm{ST}}$ values of our sites as they were sampled (with eight separate subpopulations), and based on genetic similarities and differences, we grouped them according to spatial proximity (within $200 \mathrm{~m}$ of one another) and habitat and disturbance history. We then ran a second AMOVA with data grouped as four subpopulations: F1 (a random subsample of 50 individuals from the combined data from the three F1 plots), R1/P3 (all R1 samples combined with the P3 samples), P1/P2 (all samples combined from P1 and P2) and F2 (all of the F2 samples) (see Figure 1). Because we only sampled a low number of juveniles in three of the eight sampling sites, we removed juveniles from these analyses. Significance testing was achieved by 9999 random permutations. Because $F_{\mathrm{ST}}$ has many limitations, we also used an assignment-based method that may be a more powerful alternative (Pearse and Crandall 2004, Clark et al. 2008). We calculated $D_{\mathrm{LR}}$, the genotype likelihood ratio distance (Paetkau et al. 1995), using DOH (Brzustowski 2002) with data 
grouped by sampling location. $D_{\mathrm{LR}}$ is the likelihood that a given genotype originated in the population where it was sampled relative to other populations. This measure appears to perform well at fine scales where populations show little differentiation (Paetkau et al. 1997). Significance of assignments was determined by creating random genotypes from pooled populations (in $\mathrm{DOH}$ ) and recalculating population assignments for 1000 randomized datasets. The randomized datasets are then compared to the actual datasets to determine whether the level of self assignment in actual subpopulations is greater than in randomly constructed populations.

We tested whether there was an overall pattern of isolation by distance across subpopulations. We grouped data as six subpopulations F1, F2, R1, P1, P2, and P3 because this analysis is reliant upon geographic distances. We calculated the geometric centers of individual geographic locations for each of the six subpopulations using the 'mean center' tool in ArcGIS 9.1 (ESRI). Pairwise distances between subpopulation centers were determined by performing a surface length analysis in ArcGIS 9.1 based on a 25m digital elevation model (DEM) for Stephens Island. Surface length distances are 3-dimensional lengths that take into account the topography of a landscape, thus providing more accurate estimates of distance when significant topographical features exist. Surface lengths between subpopulation centers were $1-32 \mathrm{~m}$ longer than planimetric (i.e., flat) distances. We performed a Mantel test for matrix correspondence in GENALEX 6 comparing pairwise $R_{\mathrm{ST}}$ values to pairwise surface length distances for the six subpopulations. We used $R_{\mathrm{ST}}$ because it is more appropriate for markers with high levels of variation, and $F_{\text {ST }}$ can be biased downwards when variation within subpopulations is high (Allendorf and Luikart 2007). To examine whether dispersal and movement may be limited to within a habitat type, we used a Mantel test to compare pairwise habitat difference/similarity to genetic distance (pairwise $R_{\mathrm{ST}}$ ) in GENALEX6. We generated a pairwise habitat matrix for the six sites by designating like pairs (i.e., forest-forest) with a value of 1 and unlike pairs (i.e., forest-pasture) with a value of 2 . Significance of matrix correspondence was tested by 9999 random permutations.

Because of the fragmented nature of our study site, we tested the hypothesis that individuals within historic forest fragments (F1 and F2) are more related than individuals in pasture sites (P1/P2 and R1/P3). We calculated mean pairwise 
relatedness $(R)$ using the formula of Queller and Goodnight (1989) in GENALEX 6 (Peakall and Smouse 2006) for each of the four subpopulations. We tested for significant differences in subpopulation means by performing 999 random permutations of our data and 95\% confidence intervals around each mean $R$ were estimated by 999 bootstraps.

Detailed patterns of spatial genetic structure across Stephens Island were visualized using the 'genetic landscape shape' (GLS) interpolation procedure in Alleles in Space (AIS, Miller 2005). This method is designed to facilitate visualization of patterns of diversity across a landscape by creating a 3-dimensional surface plot where $\mathrm{X}$ - and $\mathrm{Y}$-axes correspond to geographic coordinates and the Z-axis corresponds to genetic distance. The procedure thus creates peaks in areas where genetic distances between individuals are high, and valleys or troughs where genetic distances between individuals are low, and is particularly effective at identifying geographic barriers. This method has recently been used to investigate spatial genetic structure at very fine scales (e.g., Vignieri 2007) and is a powerful approach for estimating genetic structure across sampled and unsampled individuals. In AIS, we first created a pairwise location-based connectivity network for all individual locations. Pairwise genetic distances were then calculated following equation three in Miller (2005). Residual genetic distances (derived from the linear regression of all pairwise genetic distances on geographical distance) were then assigned to the midpoints of each connection in the network. Genetic structure across the landscape was inferred from measured genetic distances using an inverse distance weighted interpolation across a uniform grid laid over the entire sampling area. A grid size of 50 × 50 was selected (we also tested a $100 \times 100$, and $25 \times 25$ grid) with a distance weighting parameter $(a)$ of 0.5 (we also tested $a=0.6-1.5$ ).

\subsubsection{Individual dispersal and migration}

In addition to testing for population-wide patterns of diversity, we investigated whether there were differences at the individual level in the form of sex-biased dispersal or migration. Although male-biased dispersal is predicted in polygynous systems (Mossman and Waser 1999, Prugnolle and de Meeus 2002), nesting by forest tuatara occurs outside of home ranges and no direct evidence for natal 
philopatry exists. Thus, we hypothesized sex-biased dispersal would not be evident in pasture or forest tuatara. We conducted four separate indirect tests for sex-biased dispersal and migration of males and females across sites: 1) mean pairwise relatedness, 2) mean corrected assignment index (mAIc), 3) variance of assignment index ( $v A I c)$, and 4) spatial autocorrelation. Assignment indices are following the methodology of Favre et al. (1997) and Mossman and Waser (1999). We included all data from the F1 plots and analyzed each as separate sites (F1a, F1b, and F1c), in addition to the F2, R1/P3 and P1/P2 subpopulations. If sex-biased dispersal exists, the dispersing sex is expected to have a lower average relatedness than the nondispersing sex (Prugnolle and de Meeus 2002). Likewise, mAIc should be lower for the dispersing sex because immigrants have lower AIC values than residents, and $v A I c$ should be higher for the dispersing sex because members of the dispersing sex will include both immigrants (low AIc) and residents (high AIc) (Mossman and Waser 1999). We calculated mean relatedness between male-male and femalefemale pairs, $m A I c$, and $v A I c$ in FSTAT 2.9. Significance testing was achieved by comparing actual values to randomized values for 10000 permutations. Multi-locus spatial autocorrelation analyses, following the methods of Smouse and Peakall (1999), were performed in GENALEX 6. This technique calculates an autocorrelation coefficient $(r)$ for predefined distance classes. Under a model of restricted dispersal, the expectation is that genetic and geographic distance will be positively autocorrelated at short distances. Significance tests are performed using 1000 random permutations and 95\% confidence intervals for estimates of $r$ are determined by 1000 bootstraps.

\subsection{Results}

\subsubsection{Genetic analyses}

Expected heterozygosity ranged from $0.73-0.78$ and was highest for the F1b and P3 sites $\left(H_{E}=0.78\right)$ and lowest for the F2 site $\left(H_{E}=0.73\right)$ (Table 1$)$. Allelic richness ranged from $8.1-9.5$ alleles per locus. Individuals in the R1 subpopulation showed the highest allelic richness (9.5 alleles) while the F2 individuals showed the lowest allelic richness (8.1 alleles) (Table 1). Following the Bonferroni correction, only one 
Table 1. Sample sizes (N), habitat type, mean number of alleles, expected $\left(\mathrm{H}_{\mathrm{e}}\right)$ heterozygosity by locus, and allelic richness (number of alleles corrected for sample size) for each tuatara sampling locality on Stephens Island.

\begin{tabular}{llllll}
\hline & $\mathrm{N}$ & Habitat type & $\begin{array}{l}\text { No. } \\
\text { alleles }\end{array}$ & $H_{E}$ & $\begin{array}{l}\text { Allelic } \\
\text { richness }\end{array}$ \\
& & & & & \\
\hline F1a & 42 & Remnant forest & 11.29 & 0.76 & 8.9 \\
F1b & 47 & Remnant forest & 11.71 & 0.78 & 9.2 \\
F1c & 53 & Remnant forest & 11.57 & 0.77 & 9.0 \\
F2 & 30 & Remnant forest & 8.86 & 0.73 & 8.1 \\
R1 & 20 & Regenerating forest & 9.71 & 0.77 & 9.5 \\
P1 & 20 & Pasture & 8.86 & 0.75 & 8.7 \\
P2 & 20 & Pasture & 9.00 & 0.76 & 8.9 \\
P3 & 40 & Pasture & 11.14 & 0.78 & 9.0 \\
\hline
\end{tabular}

locus $(\mathrm{H} 5 \mathrm{~V})$ in one subpopulation $(\mathrm{P} 3)$ showed a significant deviation from HWE. We did not find any overall linkage disequilibrium between any of the loci. Although null alleles were detected at low frequencies in one locus for three subpopulations, and two loci for one subpopulation, null alleles were not detected at the same loci across subpopulations. Therefore, we retained all seven loci for analyses.

\subsubsection{Population patterns of genetic diversity}

The AMOVA with data grouped as four subpopulations based on discreet sampling locations showed generally low but significant levels of differentiation (overall $R_{\mathrm{ST}}=$ $0.012, \mathrm{p}=0.025$ ), with only $1.2 \%$ of total genetic variation due to differences among subpopulations. Pairwise estimates of $R_{\mathrm{ST}}$ between the F2 and P1/P2 and R1/P3 sites were low, but significant (Table 2). We found no evidence for an isolation by distance pattern. The F2 and R1/P3 sites (located $\sim 400 \mathrm{~m}$ from one another) were significantly genetically differentiated, while sites (F1 and F2) that were a greater distance apart ( $\sim 750 \mathrm{~m})$ were not. Pairwise $D_{L R}$ values ranged from $0.0-1.46$, indicating a low to moderate average likelihood of observing individual genotypes in the subpopulation from where they were sampled to that of other subpopulations (Clark et al. 2008). Furthermore, 29\% of individuals were correctly assigned to the 
Table 2. Pairwise population $R_{\mathrm{ST}}$ (above diagonal) and, for comparison, $F_{\mathrm{ST}}$ (below diagonal) estimates for tuatara from four subpopulations from two habitat types (forest $=\mathrm{F} 2$ and $\mathrm{F} 1$, pasture $=$ $\mathrm{P} 1 / \mathrm{P} 2$ and $\mathrm{R} 1 / \mathrm{P} 3$ ) on Stephens Island. Asterisks indicate significant differences from zero $(\mathrm{p}<0.05)$.

\begin{tabular}{lllll}
\hline & $F 2$ & $F 1$ & P1/P2 & R1/P3 \\
\hline F2 & - & 0.009 & $0.053^{*}$ & $0.030^{*}$ \\
F1 & 0.003 & - & 0.004 & 0.000 \\
P1/P2 & $0.007^{*}$ & 0.000 & - & 0.004 \\
R1/P3 & $0.011^{*}$ & 0.000 & 0.001 & - \\
\hline
\end{tabular}

subpopulation from which they were sampled and the randomization procedure showed significant self-assignment in the two forest remnant sites (F1 and F2), but not in the other sites (Table 3). No individuals from the R1 site assigned to the R1 site, but rather they assigned evenly across all other sites. The Mantel test comparing pairwise surface lengths to pairwise genetic distance showed no significant patterns of isolation by distance $(\mathrm{R}=0.47, \mathrm{p}=0.078)$. However, the Mantel test comparing pairwise habitat difference/similarity to genetic distance was weakly significant $(\mathrm{R}=$ $0.47, \mathrm{p}=0.048$ ). Mean pairwise relatedness was generally low (values ranging from $-0.14-0.062)$. Only the individuals within the F2 subpopulation were significantly

Table 3. Proportion of sampled tuatara assigned from column site to row site from six sampling sites around Stephens Island (based on genotype likelihood ratio distances). Only individuals from the two remnant forest sites (F1 and F2) showed significant self-assignment to their subpopulation of origin, as indicated by the asterisks $(\mathrm{p}<0.05)$.

\begin{tabular}{lllllll}
\hline & F2 & F1 & P3 & P2 & P1 & R1 \\
\hline F2 & $0.40^{*}$ & 0.23 & 0.10 & 0.13 & 0.00 & 0.13 \\
F1 & 0.18 & $0.36^{*}$ & 0.18 & 0.10 & 0.09 & 0.09 \\
P3 & 0.05 & 0.30 & 0.20 & 0.08 & 0.15 & 0.23 \\
P2 & 0.15 & 0.15 & 0.20 & 0.20 & 0.15 & 0.15 \\
P1 & 0.05 & 0.20 & 0.25 & 0.20 & 0.15 & 0.15 \\
R1 & 0.15 & 0.25 & 0.30 & 0.20 & 0.10 & 0.00 \\
\hline
\end{tabular}




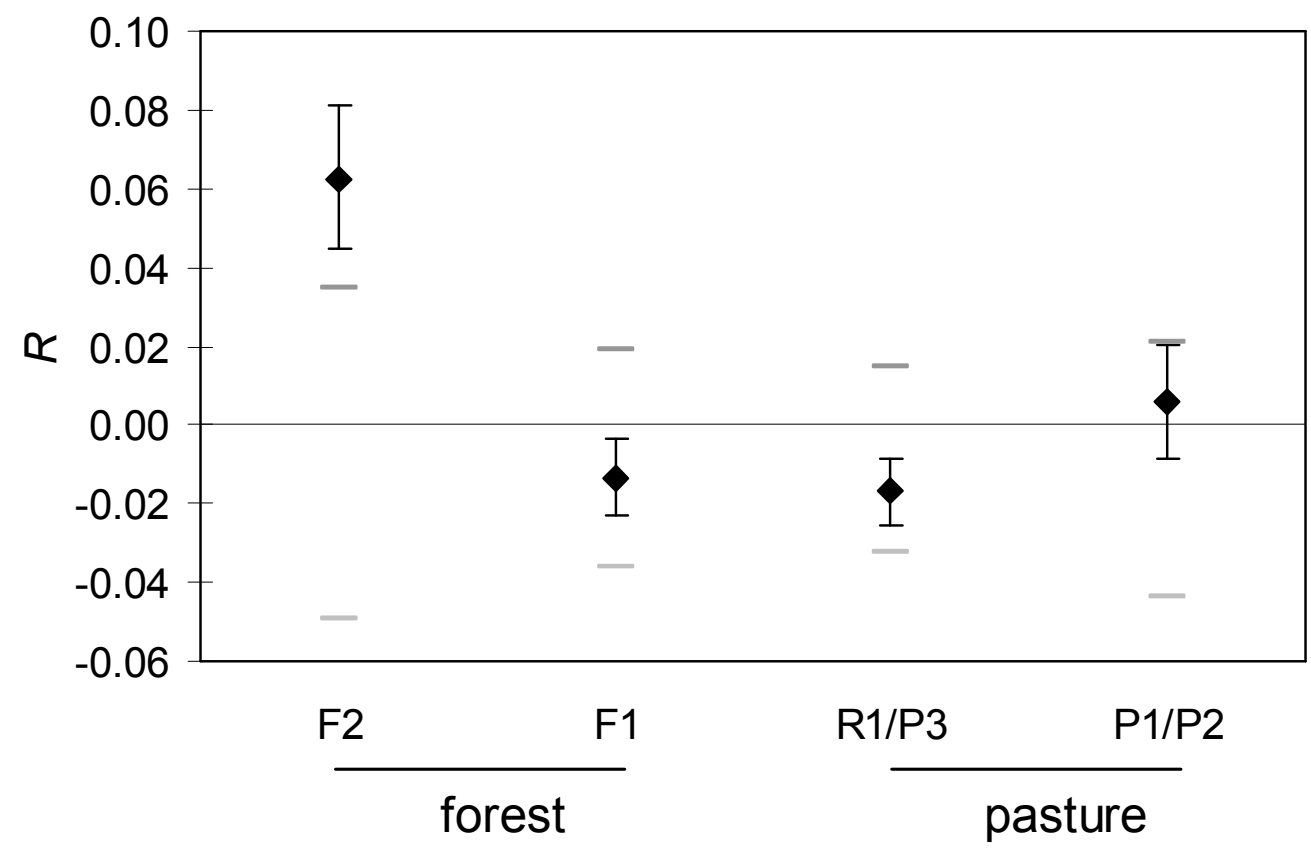

Figure 2. Mean pairwise estimates of tuatara relatedness (bound by 95\% confidence intervals) for forest (F1 and F2) and pasture subpopulations (P1/P2 and R1/P3). Individuals in the F2 subpopulation are significantly more related than expected $(\mathrm{p}=0.002)$. Gray bars are upper and lower 95\% confidence limits across subpopulations.

more related than the other three subpopulations (mean $=0.062, \mathrm{p}=0.002$; Figure 2) as determined by permutation testing.

The genetic landscape shape suggests increased genetic distance between individuals in the middle of the island, with lower genetic distance between individuals around the edges, and extremely low distances (represented as a trough) in the region of the F2 site (Figure 3). The peaks appear to approximately correspond to regions that would have historically been most disturbed (pastures), while troughs correspond to least disturbed areas (forest fragments). The interpolation is bounded by the outside of the sampling area, and thus does not include anything beyond the outermost edges of the sampling areas (e.g., cliffs).

\subsubsection{Individual dispersal and migration}

We did not detect an overall pattern of sex-biased dispersal or migration. Mean pairwise relatedness between males $(R=0.008)$ and females $(R=0.01)$ was not 
A)

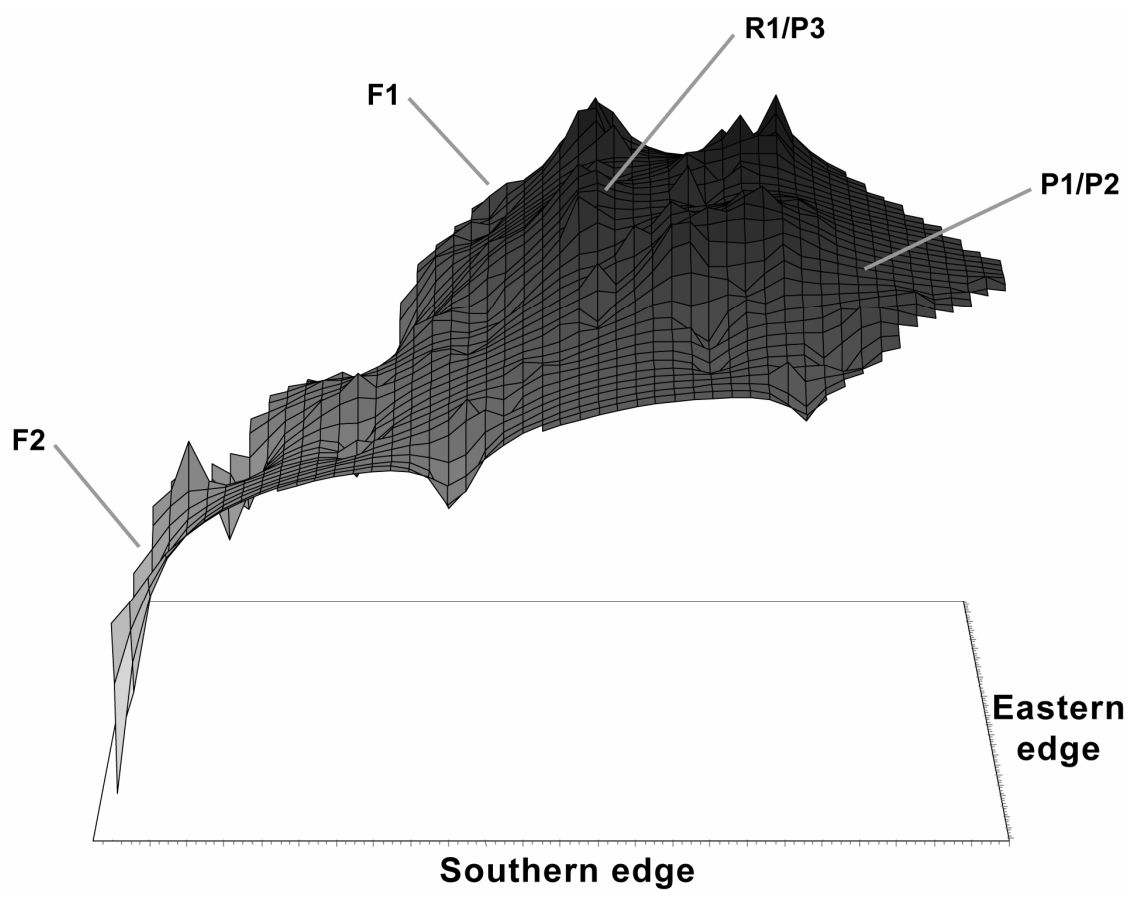

B)

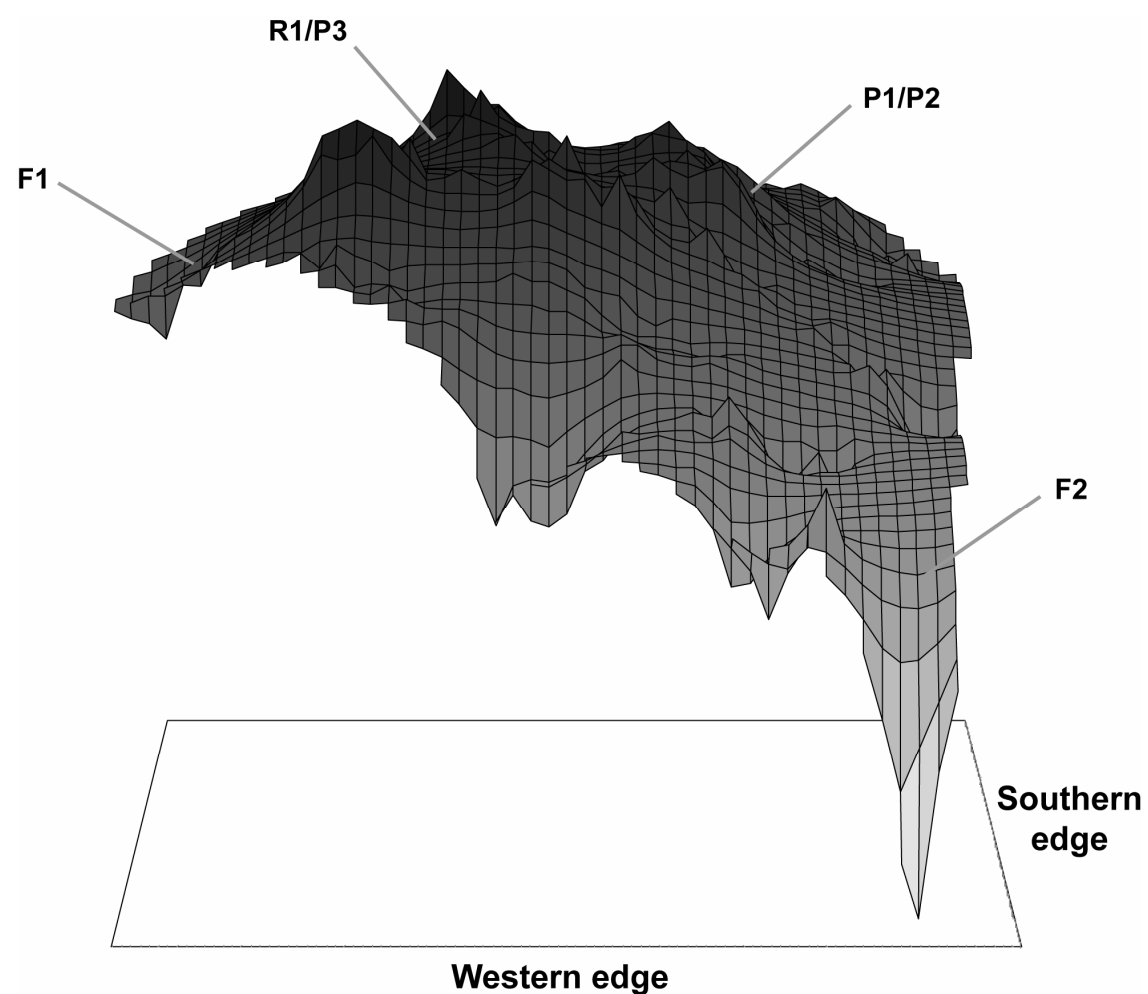

Figure 3. Genetic landscape shape showing patterns of spatial genetic distance for tuatara across Stephens Island. X- and y-axes correspond to geographic coordinates and the $\mathrm{z}$-axis (height) corresponds to genetic distance between individuals. Peaks are indicative of areas with high pairwise genetic distance and valleys or lighter colours are indicative of areas of low pairwise genetic distance. Approximate centres of sampling sites are indicated for clarity. 
significantly different $(p=0.27)$. Although the mean corrected assignment index was lower on average for males $(m A I c=-0.16)$ than females $(m A I c=0.30)$, the difference was not significant $(\mathrm{p}=0.11)$. Likewise, variance of assignment index was higher for males $(v A I c=8.01)$ than females $(v A I c=7.63)$, but the difference was not significant $(p=0.35)$. We found no obvious patterns from the spatial autocorrelation analyses. Neither sex showed a significant decline in genetic distance with geographic distance (Figure 4) suggesting that neither sex is philopatric.

A)

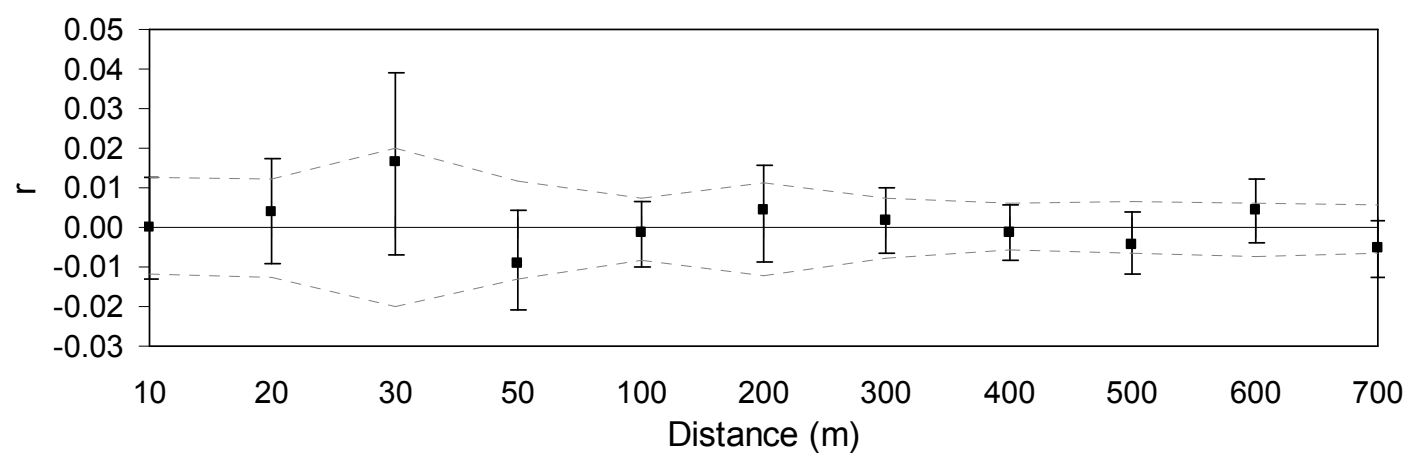

B)

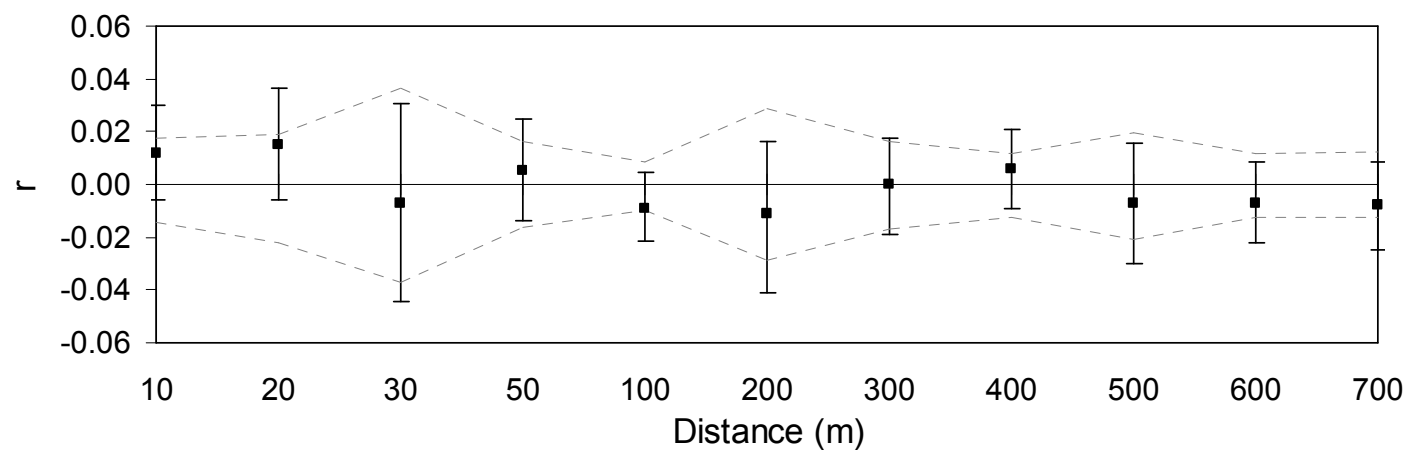

Figure 4. No significant pattern of spatial autocorrelation exists for male (A) or female (B) tuatara on Stephens Island as indicated by the correlograms of correlation coefficients (r) of geographic and genetic distance at variable distance classes. Upper and lower error bars are bound by $95 \%$ confidence intervals around each $\mathrm{r}$, and dashed lines indicate $95 \%$ confidence limits around the null hypothesis of a random spatial distribution of genotypes.

\subsection{Discussion}

We show that large populations of long-lived animals with high genetic variation can exhibit genetic structuring on a very small scale $(<500 \mathrm{~m})$, even in the absence of 
sex-biased dispersal or complex social systems. Although the level of genetic differentiation in Stephens Island tuatara was low, the fact that any significant genetic structuring exists at this scale in such a long-lived species is surprising. We found no evidence for sex-biased dispersal, and assignment tests reflect individual movement patterns consistent with recent habitat modification.

The low but significant genetic structuring of Stephens Island tuatara is primarily driven by the differentiation of the southern forest remnant (F2) individuals. The most parsimonious explanation for this result is that the F2 site has simply diverged over time because it has been the least disturbed through the history of the island (Brown 2000), and it may be naturally more isolated due to the topography of the island. However, this does not explain why the two forest remnants were not genetically differentiated, even though they were geographically more distant than sites that were. We envisage two possible explanations for this pattern. First, the scrubby cliffs along the western edge of the island may have functioned as a corridor between the two forest remnants during and after fragmentation. Although inaccessible to people and livestock, these cliffs pose no barrier to tuatara movement and probably provide greater cover than the pastures. Radiotelemetry has shown that some female tuatara from the northern forest remnant $(\mathrm{F} 1)$ nest on the western cliffs, subsequently returning to their home ranges (J. Moore, unpublished data). Juveniles dispersing from western cliff nests to either of the forest remnants, avoiding the disturbed areas in between, may have homogenized these two sites.

Secondly, allele frequencies in the forest remnants may represent what was present across the island prior to habitat modification, and increased admixture in the pasture and regenerated sites has caused these sites to exhibit different genetic profiles from the F2 site. Deforestation of pasture sites and constant disturbance from livestock grazing has altered behavior and movement patterns of adult tuatara (Gillingham et al. 1995, Moore et al. 2007) and may have caused increased mortality. Further, conversion of forest to pasture has altered the thermal regime enabling nesting in pastures that were too cold to support egg development when forested (Thompson 1990). Therefore, genetic signatures of F1 individuals are regularly introduced to the pasture sites by F1 females that now nest in these sites (N. Nelson, unpublished data). The high genetic distances (calculated in AIS) between individuals in the 
pastures (see GLS in Figure 3), the even assignment of pasture individuals across all other sites, and the lack of differentiation between the F1 and pasture sites support this supposition. In this respect, the forest fragments may have acted as refugia for established resident tuatara that were able to maintain their natural spatial structure and behavioral patterns throughout the period of disturbance, as well as nearby juveniles that may have immigrated during heavy disturbance. The significant selfassignment of only individuals from forest sites and findings from our habitat Mantel test provide evidence for this.

Our assignment tests show that individuals in the reforested R1 site are recent immigrants. The R1 site, and the entire region between the two forest remnants (Figure 1), was once completely denuded by livestock and naval activity (Brown 2000). This area was replanted in 1989 by the New Zealand Department of Conservation to provide a corridor between the remaining forest patches, which now resembles original closed canopy forest remnants. Reforestation appears to have established a refuge for pasture animals by providing increased cover from avian predators, greater food resources (Walls 1981), and little competition from already established resident tuatara. Kanowski et al. (2006) advocate revegetating corridors between remnant habitat fragments for successful re-establishment of reptile populations. Our data suggest that corridor reforestation has been a successful approach for tuatara, and most likely for other lizard species as well (Stephens 2004).

We found no strong pattern of sex-biased dispersal or migration in tuatara. Although values from the individual tests point to males being the more mobile sex and females the more philopatric sex, no test was significant. Sex-biased dispersal may evolve as a mechanism to avoid inbreeding (Perrin and Mazalov 2000, Prugnolle and de Meeus 2002), but because female tuatara in the forest do not nest in their home ranges, the risk of inbreeding in large forest remnants is low. Sex-biased dispersal may be more prevalent in reptiles that live in family groups or have more complex social systems (e.g., some lizards in the Egernia genus, Bull and Cooper 1999, Stow et al. 2001). Our ability to detect natural dispersal patterns is probably confounded by the disturbance and habitat fragmentation in this population (e.g., Stow et al. 2001, Sumner 2005). A more appropriate test may be to examine only patterns of 
juvenile dispersal, or patterns of dispersal on a warmer northern island where local climatic conditions could allow females to nest in their home ranges.

Spatial genetic structuring has now been detected at fine scales $(100 \mathrm{~m}-2 \mathrm{~km})$ in a number of mobile animal species (e.g., Gibbs et al. 1997, Spruell et al. 1999, Brouat et al. 2003, Coltman et al. 2003, Peakall et al. 2003, Double et al. 2005, Clark et al. 2008). However, many of these species have a more complex social system, and shorter lifespan, than tuatara. For instance, fine-scale genetic structuring can be reinforced by a strong tendency for female philopatry, a pattern that is common in many mammals (e.g., red deer, Cervus elaphus, Nussey et al. 2005, Frantz et al. 2008). The relatively simple territorial spatial structure of tuatara is highly stable over years (Moore et al. in review), and possibly decades. The risk that juveniles will coincidentally disperse to the same forest fragment as their parents increases when preferred forest habitat is limited, thereby increasing relatedness within small fragments (e.g., for Cunningham's skink, Egernia cunninghami, Stow et al. 2001). Thus, the sedentary lifestyle and limited dispersal of adult tuatara, and many reptiles (Gibbs et al. 1997, Prosser et al. 1999), may be strong enough to result in fine-scale genetic structuring even in the absence of a more complex social system.

We found no overall pattern of isolation by distance for Stephens Island tuatara. At mutation-migration-drift equilibrium, and for species with limited dispersal, genetic differentiation should increase with geographic distance (Slatkin 1993). Habitat fragmentation and disturbance may have caused Stephens Island tuatara to diverge from this theoretical expectation. Driscoll and Hardy (2005) found that populations of agamid lizards (Amphibolurus nobbi) in uncleared forested habitat showed significant isolation by distance, whereas populations in linear farmed habitat did not. Further, small $A$. nobbi populations in farmed habitat had similar levels of genetic variation to large populations in nature reserves, which the authors attributed to a burst of movement during land clearing resulting in migrations of lizards from many sources finding refuge in remnant forest populations (Driscoll and Hardy 2005). Stephens Island tuatara appear to reflect a similar pattern, although it is perhaps equally plausible that the isolation by distance expectation would not hold true at this fine scale. The apparent alteration of genetic structuring and dispersal across the island has occurred on a very short timescale for long-lived tuatara (only 
2-3 generations), so the current patterns are more indicative of increased migration of long-lived individuals, rather than genetic drift.

Anthropogenic habitat modification and disturbance have had a profound effect on gene flow for many reptiles, because of their naturally low dispersal and extreme sensitivity to changes in the thermal environment (Cunningham and Moritz 1998, Stow et al. 2001, Sumner et al. 2004, Driscoll and Hardy 2005, Sumner 2005, Gardner et al. 2007). If weak fine-scale genetic structuring due to limited dispersal and a sedentary lifestyle is not counteracted by extreme longevity, large population size, or a simple social structure or random dispersal pattern (e.g., for tuatara), we suspect that any species with limited dispersal or mobility could exhibit very finescale spatial genetic structuring. These species may thus be more susceptible to behavioral alteration from anthropogenic habitat fragmentation or disturbance, which would ultimately affect patterns of gene flow and genetic differentiation and potentially increase extinction risk. 


\section{CHAPTER SEVEN}

\section{Thesis Summary and Applications}

\subsection{Introduction}

This thesis examined the mating system and reproductive ecology of tuatara (Sphenodon punctatus) and their effects of individual fitness and population genetic diversity. Combining spatial, behavioural, and genetic analyses has provided the most complete picture of the reproductive ecology of tuatara to date. I have provided information on the demographic and ecological factors affecting the largest population of tuatara (on Stephens Island) as well as characterised the spatial structure and the mating system. I have also examined how variations in fitness can affect overall genetic variation and structure of populations. I addressed fundamental questions that are relevant to tuatara conservation, and have laid the groundwork for future research on sexual selection and postcopulatory phenomena in tuatara. This thesis sheds new light on the reproductive biology of these iconic reptiles, and advances the current knowledge of reptile evolutionary ecology by providing a baseline for phylogenetic comparisons of mating system evolution.

\subsection{Summary of major findings}

The major findings from the previous five data chapters are briefly summarised as follows:

1) Chapter Two - Monitoring Over 54 Years Shows a Decline in Body Condition of a Long-lived Reptile (tuatara, Sphenodon punctatus)

Body condition of tuatara on Stephens Island has significantly declined over the past 54 years, and because of large natural fluctuations the trend was not evident until monitoring for at least 22 years. The population is showing a density-dependent response driven by past habitat modification on the island. Declining body condition may affect female reproductive output, and has implications for population growth rates. Reforestation of Stephens Island 
may reverse decline in body condition by limiting available nesting sites and potentially slowing the current population growth rate.

\section{2) Chapter Three - Large Male Advantage: Phenotypic and Genetic} Correlates of Territoriality and Female Access in an Ancient Reptile (tuatara, Sphenodon punctatus)

Male tuatara are significantly more structured in space than females, and the social structure of tuatara is stable over years and potentially decades. Male body size - not individual genetic heterozygosity, core home range size, or body condition - predicts access to females. Large, more heterozygous males are more effective at monopolising areas where females are most dense and guarding females by winning intrasexual aggressive encounters. The spatial structure provided no evidence for alternative male reproductive strategies, although further research is needed to definitively rule out the potential for alternative strategies. The ability to detect potential correlations between heterozygosity and fitness probably depends on the genetic background of the population. Individual heterozygosity may have a stronger effect in a population with lower genetic variation (e.g., a bottlenecked or inbred population).

3) Chapter Four - High Reproductive Skew, Size-Assortative Mating, and Seasonal Monogamy in a Territorial Reptile (tuatara)

The mating system of tuatara is primarily seasonally monogamous and polygynous between seasons, which is consistent with a male mate guarding hypothesis. Reproduction is highly skewed toward large males. Approximately 25 - 30\% of males dominate reproduction in the population. Monogamy is probably facultative in that mate acquisition for males is limited by the spatial dispersion of females. Multiple paternity was not detected in the sampled clutches.

4) Chapter Five - Implications of Social Dominance and Multiple Paternity for the Genetic Diversity of a Captive-Bred Reptile Population (tuatara) Social dominance in captive adult tuatara on Little Barrier Island has resulted in highly skewed paternity in the offspring. Multiple paternity was found in 
$18.8 \%$ of clutches. High reproductive skew caused a loss of genetic variation in this bottlenecked population and decreased the effective population size. These results will facilitate equalising founder representation in future captive breeding efforts.

\section{5) Chapter Six - Fine-scale Genetic Structure of a Long-lived Reptile}

\section{Reflects Recent Habitat Modification}

Stephens Island tuatara exhibit genetic population structuring on a very fine scale. Isolation by distance is not evident. Rather, fine-scale genetic structuring appears to be compounded by habitat disturbance and modification and the sedentary lifestyle of tuatara. No consistent pattern of sex-biased dispersal or migration exists. Reforestation of grazed habitat appears to have provided refuges for tuatara migrating in from disturbed areas.

\subsection{Conservation implications}

The behavioural and genetic results of this thesis can be applied toward conservation management of tuatara in many ways (e.g., Moore et al. 2008a, Appendix One). Knowing that large male body size affects reproductive success (Chapters Three and Four) should enable managers to be more selective about male founders chosen for translocations. Depending on the dynamics of the source population, which should ideally be assessed prior to manipulation, this result could be applied in different ways. If the source population is large and dense, it may be advantageous to translocate small males that do not regularly breed as they may have a better chance of success on a less dense island. However, removing small, as-yet unsuccessful males from small source populations could increase the rate of genetic drift by removing genetic variation from the population. In small source populations, removing large, successful males may lessen competition and give smaller males a better chance of being reproductively successful on the source island. Likewise, only translocating males of similar body size may help to reduce the high reproductive skew due to variability in male body size. 
Manipulating the founder sex ratio (strongly toward females) could be used to reduce competition for females. Male genetic contributions may be equalised, while possibly increasing immediate population growth (e.g., for lesser kestrels, Lenz et al. 2007). However, the dynamics of the source population also need to be considered in this instance. While removal of a large number of females may not affect a large, dense source population, it could have a detrimental effect on a small source population. Likewise, if the source population is male-biased (e.g., North Brother Island, Nelson et al. 2002b), removal of a large number of females could have an extremely detrimental effect, particularly in the face of global climate change that may shift populations toward a male-biased sex ratio. Although population density and sex ratio data are essential for assessing the impacts of translocations to source populations, the detailed mark-recapture studies needed to accurately estimate these parameters can be difficult to carry out. Male tuatara are much more active than females, so even though some populations may appear male-biased because males are seen more often, a detailed mark-recapture study that takes into account sex differences in behaviour and activity (Chapter Three) is necessary to accurately estimate sex ratio and population density.

The Little Barrier Island tuatara provide a good example of the impact that the male dominance structure can have on genetic diversity of small or captive populations (Chapter Five). Tuatara are able to establish a natural spatial structure at very high densities, and do not require large spaces to maintain territories (Chapter Three). Thus, if captive tuatara are held in relatively large enclosures, they may be able to establish a semi-natural spatial structure. However, if captive populations do maintain a semi-natural territory structure, reproduction will probably be dominated by one or a few large males, especially if there is a large discrepancy in body size of the captive males. This may also be true of small wild populations, where the population census size may be quite different from the effective population size because reproduction is highly skewed.

If large, highly dense populations of tuatara can be genetically structured (Chapter Six), small, fragmented populations may be even more strongly structured. Thus, the potential for strong, fine-scale genetic structuring should be considered when sourcing animals from small populations. Taking all founders from one particular 
patch of forest may not be a good genetic representation of the source population. For large source populations (i.e., Stephens Island) sourcing founders from a large patch of forest like Keeper's Bush may provide a good genetic representation of the source because the genetic diversity in the forest remnant is high. However, on smaller islands, sourcing founders from many geographic locations within an island may capture greater genetic diversity than focusing on one location only.

We found evidence to suggest phenotypic and genetic effects of past habitat modification and disturbance on Stephens Island (Chapters Two and Six). Habitat modification is not unique to Stephens Island. Rather, many tuatara islands that have had a strong human presence have had land cleared and/or been farmed to some degree (Gaze 2001). Reforestation of cleared island habitat should be a priority for restoring populations of tuatara to their natural states. It is still unknown whether undisturbed, unfragmented populations of tuatara exhibit some genetic structuring. For instance, it may be that undisturbed populations show a pattern of isolation by distance, but this is disturbed when habitat is modified and animals are forced to relocate. In any case, reforestation should return populations back to their natural state by reconnecting isolated forest fragments and promoting increased potential for gene flow. While this may decrease the amount of tuatara nesting habitat currently available, and potentially decrease population growth rates, it is likely to have a positive effect on individual fitness by bringing populations such as Stephens Island back to carrying capacity. In addition to having positive fitness effects for tuatara, decreasing the population growth rate should reduce the pressure on their prey species, many of which are threatened or endangered themselves.

\subsection{Directions for future research}

This thesis has answered many questions regarding the reproductive ecology and genetics of tuatara, but throughout the course of this research, many new questions have arisen. The groundwork has now been laid for more complex, advanced questions of sexual selection and evolutionary ecology of tuatara that may expand on the work presented in this thesis. 
No evidence currently exists for multiple paternity in wild tuatara. In addition to the six clutches examined in this study (Chapter Five), Hay and Lambert (2008) genotyped an additional five clutches from Stephens Island tuatara, and three clutches from Brother's Island tuatara (S. guntheri) and did not find multiple paternity in any clutch. In total, 14 wild clutches (99 hatchlings) have been analysed. Although this is a relatively small sample size, the lack of multiple paternity is surprising in light of the approximately $20 \%$ of clutches $(n=16)$ from captive animals that were found to have multiple paternity (Chapter Five). Multiple paternity is not expected to be limited to captivity. However, rates of polyandry and multiple paternity are influenced by density, which affects mate-encounter rates (Uller and Olsson 2008). Even though multiple mating may have positive effects on population genetic diversity (Sugg and Chesser 1994), very little evidence suggests that multiple mating has positive consequences for individual fitness in reptiles (reviewed in Uller and Olsson 2008). A better understanding of the factors affecting multiple paternity in tuatara populations would enable predictions based on population dynamics (size, density, etc.,) that could have applications for genetic diversity of small, captive, or translocated populations.

\subsubsection{Do postcopulatory reproductive phenomena exist is tuatara?}

Female tuatara can mate repeatedly throughout the season, whether it is with the same or different males (Chapter Four). Although tuatara are not believed to be capable of long-term sperm storage (i.e., female tuatara lack specific sperm storage tubules, Gabe and Saint Girons 1964), delayed fertilisation (Cree et al. 1991a, Cree et al. 1992) potentially provides a window for short term sperm storage, sperm competition and/or cryptic female choice. Likewise, rarity of multiple paternity in wild populations may provide evidence for sperm competition (e.g., for green turtles, Chelonia mydas, Fitzsimmons 1998). Developing a method to reliably collect sperm from male tuatara would enable an assessment of sperm motility and competition. Although challenging, mate choice experiments with female tuatara could clarify whether cryptic choice occurs and if it is based on indirect (i.e., genetic) benefits. Further, developing these new techniques may make artificial insemination possible 
which would enhance management of small or captive populations by enabling direct manipulation of reproduction (Ebenhard 1995).

Additionally, the function of post-copulatory male 'shuddering' behaviour remains unknown. Gillingham et al. (1995) assumed that this behaviour was related to prolonged ejaculation. However, during the course of this study, sperm transfer in mating tuatara was observed, and it occurs prior to male shuddering. This behaviour may stimulate sperm uptake in the female, or be an immediate mate guarding tactic. Quantifying the duration of this behaviour for each reproductive event, and in relation to paternity success, may help to elucidate the function of this currently cryptic behaviour.

\subsubsection{How does density affect the mating system of tuatara on different islands?}

This thesis provides many new insights into the mating system of tuatara, but investigations were primarily restricted to Stephens Island, where tuatara are easily observed. As mating systems are known to be density-dependent (Kokko and Rankin 2006), it would be useful to compare the mating system on island populations that are ecologically similar, but vary in tuatara density. This would enable greater generalisation and application of results. If generalisations can be made broadly across populations, the effects of translocations on source populations can be predicted from population dynamics. Likewise, the optimal density for new populations could be identified prior to a translocation. 


\section{References}

Abell AJ. 1997. Estimating paternity with spatial behaviour and DNA fingerprinting in the striped plateau lizard, Sceloporus virgatus (Phrynosomatidae). Behavioral Ecology and Sociobiology 41: 217-226.

Adler GH, Levins R. 1994. The island syndrome in rodent populations. Quarterly Review of Biology 69: 473-490.

Aitken N, Hay JM, Sarre SD, Lambert DM, Daugherty CH. 2001. Microsatellite DNA markers for tuatara (Sphenodon spp.). Conservation Genetics 2: 183-185.

Akaike H. 1973. Information Theory as an Extension of the Maximum Likelihood Principle. Pages 267-281 in B. N. Petrov and F. Caski, eds. Second International Symposium on Information Theory. Academiai Kiado, Budapest.

Akcay E, Roughgarden J. 2007. Extra-pair paternity in birds: review of the genetic benefits. Evolutionary Ecology Research 9: 855-868.

Allendorf FW. 2001. Genetics and the viability of insular populations of reptiles. New Zealand Journal of Zoology 28: 361.

Allendorf FW, Luikart G. 2007. Conservation and the genetics of populations. Blackwell Publishing, Malden, MA, USA.

Amos W, Wilmer JW, Fullard K, Burg TM, Croxall JP, Bloch D, Coulson T. 2001. The influence of parental relatedness on reproductive success. Proceedings of the Royal Society of London Series B-Biological Sciences 268: 2021-2027.

Anderson A. 1996. Was Rattus exulans in New Zealand 2000 years ago? AMS radiocarbon ages from Shag River Mouth. Archaelogy in Oceania 31: 178-184.

Andersson M. 1994. Sexual selection. Princeton University Press, Princeton, New Jersey.

Andersson M, Simmons LW. 2006. Sexual selection and mate choice. Trends in Ecology and Evolution 21: 296-302.

Anthony LL, Blumstein DT. 2000. Integrating behaviour into wildlife conservation: the multiple ways that behaviour can reduce Ne. Biological Conservation 95: 303-315.

Antworth RL, Pike DA, Stiner JC. 2006. Nesting ecology, current status, and conservation of sea turtles on an uninhabited beach in Florida, USA. Biological Conservation 130: 10-15.

Avise JC, Jones AG, Walker D, DeWoody JA, Collaborators. 2002. Genetic mating systems and reproductive natural histories of fishes: Lessons for ecology and evolution. Annual Review of Genetics 36: 19-45.

Balazs GH, Chaloupka M. 2004. Thirty-year recovery trend in the once depleted Hawaiian green sea turtle stock. Biological Conservation 117: 491-498. 
Barker SC, Murrell A. 2004. Systematics and evolution of ticks with a list of valid genus and species names. Parasitology 129: S15-S36.

Ben-Ari ET. 2000. Choosy females: Exploring the role of cryptic female choice in sexual selection and battles over paternity. Bioscience 50: 7-12.

Benton MJ. 2000. Vertebrate Palaeontology. Blackwell Science, London, England.

Berger J. 1996. Animal behaviour and plundered mammals: Is the study of mating systems a scientific luxury or a conservation necessity? Oikos 77: 207-216.

Beyer HL. 2004. Hawth's Analysis Tools for ArcGIS. http://www.spatialecology.com/htools.

Birkhead TR. 1998. Cryptic female choice: Criteria for establishing female sperm choice. Evolution 52: 1212-1218.

Blaustein AR, Wake DB, Sousa WP. 1994. Amphibian declines: judging stability, persistence, and susceptibility of populations to local and global extinctions. Conservation Biology 8: 60-71.

Blossey B. 1999. Before, during and after: the need for long-term monitoring in invasive plant species management. Biological Invasions 1: 301-311.

Blouin-Demers G, Gibbs HL, Weatherhead PJ. 2005. Genetic evidence for sexual selection in black ratsnakes, Elaphe obsoleta. Animal Behaviour 69: 225-234.

Bohonak AJ. 1999. Dispersal, gene flow, and population structure. Quarterly Review of Biology 74: 21-45.

Bradshaw CJA, Davis LS, Lalas C, Harcourt RG. 2000. Geographic and temporal variation in the condition of pups of the New Zealand fur seal (Arctocephalus forsteri): evidence for density dependence and differences in the marine environment. Journal of Zoology 252: 41-51.

Bretman A, Tregenza T. 2005. Measuring polyandry in wild populations: a case study using promiscuous crickets. Molecular Ecology 14: 2169-2179.

Brouat C, Sennedot F, Audiot P, Leblois R, Rasplus JY. 2003. Fine-scale genetic structure of two carabid species with contrasted levels of habitat specialization. Molecular Ecology 12: 1731-1745.

Brown D. 2000. Stephens Island: Ark of the Light. Cloudybay Publishing, Blenheim, New Zealand.

Brown JH, Whitham TG, Ernest SKM, Gehring CA. 2001. Complex species interactions and the dynamics of ecological systems: Long-term experiments. Science 293: 643-650.

Brown JL. 1969. Territorial behavior and population regulation in birds. Wilson Bulletin 81: 293-329.

Brown JL, Orians GH. 1970. Spacing patterns in mobile animals. Annual Review of Ecology and Systematics 1:239-262. 
Brzustowski J. 2002. Doh assignment test calculator, http://www2.biology.ualberta.ca/jbrzusto/Doh.php.

Buckley LB, Jetz W. 2007. Insularity and the determinants of lizard population density. Ecology Letters 10: 481-489.

Bull CM. 2000. Monogamy in lizards. Behavioural Processes 51: 7-20.

Bull CM, Cooper SJB. 1999. Relatedness and avoidance of inbreeding in the lizard, Tiliqua rugosa. Behavioral Ecology and Sociobiology 46: 367-372.

Bull CM, Cooper SJB, Baghurst BC. 1998. Social monogamy and extra-pair fertilization in an Australian lizard, Tiliqua rugosa. Behavioral Ecology and Sociobiology 44: 6372.

Burnham KP, Anderson DR. 1998. Model Selection and Inference. A Practical InformationTheoretic Approach. Springer-Verlag Inc., New York, USA.

—. 2004. Multimodel inference: understanding AIC and BIC in model selection. Sociological methods and research 33: 261-304.

Burt WH. 1943. Territoriality and home range concepts as applied to mammals. Journal of Mammalogy 24: 346-352.

Calleri DV, Reid EM, Rosengaus RB, Vargo EL, Traniello JFA. 2006. Inbreeding and disease resistance in a social insect: effects of heterozygosity on immnnocompetence in the termite Zootermopsis angusticollis. Proceedings of the Royal Society BBiological Sciences 273: 2633-2640.

Calsbeek R, Sinervo B. 2002. An experimental test of the ideal despotic distribution. Journal of Animal Ecology 71: 513-523.

—. 2004. Within-clutch variation in offspring sex determined by differences in sire body size: cryptic mate choice in the wild. Journal of Evolutionary Biology 17: 464-470.

Candolin L, Voigt HR. 2001. Correlation between male size and territory quality: consequence of male competition or predation susceptibility? Oikos 95: 225-230.

Carmichael CK, Gillingham JC, Keall SN. 1989. Feeding ecology of the tuatara (Sphenodon punctatus) on Stephens Island based on niche diversification. New Zealand Journal of Zoology 16: 269 (abstract).

Castilla AM. 1989. Autoecologia del lagarto ocelado (Lacerta lepida). University Autonoma of Madrid, Madrid.

Chaloupka M. 2002. Stochastic simulation modelling of southern Great Barrier Reef green turtle population dynamics. Ecological Modelling 148: 79-109.

Chamaille-Jammes S, Massot M, Aragon P, Clobert J. 2006. Global warming and positive fitness response in mountain populations of common lizards Lacerta vivipara. Global Change Biology 12: 392-402. 
Chapman CA, Balcomb SR, Gillespie TR, Skorupa JP, Struhsaker TT. 2000. Long-term effects of logging on African primate communities: a 28-year comparison from Kibale National Park, Uganda. Conservation Biology 14: 207-217.

Chapple DG, Keogh JS. 2005. Complex mating system and dispersal patterns in a social lizard, Egernia whitii. Molecular Ecology 14: 1215-1227.

Chapple DG, Swain R. 2002. Effect of caudal autotomy on locomotor performance in a viviparous skink, Niveoscincus metallicus. Functional Ecology 16: 817-825.

Clark RW, Brown WS, Stechert R, Zamudio KR. 2008. Integrating individual behavior and landscape genetics: the population structure of timber rattlesnake hibernacula. Molecular Ecology 17: 719-730.

Clout MN, Craig JL. 1995. The conservation of critically endangered flightless birds in New Zealand. Ibis 1 .

Clutton-Brock TH, Albon SD, Gibson RM, Guiness FE. 1979. The logical stag: adaptive aspects of fighting in red deer (Cervus elaphus). Animal Behaviour 27.

Clutton-Brock TH, Parker GA. 1992. Potential reproductive rates and the operation of sexual selection. Quarterly Review of Biology 67: 437-456.

Coltman DW, Bowen WD, Wright JM. 1998. Birth weight and neonatal survival of harbour seal pups ape positively correlated with genetic variation measured by microsatellites. Proceedings of the Royal Society of London Series B-Biological Sciences 265: 803-809.

Coltman DW, Pilkington JG, Pemberton JM. 2003. Fine-scale genetic structure in a freeliving ungulate population. Molecular Ecology 12: 733-742.

Coltman DW, Slate J. 2003. Microsatellite measures of inbreeding: A meta-analysis. Evolution 57: 971-983.

Connell JH, Green PT. 2000. Seedling dynamics over thirty-two years in a tropical rain forest tree. Ecology 81: 568-584.

Connell JH, Hughes TE, Wallace CC, Tanner JE, Harms KE, Kerr AM. 2004. A long-term study of competition and diversity of corals. Ecological Monographs 74: 179-210.

Cooper WE, Jr., Vitt LJ. 1997. Maximizing male reproductive success in the broad-headed skink (Eumeces laticeps): preliminary evidence for mate guarding, size-assortative pairing, and opportunistic extra-pair mating. Amphibia-Reptilia 18: 59-73.

Cooper WE, Vitt LJ. 1993. Female mate choice of large male Broad-Headed Skinks. Animal Behaviour 45: 683-693.

Coulson TN, Pemberton JM, Albon SD, Beaumont M, Marshall TC, Slate J, Guinness FE, Clutton-Brock TH. 1998. Microsatellites reveal heterosis in red deer. Proceedings of the Royal Society of London Series B-Biological Sciences 265: 489-495. 
Couvet D. 2002. Deleterious effects of restricted gene flow in fragmented populations. Conservation Biology 16: 369-376.

Cox CR, Le Boeuf BJ. 1977. Female incitataion of male competition: a mechanism in sexual selection. American Naturalist 111: 317-335.

Cree A. 1994. Low annual reproductive output in female reptiles from New Zealand. New Zealand Journal of Zoology 21: 351-372.

Cree A, Butler D. 1993. Tuatara Recovery Plan (Sphenodon spp.). Threatened Species Recovery Plan Series 9. Department of Conservation, Wellington, New Zealand.

Cree A, Cockrem JF, Brown MA, Watson PR, Guillette LJ, Newman DG, Chambers GK. 1991a. Laparoscopy, radiography, and blood analyses as techniques for identifying the reproductive condition of female tuatara. Herpetologica 47: 238-249.

Cree A, Cockrem JF, Guillette Jr. LJ. 1992. Reproductive cycles of male and female tuatara (Sphenodon punctatus) on Stephens Island, New Zealand. Journal of Zoology 226: 199-217.

Cree A, Daugherty CH, Hay JM. 1995. Reproduction of a rare New Zealand reptile, the tuatara Sphenodon punctatus, on rat-free and rat-inhabited islands. Conservation Biology 9: 373-383.

Cree A, Daugherty CH, Schafer SF, Brown D. 1991b. Nesting and clutch size of tuatara (Sphenodon guntheri) on North Brother Island, Cook Strait. Tuatara 31: 9-16.

Cree A, Thompson MB. 1988. Unravelling the mysteries of tuatara reproduction. Forest and Bird 250: 14-16.

Crespi BJ. 1989. Causes of assortative mating in arthropods. Animal Behaviour 38: 9801000.

Crews D. 1975. Psychobiology of reptilian reproduction. Science 189: 1059-1065.

Crow JF, Kimura M. 1970. An Introduction to Population Genetics. Harper \& Row, New York.

Cuadrado M. 1998. The influence of female size on the extent and intensity of mate guarding by males in Chamaeleo chamaeleon. Journal of Zoology 246: 351-358.

Cunningham M, Moritz C. 1998. Genetic effects of forest fragmentation on a rainforest restricted lizard (Scincidae: Gnypetoscincus queenslandiae). Biological Conservation 83: 19-30.

Dakin EE, Avise JC. 2004. Microsatellite null alleles in parentage analysis. Heredity 93: 504-509.

Darwin C. 1871. The Descent of Man, and Selection in Relation to Sex. Murray, London.

Daugherty CH, Cree A, Hay JM, Thompson MB. 1990. Neglected taxonomy and continuing extinctions of tuatara (Sphenodon). Nature 347: 177-179. 
Davis LM, Glenn TC, Elsey RM, Dessauer HC, Sawyer RH. 2001. Multiple paternity and mating patterns in the American alligator, Alligator mississippiensis. Molecular Ecology 10: 1011-1024.

Dawbin WH. 1949. The tuatara. Tuatara 2: 91-96.

—. 1962. The tuatara in its natural habitat. Endeavour 21: 16-24.

—. 1982a. The Tuatara, Sphenodon punctatus (Reptilia: Rhynchocephalia): a Review. Pages 149-181 in D. G. Newman, ed. New Zealand Herpetology. New Zealand Wildlife Service, Wellington.

—. 1982b. The Tuatara, Sphenodon punctatus: Aspects of Life History, Growth and Longevity. Pages 237-250 in D. G. Newman, ed. New Zealand Herpetology. New Zealand Wildlife Service, Wellington.

Debinski DM, Holt RD. 2000. A survey and overview of habitat fragmentation experiments. Conservation Biology 14: 342-355.

Denardo DF, Sinervo B. 1994. Effects of steroid-hormone interaction on activity and homerange size of male lizards. Hormones and Behavior 28: 273-287.

DeWoody JA. 2005. Molecular approaches to the study of parentage, relatedness, and fitness: practical applications for wild animals. Journal of Wildlife Management 69: 1400-1418.

Dial BE, Fitzpatrick LC. 1981. The energetic costs of tail autotomy to reproduction in the lizard Coleonyx brevis (Sauria, Gekkonidae). Oecologia 51: 310-317.

Dieffenbach E. 1843. Fauna of New Zealand; Reptiles. Pages 204-205. Travel in New Zealand. John Murray, London.

Double MC, Peakall R, Beck NR, Cockburn A. 2005. Dispersal, philopatry, and infidelity: Dissecting local genetic structure in superb fairy-wrens (Malurus cyaneus). Evolution 59: 625-635.

Doughty P, Shine R. 1998. Reproductive energy allocation and long-term energy stores in a viviparous lizard (Eulamprus tympanum). Ecology 79: 1073-1083.

Driscoll DA, Hardy CM. 2005. Dispersal and phylogeography of the agamid lizard Amphibolurus nobbi in fragmented and continuous habitat. Molecular Ecology 14: 1613-1629.

Dufty AM, Clobert J, Moller AP. 2002. Hormones, developmental plasticity and adaptation. Trends in Ecology and Evolution 17: 190-196.

Dunn PO, Winkler DW. 1999. Climate change has affected the breeding date of tree swallows throughout North America. Proceedings of the Royal Society of London B 266: 2487-2490.

Ebenhard T. 1995. Conservation breeding as a tool for saving animal species from extinction. Trends in Ecology and Evolution 10: 438-443. 
Eberhard WG. 1985. Sexual Selection and Animal Genitalia. Harvard University Press, Cambridge, MA, USA.

Eberhard WG, Cordero C. 2003. Sexual conflict and female choice. Trends in Ecology and Evolution 18: 438-439.

Eberle M, Kappeler PM. 2004. Sex in the dark: determinants and consequences of mixed male mating tactics in Microcebus murinus, a small solitary nocturnal primate. Behavioral Ecology and Sociobiology 57: 77-90.

Elliott JM, Hurley MA, Elliott JA. 1997. Variable effects of droughts on the density of a seatrout Salmo trutta population over 30 years. Journal of Applied Ecology 34: 12291238.

Emlen ST, Oring LW. 1977. Ecology, sexual selection, and evolution of mating systems. Science 197: 215-223.

Excoffier L, Smouse PE, Quattro JM. 1992. Analysis of molecular variance inferred from metric distances among DNA haplotypes - application to human mitochondrialDNA restriction data. Genetics 131: 479-491.

Favre L, Balloux F, Goudet J, Perrin N. 1997. Female-biased dispersal in the monogamous mammal Crocidura russula: evidence from field data and microsatellite patterns. Proceedings of the Royal Society of London Series B-Biological Sciences 264: 127132.

Fisher M, Muth A. 1989. A technique for permanently marking lizards. Herpetological Review 20: 45-46.

Fitze PS, Le Galliard JF, Federici P, Richard M, Clobert J. 2005. Conflict over multiplepartner mating between males and females of the polygynandrous common lizards. Evolution 59: 2451-2459.

Fitzsimmons NN. 1998. Single paternity of clutches and sperm storage in the promiscuous green turtle (Chelonia mydas). Molecular Ecology 7: 575-584.

Fiumera AC, Porter BA, Grossman GD, Avise JC. 2002. Intensive genetic assessment of the mating system and reproductive success in a semi-closed population of the mottled sculpin, Cottus bairdi. Molecular Ecology 11: 2367-2377.

Folstad I, Karter AJ. 1992. Parasites, bright males, and the immunocompetence handicap hypothesis. American Naturalist 139: 603-622.

Fox SF, McCoy JK. 2000. The effects of tail loss on survival, growth, reproduction, and sex ratio of offspring in the lizard Uta stansburiana in the field. Oecologia 122: 327334.

Frantz AC, Hamann JL, Klein F. 2008. Fine-scale genetic structure of red deer (Cervus elaphus) in a French temperate forest. European Journal of Wildlife Research 54: 44-52. 
Gabe M, Saint Girons H. 1964. Contribution a l'histologie de Sphenodon punctatus Gray. Centre National de la Recherche Scientifique, Paris, France.

Gans C, Gillingham JC, Clark DL. 1984. Courtship, mating and male combat in tuatara, Sphenodon punctatus. Journal of Herpetology 18: 194-197.

Gardner MG, Bull CM, Cooper SJB, Duffield GA. 2001. Genetic evidence for a family structure in stable social aggregations of the Australian lizard Egernia stokesii. Molecular Ecology 10: 175-183.

Gardner TA, Barlow J, Peres CA. 2007. Paradox, presumption and pitfalls in conservation biology: The importance of habitat change for amphibians and reptiles. Biological Conservation 138: 166-179.

Garza JC, Williamson EG. 2001. Detection of reduction in population size using data from microsatellite loci. Molecular Ecology 10: 305-318.

Gaze P. 2001. Tuatara Recovery Plan 2001-2011. Pages 1-37. Biodiversity Recovery Unit, New Zealand Department of Conservation, Wellington, New Zealand.

Gibbons JW, Scott DE, Ryan TJ, Buhlmann KA, Tuberville TD, Metts BS, Greene JL, Mills T, Leiden Y, Poppy S, Winne CT. 2000. The global decline of reptiles, Deja Vu amphibians. Bioscience 50: 653-666.

Gibbs HL, Prior KA, Weatherhead PJ, Johnson G. 1997. Genetic structure of populations of the threatened eastern massasauga rattlesnake, Sistrurus c catenatus: evidence from microsatellite DNA markers. Molecular Ecology 6: 1123-1132.

Gibbs HL, Weatherhead PJ. 2001. Insights into population ecology and sexual selection in snakes through the application of DNA-based genetic markers. Journal of Heredity 92: 173-179.

Gibbs HL, Weatherhead PJ, Boag PT, White BN, Tabak LM, Hoysak DJ. 1990. Realized reproductive success of polygynous Red-Winged Blackbirds revealed by DNA markers. Science 250: 1394-1397.

Gillingham JC, Carmichael C, Miller T. 1995. Social behavior of the tuatara, Sphenodon punctatus. Herpetological Monographs 9: 5-16.

Gillingham JC, Miller TJ. 1991. Reproductive ethology of the tuatara Sphenodon punctatus: applications in captive breeding. International Zoo Yearbook 30: 157-164.

Girardet SAB, Veitch CR, Craig JL. 2001. Bird and rat numbers on Little Barrier Island, New Zealand, over the period of cat eradication 1976-80. New Zealand Journal of Zoology 28: 13-29.

Goff ML, Loomis RB, Ainsworth R. 1987. Redescription of Neotrombicula naultini (Dumbleton, 1947) and description of two new species of chiggers from New Zealand (Acari: Trombiculidae). New Zealand Journal of Zoology 14: 385-390. 
Gopurenko D, Williams RN, McCormick CR, DeWoody JA. 2006. Insights into the mating habits of the tiger salamander (Ambystoma tigrinum tigrinum) as revealed by genetic parentage analyses. Molecular Ecology 15: 1917-1928.

Goudet J. 1995. FSTAT (Version 1.2): A computer program to calculate F-statistics. Journal of Heredity 86: 485-486.

Goyache F, Gutierrez JP, Fernandez I, Gomez E, Alvarez I, Diez J, Royo LJ. 2003. Using pedigree information to monitor genetic variability of endangered populations: the Xalda sheep breed of Asturias as an example. Journal of Animal Breeding and Genetics 120: 95-105.

Green AJ. 2001. Mass/length residuals: measures of body condition or generators of spurious results? Ecology 82: 1473-1483.

Greer AE. 1975. Clutch size in crocodilians. Journal of Herpetology 9: 319-322.

Griffith SC, Owens IPF, Thuman KA. 2002. Extra pair paternity in birds: a review of interspecific variation and adaptive function. Molecular Ecology 11: 2195-2212.

Griffiths AD. 1999. Demography and home range of the Frillneck lizard, Chlamydosaurus kingii (Agamidae) in Northern Australia. Copeia 1999: 1089-1096.

Guillette LJJ, Cree A, Gross TS. 1990. Endocrinology of oviposition in the tuatara

(Sphenodon punctatus): I. Plasma steroids and prostoglandins during natural nesting. Biology of Reproduction 43: 285-289.

Gullberg A, Olsson M, Tegelstrom H. 1997. Male mating success, reproductive success and multiple paternity in a natural population of sand lizards: Behavioural and molecular genetics data. Molecular Ecology 6: 105-112.

Guo SW, Thompson EA. 1992. A Monte Carlo method for combined segregation and linkage analysis. American Journal of Human Genetics 51: 1111-1126.

Gutierrez JP, Altarriba J, Diaz C, Quintanilla R, Canon J, Piedrafita J. 2003. Pedigree analysis of eight Spanish beef cattle breeds. Genetics Selection Evolution 35: 43-63.

Gutierrez JP, Goyache F. 2005. A note on ENDOG: a computer program for analysing pedigree information. Journal of Animal Breeding and Genetics 122: 172-176.

Hamilton WD, Zuk M. 1992. Heritable true fitness and bright birds: A role for parasites? Science 218: 384-387.

Hansson B. 2004. Marker-based relatedness predicts egg-hatching failure in great reed warblers. Conservation Genetics 5: 339-348.

Hansson B, Westerberg L. 2002. On the correlation between heterozygosity and fitness in natural populations. Molecular Ecology 11: 2467-2474.

Hare KM, Cree A. 2005. Natural history of Hoplodactylus stephensi (Reptilia : Gekkonidae) on Stephens Island, Cook Strait, New Zealand. New Zealand Journal of Ecology 29: 137-142. 
Hay JM, Daugherty CH, Cree A, Maxson LR. 2003. Low genetic divergence obscures phylogeny among populations of Sphenodon, remnant of an ancient reptile lineage. Molecular Phylogenetics and Evolution 29: 1-19.

Hay JM, Lambert DM. 2008. Microsatellite DNA loci identify individuals and provide no evidence for multiple paternity in wild tuatara (Sphenodon: Reptilia). Conservation Genetics 9: 1039-1043.

Hayne DW. 1949. Calculation of size of home range. Journal of Mammalogy 30: 1-18. Healy JM, Jamieson BGM. 1992. Ultrastructure of the spermatozoon of the tuatara (Sphenodon punctatus) and its relevance to the relationships of the Sphenodontida. Philosophical Transactions of the Royal Society of London Series B-Biological Sciences 335: 193-205.

Hews DK. 1990. Examining hypotheses generated by field measures of sexual selection on male lizards, Uta palmeri. Evolution 44: 1956-1966.

Hoare J, Pledger S, Keall SN, Nelson NJ, Mitchell NJ, Daugherty CH. 2006. Conservation implications of a long term decline in body condition of the Brothers Island tuatara, Sphenodon guntheri. Animal Conservation 9: 456-462.

Hoelzel AR, Le Boeuf BJ, Reiter J, Campagna C. 1999. Alpha-male paternity in elephant seals. Behavioral Ecology and Sociobiology 46: 298-306.

Hoffman JI, Boyd IL, Amos W. 2004. Exploring the relationship between parental relatedness and male reproductive success in the antarctic fur seal Arctocephalus gazella. Evolution 58: 2087-2099.

Hofmann S, Henle K. 2006. Male reproductive success and intrasexual selection in the common lizard determined by DNA-microsatellites. Journal of Herpetology 40: 1-6.

Höglund J, Piertney SB, Alatalo RV, Lindell J, Lundberg A, Rintamaki PT. 2002. Inbreeding depression and male fitness in black grouse. Proceedings of the Royal Society of London Series B-Biological Sciences 269: 711-715.

Holdaway RN, Worthy TH. 1997. A reappraisal of the late Quaternary fossil vertebrates of Pyramid Valley Swamp, north Canterbury, New Zealand. New Zealand Journal of Zoology 29: 69-121.

Howard RD, Moorman RS, Whiteman HH. 1997. Differential effects of mate competition and mate choice on eastern tiger salamanders. Animal Behaviour 53: 1345-1356.

Hughes C. 1998. Integrating molecular techniques with field methods in studies of social behavior: A revolution results. Ecology 79: 383-399.

Hughes TP, Connell JH. 1999. Multiple stressors on coral reefs: a long-term perspective. Limnology and Oceanography 44: 932-940.

Hunter FM, Petrie M, Otronen M, Birkhead T, Moller AP. 1993. Why do females copulate repeatedly with one male. Trends in Ecology \& Evolution 8: 21-26. 
Iverson JB. 1979. Behavior and ecology of the rock iguana Cyclura carinata. Bulletin of the Florida State Museum of Biological Science 24: 175-358.

Iverson JB, Converse SJ, Smith GR, Valiulis JM. 2006. Long-term trends in the demography of the Allen Cays Rock Iguana (Cyclura cychlura inornata): Human disturbance and density-dependent effects. Biological Conservation 132: 300-310.

Jamieson IG, Quinn JS, Rose PA, White BN. 1994. Shared paternity among non-relatives is a result of an egalitarian mating system in a communally breeding bird, the Pukeko. Proceedings of the Royal Society of London Series B-Biological Sciences 257: 271277.

Janzen FJ. 1994a. Climate change and temperature-dependent sex determination in reptiles. Proceedings of the National Academy of Sciences of the United States of America 91: 7487-7490.

—. 1994b. Vegetational cover predicts the sex ratio of hatchling turtles in natural nests. Ecology 75: 1593-1599.

Jennions MD, Petrie M. 1997. Variation in mate choice and mating preferences: A review of causes and consequences. Biological Reviews of the Cambridge Philosophical Society $72: 283-327$.

- 2000. Why do females mate multiply? A review of the genetic benefits. Biological Review 75: 21-64.

Johnson SR. 1965. An ecological study of Chuckwalla Sauromalus obesus Baird in Western Mojave Desert. American Midland Naturalist 73: 1-\&.

Johnstone RA. 2000. Models of reproductive skew: A review and synthesis (invited article). Ethology 106: 5-26.

Kalinowski ST, Taper ML, Marshall TC. 2007. Revising how the computer program CERVUS accommodates genotyping error increases success in paternity assignment. Molecular Ecology 16: 1099-1106.

Kanowski JJ, Reis TM, Catterall CP, Piper SD. 2006. Factors affecting the use of reforested sites by reptiles in cleared rainforest landscapes in tropical and subtropical Australia. Restoration Ecology 14: 67-76.

Keller L, Reeve HK. 1994. Partitioning of reproduction in animal societies. Trends in Ecology \& Evolution 9: 98-102.

Keller LF, Waller DM. 2002. Inbreeding effects in wild populations. Trends in Ecology and Evolution 17: 230-241.

Ketterson ED, Nolan V. 1992. Hormones and life histories - an integrative approach. American Naturalist 140: S33-S62.

Kimura M, Crow JF. 1963. Measurement of effective population number. Evolution 17: 279$\&$. 
Kissner KJ, Weatherhead PJ, Gibbs HL. 2005. Experimental assessment of ecological and phenotypic factors affecting male mating success and polyandry in northern watersnakes, Nerodia sipedon. Behavioral Ecology and Sociobiology 59: 207-214.

Knutsen H, Jorde PE, Andre C, Stenseth NC. 2003. Fine-scaled geographical population structuring in a highly mobile marine species: the Atlantic cod. Molecular Ecology 12: $385-394$.

Kokko H, Brooks R, Jennions MD, Morley J. 2003. The evolution of mate choice and mating biases. Proceedings of the Royal Society of London B 270: 653-664.

Kokko H, Rankin DJ. 2006. Lonely hearts or sex in the city? Density-dependent effects in mating systems. Philosophical Transactions of the Royal Society B-Biological Sciences 361: 319-334.

Kwiatkowski MA, Sullivan BK. 2002. Mating system structure and population density in a polygynous lizard, Sauromalus obesus (=ater). Behavioral Ecology 13: 201-208.

Lappin AK, Husak JF. 2005. Weapon performance, not size, determines mating success and potential reproductive output in the collared lizard (Crotaphytus collaris). American Naturalist 166: 426-436.

Laver P. 2005. ABODE: Kernel home range estimation for ArcGIS, Department of Fisheries and Wildlife Sciences, Virginia Tech, Blacksburg, VA.

Lawton-Rauh A. 2008. Demographic processes shaping genetic variation. Current Opinions in Plant Biology 11: 103-109.

Lebas NR. 2001. Microsatellite determination of male reproductive success in a natural population of the territorial ornate dragon lizard, Ctenophorus ornatus. Molecular Ecology 10: 193-203.

Lee PLM, Hays GC. 2004. Polyandry in a marine turtle: females make the best of a bad job. Proceedings of the National Academy of Sciences of the United States of America 101: 6530-6535.

Legendre S, Clobert J, Moller AP, Sorci G. 1999. Demographic stochasticity and social mating system in the process of extinction of small populations: The case of passerines introduced to New Zealand. American Naturalist 153: 449-463.

Lenz TL, Jacob A, Wedekind C. 2007. Manipulating sex ratio to increase population growth: the example of the Lesser Kestrel. Animal Conservation 10: 236-244.

Levitan DR, Petersen C. 1995. Sperm limitation in the sea. Trends in Ecology \& Evolution 10: $228-231$.

Lewis AR, Tirado G, Sepulveda J. 2000. Body size and paternity in a teiid lizard (Ameiva exsul). Journal of Herpetology 34: 110-120.

Lieutenant-Gosselin M, Bernatchez L. 2006. Local heterozygosity-fitness correlations with global positive effects on fitness in threespine stickleback. Evolution 60: 1658-1668. 
Likens GE. 1989. Long-Term Studies in Ecology: Approaches and Alternatives. SpringerVerlag, New York, USA.

Luikart G, Cornuet JM. 1999. Estimating the effective number of breeders from heterozygote excess in progeny. Genetics 151: 1211-1216.

MacAvoy ES, McGibbon LM, Sainsbury JP, Lawrence H, Wilson CA, Daugherty CH, Chambers GK. 2007. Genetic variation in island populations of tuatara (Sphenodon spp) inferred from microsatellite markers. Conservation Genetics 8: 305-318.

Madsen T, Shine R. 2001. Conflicting conclusions from long-term versus short-term studies on growth and reproduction of a tropical snake. Herpetologica 57: 147-156.

Madsen T, Shine R, Loman J, Hakansson T. 1992. Why do female adders copulate so frequently. Nature 355: 440-441.

Madsen T, Stille B, Shine R. 1996. Inbreeding depression in an isolated population of adders Vipera berus. Biological Conservation 75: 113-118.

Madsen T, Ujvari B, Olsson M, Shine R. 2005. Paternal alleles enhance female reproductive success in tropical pythons. Molecular Ecology 14: 1783-1787.

Maher CR, Lott DF. 1995. Definitions of territoriality used in the study of variation in vertebrate spacing systems. Animal Behaviour 49: 1581-1597.

- 2000. A review of ecological determinants of territoriality within vertebrate species. American Midland Naturalist 143: 1-29.

Manel S, Schwartz MK, Luikart G, Taberlet P. 2003. Landscape genetics: combining landscape ecology and population genetics. Trends in Ecology and Evolution 18: 189-197.

Marshall TC, Slate J, Kruuk LEB, Pemberton JM. 1998. Statistical confidence for likelihood-based paternity inference in natural populations. Molecular Ecology 7: 639-655.

Martin J. 1996. Effects of recent feeding on locomotor performance of juvenile Psammodromus algirus lizards. Functional Ecology 10: 390-395.

Martin J, Salvador A. 1993. Tail loss reduces mating success in the Iberian rock-lizard, Lacerta monticola. Behavioral Ecology and Sociobiology 32: 185-189.

Mateos C, Carranza J. 1999. Effects of male dominance and courtship display on female choice in the ring-necked pheasant. Behavioral Ecology and Sociobiology 45: 235244.

McElligott AG, Hayden TJ. 2000. Lifetime mating success, sexual selection and life history of fallow bucks (Dama dama). Behavioral Ecology and Sociobiology 48: 203-210.

Mcloskey RT, Baia KA, Russell RW. 1987. Tree Lizard (Urosaurus ornatus) territories: experimental perturbation of the sex ratio. Ecology 68: 2059-2062. 
Miller HC, Andrews-Cookson M, Daugherty CH. 2007. Two patterns of variation among MHC class I loci in tuatara (Sphenodon punctatus). Journal of Heredity 98(7): 666677.

Miller MP. 2005. Alleles In Space (AIS): Computer software for the joint analysis of interindividual spatial and genetic information. Journal of Heredity 96: 722-724.

Mitsch WJ, Wilson RF. 1996. Improving the success of wetland creation and restoration with know-how, time, and self-design. Ecological Applications 6: 77-83.

Moller AP. 1998. Sperm competition and sexual selection. Pages 55-90 in T. R. Birkhead and A. P. Moller, eds. Sperm Competition and Sexual Selection Academic Press, Cambridge.

Moller AP, Christe P, Lux E. 1999. Parasitism, host immune function, and sexual selection. Quarterly Review of Biology 74: 3-20.

Moore IT, Lerner JP, Lerner DT, Mason RT. 2000. Relationships between annual cycles of testosterone, corticosterone, and body condition in male red-spotted garter snakes, Thamnophis sirtalis concinnus. Physiological and Biochemical Zoology 73: 307312.

Moore JA, Bell BD, Linklater WL. 2008a. The debate on behavior in conservation: New Zealand integrates theory with practice. Bioscience 58: 454-459.

Moore JA, Daugherty CH, Nelson NJ. in review. Large male advantage: phenotypic and genetic correlates of territoriality and female access in an ancient reptile (tuatara, Sphenodon punctatus). Journal of Herpetology.

Moore JA, Hoare JM, Daugherty CH, Nelson NJ. 2007. Waiting reveals waning weight: Monitoring over 54 years shows a decline in body condition of a long-lived reptile (tuatara, Sphenodon punctatus). Biological Conservation 135: 181-188.

Moore JA, Nelson NJ, Keall SN, Daugherty CH. 2008b. Implications of social dominance and multiple paternity for the genetic diversity of a captive-bred reptile population (tuatara). Conservation Genetics 9: 1243-1251.

Morrison SF, Keogh JS, Scott IAW. 2002. Molecular determination of paternity in a natural population of the multiply mating polygynous lizard Eulamprus heatwolei. Molecular Ecology 11: 535-545.

Mossman CA, Waser PM. 1999. Genetic detection of sex-biased dispersal. Molecular Ecology 8: 1063-1067.

Mulder CPH, Keall SN. 2001. Burrowing seabirds and reptiles: impacts on seeds, seedlings and soils in an island forest in New Zealand. Oecologia 127: 350-360.

Nelson NJ, Cree A, Thompson MB, Keall SN, Daugherty CH. 2004a. Temperaturedependent sex determination in tuatara in N. Valenzuela and V. Lance, eds. 
Temperature Dependent Sex Determination in Vertebrates. Smithsonian Books, Washington, D.C.

Nelson NJ, Keall SN, Brown D, Daugherty CH. 2002a. Establishing a new wild population of tuatara (Sphenodon guntheri). Conservation Biology 16: 887-894.

Nelson NJ, Keall SN, Pledger S, Daugherty CH. 2002b. Male-biased sex ratio in a small tuatara population. Journal of Biogeography 29: 633-640.

Nelson NJ, Thompson MB, Pledger S, Keall SN, Daugherty CH. 2004b. Do TSD, sex ratios, and nest characteristics influence the vulnerability of tuatara to global warming? International Congress Series 1275: 250-257.

Newman DG. 1987. Burrow use and population densities of tuatara (Sphenodon punctatus) and how they are influenced by fairy prions (Pachyptila turtur) on Stephen's Island, New Zealand. Herpetologica 43: 336-344.

Newman DG, Watson PR, McFadden I. 1994. Egg production by tuatara on Lady Alice and Stephens Island, New Zealand. New Zealand Journal of Zoology 21: 387-398.

Nussey DH, Coltman DW, Coulson T, Kruuk LEB, Donald A, Morris SJ, Clutton-Brock TH, Pemberton J. 2005. Rapidly declining fine-scale spatial genetic structure in female red deer. Molecular Ecology 14: 3395-3405.

O'Connor D, Shine R. 2003. Lizards in 'nuclear families': a novel reptilian social system in Egernia saxatilis (Scincidae). Molecular Ecology 12: 743-752.

Olsson M, Gullberg A, Tegelstrom H. 1996. Mate guarding in male sand lizards (Lacerta agilis). Behaviour 133: 367-386.

Olsson M, Healey M, Wapstra E, Schwartz T, Lebas N, Uller T. 2007. Mating system variation and morph fluctuations in a polymorphic lizard. Molecular Ecology 16: 5307-5315.

Olsson M, Madsen T. 1995. Female choice on male quanitative traits in lizards: why is it so rare? Behavioral Ecology and Sociobiology 36: 179-184.

—. 1998. Sexual selection and sperm competition in reptiles. Pages 503-564 in T. R. Birkhead and A. P. Moller, eds. Sperm Competition and Sexual Selection Academic Press, Cambridge.

—. 2001. Promiscuity in sand lizards (Lacerta agilis) and adder snakes (Vipera berus): Causes and consequences. Journal of Heredity 92: 190-197.

Olsson M, Shine R. 1997. Advantages of multiple matings to females: A test of the infertility hypothesis using lizards. Evolution 51: 1684-1688.

Olsson M, Shine R, Wapstra E, Ujvari B, Madsen T. 2002. Sexual dimorphism in lizard body shape: The roles of sexual selection and fecundity selection. Evolution 56 : 1538-1542. 
Oppliger A, Degen L, Bouteiller-Reuter C, John-Alder HB. 2007. Promiscuity and high level of multiple paternity in common wall lizards (Podarcis muralis): data from microsatellite markers. Amphibia-Reptilia 28: 301-303.

Orians GH. 1969. On the evolution of mating systems in birds and mammals. American Naturalist 103: 589-602.

Otronen M. 1993. Size assortative mating in the yellow dung fly Scatophaga stercoraria. Behaviour 126: 63-76.

Paetkau D, Calvert W, Stirling I, Strobeck C. 1995. Microsatellite analysis of population structure in canadian polar bears. Molecular Ecology 4: 347-354.

Paetkau D, Waits LP, Clarkson PL, Craighead L, Strobeck C. 1997. An empirical evaluation of genetic distance statistics using microsatellite data from bear (Ursidae) populations. Genetics 147: 1943-1957.

Partecke J, von Haeseler A, Wikelski M. 2002. Territory establishment in lekking marine iguanas, Amblyrhynchus cristatus: support for the hotshot mechanism. Behavioral Ecology and Sociobiology 51: 579-587.

Peakall R, Ruibal M, Lindenmayer DB. 2003. Spatial autocorrelation analysis offers new insights into gene flow in the Australian bush rat, Rattus fuscipes. Evolution 57: 1182-1195.

Peakall R, Smouse PE. 2006. GENALEX 6: genetic analysis in Excel. Population genetic software for teaching and research. Molecular Ecology Notes 6: 288-295.

Pearse DE, Avise JC. 2001. Turtle mating systems: Behavior, sperm storage, and genetic paternity. Journal of Heredity 92: 206-211.

Pearse DE, Crandall KA. 2004. Beyond $\mathrm{F}_{\mathrm{ST}}$ : analysis of population genetic data for conservation. Conservation Genetics 5: 585-602.

Penn DJ, Potts WK. 1999. The evolution of mating preferences and major histocompatibility complex genes. American Naturalist 153: 145-164.

Perrin N, Mazalov V. 2000. Local competition, inbreeding, and the evolution of sex-biased dispersal. American Naturalist 155: 116-127.

Perry G, Garland T. 2002. Lizard home ranges revisited: effects of sex, body size, diet, habitat, and phylogeny. Ecology 83: 1870-1885.

Prosser MR, Gibbs HL, Weatherhead PJ. 1999. Microgeographic population genetic structure in the northern water snake, Nerodia sipedon sipedon detected using microsatellite DNA loci. Molecular Ecology 8: 329-333.

Prugnolle F, de Meeus T. 2002. Inferring sex-biased dispersal from population genetic tools: a review. Heredity 88: 161-165.

Pudovkin AI, Zaykin DV, Hedgecock D. 1996. On the potential for estimating the effective number of breeders from heterozygote excess in progeny. Genetics 144: 383-387. 
Pusey A, Wolf M. 1996. Inbreeding avoidance in animals. Trends in Ecology and Evolution 11: 201-206.

Queller DC, Goodnight KF. 1989. Estimating relatedness using genetic markers. Evolution 43: $258-275$.

R Core Development Team. 2006. R: A Language and Environment for Statistical Computing. R Foundation for Statistical Computing, Vienna, Austria.

Ralls K, Ballou J. 1986. Captive breeding programs for populations with a small number of founders. Trends in Ecology and Evolution 1: 19-22.

Rand AS, Font E, Ramos D, Iwerner D, Bock BC. 1989. Home range in green iguanas (Iguana iguana) in Panama. Copeia: 217-221.

Raymond M, Rousset F. 1995. GENEPOP (version 1.2): population genetics software for exact tests and ecumenicism. Journal of Heredity 86.

Reed DH, Frankham R. 2003. Correlation between fitness and genetic diversity. Conservation Biology 17: 230-237.

Refsnider JM, Keall SN, Daugherty CH, Nelson NJ. in review. Nest-guarding decreases conspecific nest destruction in tuatara (Sphenodon punctatus).

Reischek A. 1886. Observations on Sphenodon punctatum, fringe-back lizard (tuatara). Transactions and Proceedings of the New Zealand Institute 18: 108-110.

Rest JS, Ast JC, Austin CC, Waddell PJ, Tibbetts EA, Hay JM, Mindell DP. 2003. Molecular systematics of primary reptilian lineages and the tuatara mitochondrial genome. Molecular Phylogenetics and Evolution 29: 289-297.

Reyer HU, Frei G, Som C. 1999. Cryptic female choice: frogs reduce clutch size when amplexed by undesired males. Proceedings of the Royal Society of London Series B-Biological Sciences 266: 2101-2107.

Reynolds JD. 1996. Animal breeding systems. Trends in Ecology and Evolution 11: 68-72.

Roberts SC, Gosling LM. 2003. Genetic similarity and quality interact in mate choice decisions by female mice. Nature Genetics 35: 103-106.

Rogers AR, Carr AP, Smith L, Kie JG. 2005. HRT: Home Range Tools for ArcGIS. Ontario Ministry of Natural Resources, Centre for Northern Forest Ecosystem Research, Thunder Bay, Ontario, Canada.

Ross KG. 2001. Molecular ecology of social behaviour: analyses of breeding systems and genetic structure. Molecular Ecology 10: 265-284.

Row JR, Blouin-Demers G. 2006. Kernels are not accurate estimators of home-range size for herpetofauna. Copeia 2006(4): 797-802.

Saint Girons H. 1983. The tuatara: ecological features and some hypotheses concerning its evolution. Bulletin de la Société Zoologique de France 108: 631-634. 
Saint Girons H, Bell BD, Newman DG. 1980. Observations on the activity and thermoregulation of the tuatara, Sphenodon punctatus (Reptilia: Rhynchocephalia), on Stephens Island. New Zealand Journal of Zoology 7: 551-556.

Saint Girons H, Newman DG. 1987. The reproductive cycle of the male tuatara, Sphenodon punctatus, on Stephens Island, New Zealand. New Zealand Journal of Zoology 14: 231-237.

Salvador A, Diaz JA, Veiga JP, Bloor P, Brown RP. 2008. Correlates of reproductive success in male lizards of the alpine species Iberolacerta cyreni. Behavioral Ecology 19: $169-176$.

Salvador A, Veiga JP. 2001. Male traits and pairing success in the lizard Psammodromus algirus. Herpetologica 57: 77-86.

Salvador A, Veiga JP, Lopez P, Abelenda M, Puerta M. 1996. The cost of producing a sexual signal: testosterone increases the susceptibility of male lizards to ectoparasitic infection. Behavioral Ecology 7: 145-150.

Sambrook J, Fritsch E, Maniatis T. 1989. Molecular Cloning. A Laboratory Manual. Cold Spring Harbor Laboratory Press, Cold Springs Harbor, NY.

Sarrazin F, Barbault R. 1996. Reintroduction: challenges and lessons for basic ecology. Trends in Ecology and Evolution 11: 474-478.

Saunders DA, Hobbs RJ, Margules CR. 1991. Biological consequences of ecosystem fragmentation - a review. Conservation Biology 5: 18-32.

Schoener TW, Schoener A. 1982. Intraspecific variation in home range size in some Anolis lizards. Ecology 63: 809-823.

Schrey NM, Schrey AW, Heist EJ, Reeve JD. 2008. Fine-scale genetic population structure of southern pine beetle (Coleoptera : Curculionidae) in Mississippi forests. Environmental Entomology 37: 271-276.

Schulte-Hostedde AI, Millar JS, Hickling GJ. 2001. Evaluating body condition in small mammals. Canadian Journal of Zoology 79: 1021-1029.

Schulte-Hostedde AI, Zinner B, Millar JS, Hickling GJ. 2005. Restitution of mass-size residuals: validating body condition indices. Ecology 86: 155-163.

Seddon N, Amos W, Mulder RA, Tobias JA. 2004. Male heterozygosity predicts territory size, song structure and reproductive success in a cooperatively breeding bird. Proceedings of the Royal Society of London Series B-Biological Sciences 271: 1823-1829.

Shine R. 1988. Parental care in reptiles. Pages 275-329 in C. Gans and R. B. Huey, eds. Biology of the Reptilia, Ecology B: Defense and Life History. A.R. Liss, New York. 
Shine R, LeMaster MP, Moore IT, Olsson MM, Mason RT. 2001. Bumpus in the snake den: effects of sex, size, and body condition on mortality of red-sided garter snakes. Evolution 55: 598-604.

Shine R, Olsson M, Moore IT, LeMaster MP, Greene M, Mason RT. 2000. Body size enhances mating success in garter snakes. Animal Behaviour 59: F4-F11.

Slate J, David P, Dodds KG, Veenvliet BA, Glass BC, Broad TE, McEwan JC. 2004. Understanding the relationship between the inbreeding coefficient and multilocus heterozygosity: theoretical expectations and empirical data. Heredity 93: 255-265.

Slatkin M. 1993. Isolation by distance in equilibrium and nonequilibrium populations. Evolution 47: 264-279.

Smouse PE, Peakall R. 1999. Spatial autocorrelation analysis of individual multiallele and multilocus genetic structure. Heredity 82: 561-573.

Snyder NFR, Derrickson SR, Beissinger SR, Wiley JW, Smith TB, Toone WD, Miller B. 1996. Limitations of captive breeding in endangered species recovery. Conservation Biology 10: 338-348.

Spear SF, Peterson CR, Matocq MD, Storfer A. 2005. Landscape genetics of the blotched tiger salamander (Ambystoma tigrinum melanostictum). Molecular Ecology 14: 2553-2564.

Spruell P, Rieman BE, Knudsen KL, Utter FM, Allendorf FW. 1999. Genetic population structure within streams: microsatellite analysis of bull trout populations. Ecology of Freshwater Fish 8: 114-121.

Stamps JA. 1983. Sexual selection, sexual dimorphism, and territoriality. Pages 169-204 in R. B. Huey, E. R. Pianka, and T. W. Schoener, eds. Lizard Ecology: Studies of a Model Organism. Harvard Univeristy Press, Cambridge.

Stapley J, Keogh JS. 2005. Behavioral syndromes influence mating systems: floater pairs of a lizard have heavier offspring. Behavioral Ecology 16: 514-520.

Stephens CL. 2004. Plant succession, ecological restoration \& the skinks of Stephens Island/Takapourewa. Pages 207. Biological Sciences. Victoria University of Wellington, Wellington, New Zealand.

Stephens PA, Sutherland WJ. 1999. Consequences of the Allee effect for behaviour, ecology and conservation. Trends in Ecology \& Evolution 14: 401-405.

Storfer A, Murphy MA, Evans JS, Goldberg CS, Robinson S, Spear SF, Dezzani R, Delmelle E, Vierling L, Waits LP. 2007. Putting the 'landscape' in landscape genetics. Heredity 98: 128-142.

Stow AJ, Sunnucks P. 2004a. High mate and site fidelity in Cunningham's skinks (Egernia cunninghami) in natural and fragmented habitat. Molecular Ecology 13: 419-430. 
—. 2004b. Inbreeding avoidance in Cunningham's skinks (Egernia cunninghami) in natural and fragmented habitat. Molecular Ecology 13: 443-447.

Stow AJ, Sunnucks P, Briscoe DA, Gardner MG. 2001. The impact of habitat fragmentation on dispersal of Cunningham's skink (Egernia cunninghami): evidence from allelic and genotypic analyses of microsatellites. Molecular Ecology 10: 867-878.

Sugg DW, Chesser RK. 1994. Effective population sizes with multiple paternity. Genetics 137: $1147-1155$.

Sumner J. 2005. Decreased relatedness between male prickly forest skinks (Gnypetoscincus queenslandiae) in habitat fragments. Conservation Genetics 6: 333-340.

Sumner J, Jessop T, Paetkau D, Moritz C. 2004. Limited effect of anthropogenic habitat fragmentation on molecular diversity in a rain forest skink, Gnypetoscincus queenslandiae. Molecular Ecology 13: 259-269.

Sumner J, Moritz C, Shine R. 1999. Shrinking forest shrinks skink: morphological change in response to rainforest fragmentation in the prickly forest skink (Gnypetoscincus queenslandiae). Biological Conservation 91: 159-167.

Telles MPC, Diniz JAF, Bastos RP, Soares TN, Guimaraes LD, Lima LP. 2007. Landscape genetics of Physalaemus cuvieri in Brazilian Cerrado: Correspondence between population structure and patterns of human occupation and habitat loss. Biological Conservation 139: 37-46.

Thomas CD, Wilson RJ, Lewis OT. 2002. Short-term studies underestimate 30-generation changes in a butterfly metapopulation. Proceedings of the Royal Society of London B 269: 563-569.

Thompson MB. 1990. Incubation of eggs of tuatara, Sphenodon punctatus. Journal of Zoology 222: 303-318.

Thornhill R. 1983. Cryptic female choice and its implications in the scorpionfly Harpobittacus nigriceps. American Naturalist 122: 765-788.

Thornhill R, Alcock J. 1983. The Evolution of Insect Mating Systems. Harvard University Press, Cambridge, MA.

Tiira K, Laurila A, Enberg K, Piironen J, Aikio S, Ranta E, Primmer CR. 2006. Do dominants have higher heterozygosity? Social status and genetic variation in brown trout, Salmo trutta. Behavioral Ecology and Sociobiology 59: 657-665.

Tiira K, Laurila A, Peuhkuri N, Piironen J, Ranta E, Primmer CR. 2003. Aggressiveness is associated with genetic diversity in landlocked salmon (Salmo salar). Molecular Ecology 12: 2399-2407.

Tinkle DW. 1979. Long-term field studies. Bioscience 20: 717.

Tokarz RR. 1995. Mate choice in lizards: A review. Herpetological Monographs 9: 17-40. 
Tregenza T, Wedell N. 2000. Genetic compatibility, mate choice and patterns of parentage: invited review. Molecular Ecology 9: 1013-1027.

Troeng S, Rankin E. 2005. Long-term conservation efforts contribute to positive green turtle Chelonia mydas nesting trend at Tortuguero, Costa Rica. Biological Conservation 121: 111-116.

Tyrrell CL, Cree A. 1998. Relationships between corticosterone concentration and season, time of day and confinement in a wild reptile (tuatara, Sphenodon punctatus). General and Comparative Endocrinology 110: 97-108.

Uller T, Olsson M. 2005. Multiple copulations in natural populations of lizards: evidence for the fertility assurance hypothesis. Behaviour 142: 45-56.

—. 2008. Multiple paternity in reptiles: patterns and processes. Molecular Ecology 17: 25662580.

Välimäki K, Hinten G, Hanski I. 2007. Inbreeding and competitive ability in the common shrew (Sorex araneus). Behavioral Ecology and Sociobiology 61: 997-1005.

Van Oosterhout C, Hutchinson WF, Wills DPM, Shipley P. 2004. MICRO-CHECKER: software for identifying and correcting genotyping errors in microsatellite data. Molecular Ecology Notes 4: 535-538.

Vekemans X, Hardy OJ. 2004. New insights from fine-scale spatial genetic structure analyses in plant populations. Molecular Ecology 13: 921-935.

Vignieri SN. 2007. Cryptic behaviours, inverse genetic landscapes, and spatial avoidance of inbreeding in the Pacific jumping mouse. Molecular Ecology 16: 853-866.

Visser ME, van Noordwijk AJ, Tinbergen JM, Lessells CM. 1998. Warmer springs lead to mistimed reproduction in great tits (Parus major). Proceedings of the Royal Society of London B 265: 1867-1870.

Wada M. 1982. Effects of sex steroids on calling, locomotor activity, and sexual behavior in castrated male Japanese quail. Hormones and Behavior 16: 147-157.

Walker FM, Sunnucks P, Taylor AC. 2008. Evidence for habitat fragmentation altering within-population processes in wombats. Molecular Ecology 17: 1674-1684.

Walls GY. 1981. Feeding ecology of the tuatara (Sphenodon punctatus) on Stephens Island, Cook Strait. New Zealand Journal of Ecology 4: 89-97.

Walther GR, Post E, Convey P, Menzel A, Parmesan C, Beebee TJC, Fromentin JM, HoeghGuldberg O, Bairlein F. 2002. Ecological responses to recent climate change. Nature 416: 389-395.

Waples RS. 1989. A generalized approach for estimating effective population size from temporal changes in allele frequency. Genetics 121: 379-391.

Weir BS, Cockerham CC. 1984. Estimating F-statistics for the analysis of population structure. Evolution 38: 1358-1370. 
Westemeier RL, Brawn JD, Simpson SA, Esker TL, Jansen RW, Walk JW, Kershner EL, Bouzat JL, Paige KN. 1998. Tracking the long-term decline and recovery of an isolated population. Science 282: 1695-1698.

Westerdahl H. 2004. No evidence of an MHC-based female mating preference in great reed warblers. Molecular Ecology 13: 2465-2470.

Westneat DF, Mays HL. 2005. Tests of spatial and temporal factors influencing extra-pair paternity in red-winged blackbirds. Molecular Ecology 14: 2155-2167.

Whitaker AH. 1993. Research on the tuatara (Sphenodon punctatus) of Little Barrier Island, 6-20 October 1992. Pages 52. Unpublished report, Auckland Conservancy, New Zealand Department of Conservation, Auckland.

Whitaker AH, Daugherty CH. 1991. Research on the tuatara (Sphenodon punctatus) of Little Barrier Island, 5 - 12 February 1991. Pages 54. Unpublished report, Auckland Conservancy, New Zealand Department of Conservation, Auckland.

White GC, Burnham KP. 1999. Program MARK: survival estimation from populations of marked animals. Bird Study 46: 120-139.

Whiteman NK, Parker PG. 2004. Body condition and parasite load predict territory ownership in the Galapagos Hawk. Condor 106: 915-921.

Wikelski M, Carbone C, Bednekoff PA, Choudhury S, Tebbich S. 2001. Why is female choice not unanimous? Insights from costly mate sampling in marine iguanas. Ethology 107: 623-638.

Wikelski M, Carbone C, Trillmich F. 1996. Lekking in marine iguanas: Female grouping and male reproductive strategies. Animal Behaviour 52: 581-596.

Wooller RD, Bradley JS, Croxall JP. 1992. Long-term population studies of seabirds. Trends in Ecology and Evolution 7: 111-114.

Wright S. 1931. Evolution in Mendelian populations. Genetics 16: 0097-0159.

-. 1978. Evolution and the Genetics of Populations. University of Chicago Press, Chicago.

Xu QH, Fang SG, Wang ZP, Wang ZW. 2005. Microsatellite analysis of genetic diversity in the Chinese alligator (Alligator sinensis) Changxing captive population. Conservation Genetics 6: 941-951.

Yoccoz NG, Nichols JD, Boulinier T. 2001. Monitoring of biological diversity in space and time. Trends in Ecology and Evolution 16: 446-453.

Zamudio KR, Sinervo E. 2000. Polygyny, mate-guarding, and posthumous fertilization as alternative male mating strategies. Proceedings of the National Academy of Sciences of the United States of America 97: 14427-14432.

Zbinden JA, Largiader AR, Leippert F, Margaritoulis D, Arlettaz R. 2007. High frequency of multiple paternity in the largest rookery of Mediterranean loggerhead sea turtles. Molecular Ecology 16: 3703-3711. 
Zeh JA, Zeh DW. 1997. The evolution of polyandry 2. Post-copulatory defences against genetic incompatibility. Proceedings of the Royal Society of London Series BBiological Sciences 264: 69-75. 
Appendix One. The Debate on Behavior in Conservation: New Zealand Integrates Theory with Practice 


\title{
The Debate on Behavior in Conservation: New Zealand Integrates Theory with Practice
}

\author{
JENNIFER A. MOORE, BEN D. BELL, AND WAYNE L. LINKLATER
}

Behavioral research is increasingly a part of species conservation, yet the debate over its relevance to conservation continues. We use New Zealanda world leader in conservation management - as a case study to illustrate the integration of behavior and conservation. Advanced through adaptive management, conceptual behavioral research has been critical to the recovery of many threatened New Zealand species, and the percentage of published research addressing behavioral questions while being applied to conservation has grown considerably in the last 16 years. Much of this research has been incorporated directly into recovery plans for threatened species. Examples range from the cross-fostering of endangered native birds to behavioral plasticity of native fauna in the face of invasive rodents, to mating systems and potential control measures for invasive species. Our case studies not only address major themes in behavior but also provide reason for optimism about the future of the fledgling field of conservation behavior:

Keywords: animal behavior, conservation, management, threatened species, New Zealand

ehavioral research is increasingly a part of species conservation (Buchholz 2007), but debate over its relevance to conservation continues. In a recent commentary, Caro (2007) asserted that theoretical advances in animal behavior are unlikely to find utility in conservation, and he thus advocates a return to prosaic goals. Progress in science depends on integrating concepts into theoretical frameworks that provide testable hypotheses to guide scientific practice toward new knowledge and tools that in turn feed back into conceptual change (Peters 1991). Scientific maturation depends on progressing from description to evaluation and on to synthesis, and this maturation cannot occur in the absence of a theoretical framework (Altmann and Altmann 2003). Further, when two different fields merge, their integration is assisted and more successful if each discovers value in applying the different concepts, theoretical frameworks, and approach of the other.

There is a mismatch between conservation biology and behavioral research, but Linklater (2004) proposed a solution, termed "integrative pluralism," that applies a fundamental behavioral paradigm (Tinbergen's four questions; Tinbergen 1963 ) into conservation theory and practice to advance from parochially descriptive studies of behavior to behavioral problem solving. In this article we showcase advances and examples from New Zealand that illustrate the application of behavioral theory to species conservation. This approach gives reason for optimism, and we demonstrate progress in conservation behavior at both theoretic and pragmatic levels.

\section{The New Zealand case study}

There is no question that New Zealand ranks highly in its level of endemism, and that it has suffered major species declines and extinctions since human settlement and the arrival of invasive species (Gibbs 2006). New Zealand has no native terrestrial mammals, but it now supports a range of introduced mammals - one of the main causes of extinctions and continued threats to much of the endemic flora and fauna. For these reasons, New Zealand has a strong inherent commitment to conservation. For example, Bell (1991) reported that 39 percent of New Zealand contributions to an international ornithological congress were on conservation themes, compared with, on average, only 12 percent from other countries. This commitment to conservation-oriented research is apparent in New Zealand's governmental organizations (e.g., Department of Conservation, Landcare Research Limited) as well as in its universities. Indeed, many graduate research projects in ecology and biology are focused directly on nationally threatened species.

Because of the precarious status of much of its biodiversity, New Zealand has become a world leader in species management (Bell and Merton 2002). Rapid endangerment necessi-

Jennifer A. Moore (e-mail: Jennifer.Moore@vuw.ac.nz) is a doctoral candidate in the Allan Wilson Centre for Molecular Ecology and Evolution at Victoria University of Wellington in New Zealand. Ben D. Bell and Wayne L. Linklater are with the Centre for Biodiversity and Restoration Ecology, School of Biological Sciences, Victoria University of Wellington. $\odot 2008$ American Institute of Biological Sciences. 
tated innovative and swift solutions that have been key to many successful recoveries. Advanced through adaptive management, behavioral research has been critical to the recovery of many threatened New Zealand species (Reed and Merton 1991). For 11 of 25 critically endangered bird species (44 percent), "behavioral techniques" are listed as a principle management tool (Bell and Merton 2002).

New Zealand conservation managers, unlike those in larger nations, appear to be less constrained by multilayered bureaucracy and conflicting interest groups when making decisions. Additionally, because the New Zealand conservation community is small and well connected, conservationfocused researchers usually communicate directly with easily accessible local managers, and thus research results can be quickly integrated into species recovery plans. Management decisions based on research results are often innovative and groundbreaking, albeit sometimes a balance of risks (e.g., the translocation of the endangered Hamilton's frog Leiopelma hamiltoni to Nukuwaiata Island from the small remnant population on Stephens Island; Tocher et al. 2006).

It is not surprising, therefore, that the conservation and behavior literature from New Zealand has grown dramatically during the last 16 years. Two searches of ISI's Web-of-Science bibliometric database (ISI Research Soft 2007), using "behavio* AND New Zealand" and "conservation AND New Zealand," with "New Zealand" also as an author's address search term, generated a similar number of behavior $(n=657)$ and conservation $(n=647)$ articles from 1991 to 2007 (articles from unrelated fields were removed). Annual numbers of behavior and conservation articles ranged from a low of 29 in the early 1990 s to 138 in 2006, reflecting the growth observed globally in conservation and behavioral and animal biology generally (Linklater 2004). The sample of the conservation behavior literature and its authors was obtained from the intersection of the two searches (i.e., those articles and authors present in both the conservation and behavior literature). Fifty articles and their 40 leading authors were found in both searches. The contribution of conservation behaviorists has grown dramatically in recent years relative to the size of the behavioral literature (3 percent to 13 percent from 1991-2007).

Publishing patterns by conservation behaviorists in New Zealand indicate that their research addressed problems that were exclusive, as well as inclusive, of the other field (figure 1). The conservation behavior community in New Zealand, particularly among its most prolific publishers, is well represented by the two types of conservation behaviorists identified by Linklater (2004): (1) those whose main focus is conservation but who use behavioral research as part of larger multidisciplinary research objectives, and (2) those whose primary focus is animal behavior and who apply their expertise in conservation (figure 1). Overall, however, there were more conservation behaviorists whose publications span the conservation and behavioral literature equally. Thus, there is diversity in approach and perspective among conservation behaviorists, which explains why behavioral theory and practice has been so thoroughly integrated with

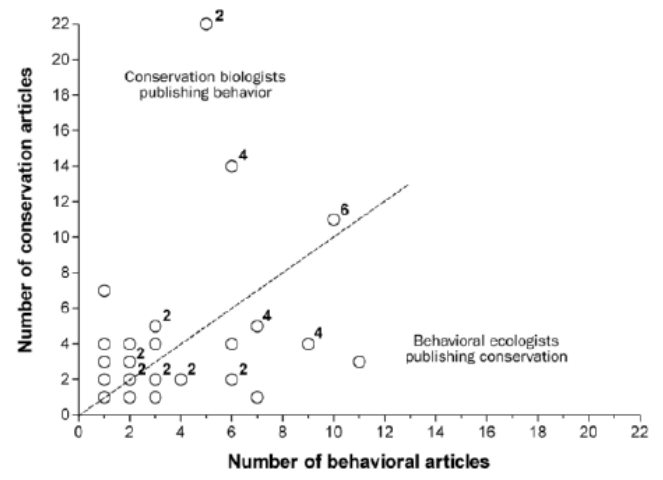

Figure 1. The relative contributions of the 40 leading authors whose 50 articles were featured in both the behavioral and conservation literature from New Zealand (1991-2007). The axes represent their total contribution to the behavioral ( $\mathrm{x}$-axis) and conservation (y-axis) literature. The community of conservation behaviorists is broadly based, from conservation biologists studying behavior in multidisciplinary research (upper left) to behaviorists applying their expertise to conservation (lower right). Numbers of articles that were present in both samples of the literature, and therefore classified as conservation behavior, are indicated by small numerals to the right of and above each open dot. Authors represented by dots without numbers published one conservation behavior article.

conservation in New Zealand, as we discuss in the next section. Nevertheless, the relatively low, but growing, proportion of articles that can be described as "conservation behavior" indicates that the potential for continued growth of the field is huge, such that the field might benefit from having its own specialist journals.

\section{Integrative pluralism in conservation behavior}

In his influential paper on ethology, Tinbergen (1963), noting that "ethologists differ widely in their opinion of what their science is about," proposed a paradigm uniting behavioral research through common themes, a paradigm that is still widely used today. Tinbergen's approach was advocated as a better way of understanding how behavior can be integrated with conservation (Linklater 2004, Buchholz 2007). The beauty of Tinbergen's four questions regarding causation, ontogeny, phylogeny, and adaptation is that they force us to consider multiple, complementary explanations for behavior, rendering ways of predicting and modifying behavior and behavioral outcomes in conservation. We adopt this approach here to demonstrate how fundamental questions in behavior have contributed to innovative conservation solutions in New Zealand. 
Causative mechanisms. When applied to conservation questions, an understanding of behavior's causative mechanisms provides a route for understanding or manipulating behavior or allows us to predict the outcomes of ecological perturbations (e.g., climate change and exotic species invasion), or both. For example, Sol and colleagues (2002) analyzed factors affecting invasion success by 69 exotic bird species in New Zealand and Australia, and found relative brain size to be the strongest predictor. They concluded that behavioral flexibility (known to be correlated with brain size) is a major determinant of invasion success in birds. Theory on behavioral flexibility and brain size can be applied to explain and predict bird translocation success where limited behavioral repertoire or flexibility may have caused conservation efforts to fail. For example, many early attempts to translocate bellbirds (Anthornis melanura) were unsuccessful (Lee 2005). One of the reasons implicated in the failure is that naive birds were sourced from mammal-free islands and translocated to islands with mammalian predators, whereas birds could have been sourced from islands where they had been exposed to predators, as these birds were known to have modified their behavioral repertoire to coexist with predators (Lee 2005).

Rowe and Bell (2007) found that mate choice by reintroduced North Island kokako (Callaeas cinerea wilsoni) could be predicted from the similarity of the song repertoire of a chosen mate to that of kokako in the pretranslocation acoustic environment, a result that has direct application to future translocations of kokako and other rare birds. Trewenack and colleagues (2007) presented a model describing dispersal and settling of translocated animals and applied it to the translocation of the Maud Island frog (Leiopelma pakeka). The model showed that settling occurs at a constant rate, with repulsion (from chemical signals) probably playing a significant role. These examples demonstrate the utility of conspecific attraction or avoidance theory, which has been used in designing translocation programs for threatened seabirds (Gummer 2003, Stamps and Swaisgood 2006).

Sex allocation theory has played a role in conservation of one of the world's most endangered parrots, the kakapo (Strigops habroptilus). A strongly male-biased sex ratio of chicks jeopardized kakapo recovery until the cause of the bias was identified through sex allocation and parental investment theory, according to which mothers in good condition increase investment in male offspring (Clout et al. 2002). Excessive supplementary feeding, a common practice in species recovery programs, was replaced by a new optimized feeding regime through which the weight of all females rose just enough to boost breeding frequency while stabilizing the sex ratio of offspring; thus a major goal in kakapo recovery was achieved (Robertson et al. 2006).

Ontogeny. Behavioral learning and retention theory (e.g., operant conditioning) is finding growing application in conservation, particularly in predator-avoidance training of translocated wildlife, which improves postrelease survival rates. Exposing naive animals (which are often captive-reared or sequestered on islands) to artificial predators is designed to "teach" them to better evade real predators in the wild. McLean and colleagues (1999) presented young New Zealand robins (Petroica australis) with artificial predators, and demonstrated the ability of these naive birds to respond to the simulated predators with appropriate evasive behavior.

Another commonly used technique in avian conservation management is cross-fostering, whereby the young of a rare species are reared by surrogate parents in a closely related common species. Cross-fostering was successfully used for incubating eggs of the endangered takahe (Porphyrio mantelli) by a close common relative, the pukeko (Porphyrio porphyrio) (Bunin and Jamieson 1996a). The incubation of takahe eggs by pukeko was not only successful, but cross-fostered yearling takahe exhibited higher levels of alertness and avoidance than parent-reared takahe, indicating that cross-fostered animals can learn behaviors that will improve their success in the wild (Bunin and Jamieson 1996b). Cross-fostering has since been integrated into numerous species recovery plans, including takahe, fairy terns (Sterna nereis davisae), and black stilts (Himantopus novaezelandiae), or kakī, and is now widely implemented. Brood parasite and predator recognition theory has been key to understanding in which species, and under what circumstances, cross-fostering is most likely to succeed.

Theoretical and empirical knowledge of imprinting has minimized the problems associated with foster parents, including humans. Experience and an extensive literature on imprinting behavior of common and economically important species were critical to the success of conservation directives for threatened species in New Zealand. For example, takahe chicks have been routinely hand-fed using takahe-head puppets (figure 2) with internal speakers playing adult feeding calls (Eason and Williams 2001). Likewise, because young black robins (Petroica traversi) malimprinted on and hybridized with their Chatham Island tomtit (Petroica macrocephala chathamensis) foster parents, careful management was required, including translocation to a tomtit-free island (Butler and Merton 1992).

Adaptive value. Historically, the majority of studies involving a behavioral component in conservation address the adaptive value of the behavior (Linklater 2004). Knowledge of the adaptive value of behavior can be used to determine what impact an environmental change or conservation action might have on the performance (fitness) of individuals and populations through intended or unintended changes in behavior. The guiding theories in these studies focus on optimality (i.e., the expectation that fitness will be optimized or maximized). Examples range from monitoring the posttranslocation behavior and success of birds (e.g., Armstrong et al. 1999) and investigating the effects of human presence on animal behavior (and, ultimately, fitness; e.g., Cole 1994), to understanding the behavior of introduced pests (e.g., Russell et al. 2005). 


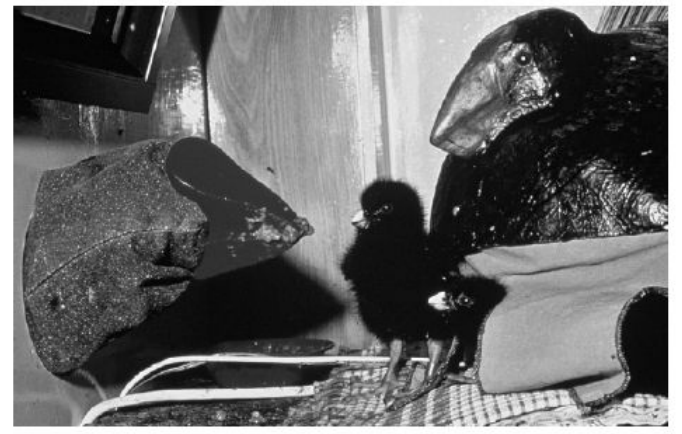

Figure 2. Captive raising endangered takahe chicks involves feeding with takahe-head puppets (left) and brooding under an adult female model (right), to avoid the chicks' imprinting on humans.

Ecotourism can adversely affect wildlife, and studying the behavioral responses of animals and their consequences for fitness is one way to gauge this form of human impact. In a study of the spatial patterns of fish in marine reserves, researchers found that large benthic fishes were attracted to divers - who often feed the fish — and thus the fishes' movement patterns are altered (Cole 1994). The attraction to divers and resultant changes in movement patterns confound attempts to assess the success of marine reserves at protecting fish from harvest, and very likely have adverse effects on large prey organisms. Human disturbance is also a problem on busy beaches, where seabirds and shorebirds nest. By approaching the nests of threatened New Zealand dotterels (Charadrius obscurus aquilonius), Lord and colleagues (2001) found that the birds were habituated to humans on busy beaches, and also that the biggest threat to normal avian parenting behavior came from dogs. The parent birds' avoidance behavior was strongest when they were approached by a dog, indicating that walking dogs near nesting seabirds may severely affect nest success. Because of the potentially devastating effects that dogs may have on bird survival, the New Zealand Department of Conservation has initiated an avian awareness and avoidance training program. Dog owners are educated about the dangers their dogs may pose to ground-dwelling native birds, and dogs are trained to avoid these birds.

Phenotypic plasticity theory can help predict and explain how native species interact with and respond to the threat of an exotic predator. For example, Hoare and colleagues (2007) found that large, nocturnal geckos (Hoplodactylus duvaucelii) were able to coexist with introduced and predatory ship rats (Rattus exulans) because they modified their movement patterns in the presence of rats. The authors concluded that the highly plastic spatial avoidance behavior of these geckos may enable short-term sympatry with introduced rats. Likewise, Rufaut and Gibbs (2003) reported that endemic tree weta (Hemideina crassidens) modified their behavior in the presence of introduced rats, suggesting that their behavioral flexibility may enable them to withstand a small degree of predation pressure from introduced vertebrates, which allows managers to prioritize conservation efforts.

Theory about the adaptive function of dispersal and its demographic implications is being applied to understand the behavior of invasive species. For instance, the dispersal behavior of Norway rats (Russell et al. 2005) is being used to predict invasion patterns and risk and to redesign biosecurity measures on island sanctuaries. Also, Stringer and Lester (2007), after investigating the mating system and foraging behavior of an invasive ant (Monomorium sydneyense), were able to predict that the potential ecosystem damage caused by this species would probably be very low compared with other invasive ant species.

Mating system theory has been used further to predict the applicability of biological control to invasive species. One of the greatest threats to New Zealand's biodiversity is an introduced Australian marsupial, the brushtail possum (Trichosurus vulpecula) (Jolly 1993). Biological control, in the form of a sexually transmitted immunocontraceptive, has been proposed as a potential control technique. To determine the potential efficacy of such a control, Sarre and colleagues (2000) investigated the mating system of possums and found that male reproductive success was extremely variable. The authors concluded that this highly polygynous mating system would very likely facilitate the spread of a sexually transmitted immunocontraceptive, which could be a potentially valuable possum control measure. Likewise, Ji and colleagues (2000) found that male possums were attracted to experimentally sterilized female possums, whose resultant prolonged period of estrus left males in poorer body condition and hence at greater risk of death. Their results bolster the viability of immunocontraception or sterilization as a method of control for this extremely destructive invader, and these options will most likely be employed in the near future.

Phylogeny. Studies of behavioral phylogeny and evolution, which have played a much smaller role in conservation (Linklater 2004) than the studies discussed above, may be an area in which behaviorists might expand their contribution. For instance, Paterson and colleagues (1995) found that a cladistic analysis of behavior reflected seabird phylogeny; the 18 species studied included albatrosses, petrels, and penguins. Their behavior and life-history data set ( 72 characters) was no more congruent than molecular data, and the resulting trees matched molecular trees. Again, Kennedy and colleagues (1996) revive the older ecological claim that behavioral characters could be used to provide accurate estimates of phylogeny, constructing a 37-character behavioral data set on the basis of van Tets' (1965) finding that parsimony analysis of 20 taxa produced 12 shortest trees that fit the behavior data well. Thus, we might consider that behavior should contribute to the definition of evolutionary significant units (or equivalent classifications) in conservation, particularly where behavioral theory predicts behaviors critical to fitness. 
Life-history theory and the evolutionary transition from a recent $r$-selected colonizer to a $K$-selected endemic predict that many New Zealand avian species pairs are double invasions of the same stock (Fleming 1962; e.g., the $r$-selected pukeko, Porphyrio porphyrio, compared with the $K$-selected takahe, Porphyrio mantelli; Bell 1991). Differences between these two species include a suite of behavioral traits that explain the takahe's greater vulnerability to environmental disturbance and its current endangered status; therefore, its need for conservation management is greater than it is for its $r$-selected relative. Furthermore, in a test of the relative contributions of phylogeny and sociality to the evolution of play, Diamond and colleagues (2006) contrast the relatively solitary and highly endangered kakapo (S. habroptilus) with the more social kaka (Nestor meridionalis) and kea (Nestor notabilis). They concluded that social play in these parrots appears to be most readily predicted from their patterns of social development, emerging within a constellation of behaviors associated with independent young that remain in the vicinity of adult groups. Kaka and kea recovery plans now require captive-bred individuals to be raised in social groups, which aids normal development and improves the likelihood of success once the birds are introduced into the wild.

\section{Conclusions}

The examples we have highlighted, summarized in table 1, addressed fundamental behavioral questions and applied behavioral theory yet were integrated well into conservation to provide innovative solutions to problems. Although we offer numerous examples in which behavioral research was successfully applied to conservation, there have also been

\begin{tabular}{|c|c|c|}
\hline $\begin{array}{l}\text { Behavioral question } \\
\text { and examples }\end{array}$ & Reference(s) & Applicability to conservation \\
\hline \multicolumn{3}{|l|}{ Causative mechanisms } \\
\hline $\begin{array}{l}\text { Relative brain size predicts invasion } \\
\text { success in birds }\end{array}$ & Sol et al. 2002 & $\begin{array}{l}\text { Used to predict success/failure of bird translocations and aid in translocation } \\
\text { programs }\end{array}$ \\
\hline $\begin{array}{l}\text { Kokako choose mates on the basis } \\
\text { of song repertoire }\end{array}$ & Rowe and Bell 2007 & $\begin{array}{l}\text { Increased success of translocated kokako by matching the song repertoire of } \\
\text { release cohorts }\end{array}$ \\
\hline $\begin{array}{l}\text { Chemical repulsion plays a role in } \\
\text { settling of Maud Island frogs }\end{array}$ & Trewenack et al. 2007 & Conspecific interactions integrated into designing translocation programs \\
\hline $\begin{array}{l}\text { Sex allocation theory invoked to explain } \\
\text { male bias in kakapo chicks }\end{array}$ & Robertson et al. 2006 & $\begin{array}{l}\text { Kakapo supplementary feeding regime optimized, which increased reproduc- } \\
\text { tive output and equalized chick sex ratio }\end{array}$ \\
\hline \multicolumn{3}{|l|}{ Ontogeny } \\
\hline $\begin{array}{l}\text { Predator training teaches young, naive } \\
\text { birds to avoid predators }\end{array}$ & McLean et al. 1999 & $\begin{array}{l}\text { Increased success of translocated individuals that have leamed to avoid } \\
\text { predators }\end{array}$ \\
\hline $\begin{array}{l}\text { Crossfostering increases hatching } \\
\text { success and predator avoidance }\end{array}$ & $\begin{array}{l}\text { Bunin and Jamieson } \\
1996 \mathrm{a}, 1996 \mathrm{~b}\end{array}$ & $\begin{array}{l}\text { Incorporated into recovery plans for numerous species, which has improved } \\
\text { hatchling success, and translocated or captive-reared birds have learned } \\
\text { predator avoidance }\end{array}$ \\
\hline \multicolumn{3}{|l|}{ Adaptive/functional value } \\
\hline $\begin{array}{l}\text { Foraging and dispersal behavior of hihi } \\
\text { not adversely affected by translocations }\end{array}$ & Armstrong et al. 1999 & Immediate success of hihi translocations has been confirmed \\
\hline $\begin{array}{l}\text { Behavior of marine fish altered by } \\
\text { human presence }\end{array}$ & Cole 1994 & $\begin{array}{l}\text { Altered protocols for determining success of protection from harvesting; } \\
\text { modification of ecotourism management }\end{array}$ \\
\hline $\begin{array}{l}\text { Dogs elicit strong avoidance behavior of } \\
\text { nesting shorebirds }\end{array}$ & Lord et al. 2001 & $\begin{array}{l}\text { Human presence on beaches with high shorebird nesting activity has been } \\
\text { limited, avian awareness and avoidance training program initiated for dogs and } \\
\text { their owners }\end{array}$ \\
\hline $\begin{array}{l}\text { Geckos modify spatial behavior in the } \\
\text { presence of introduced rats }\end{array}$ & Hoare et al. 2007 & $\begin{array}{l}\text { Managers were able to prioritize costly pest eradication and predict effects on } \\
\text { native species }\end{array}$ \\
\hline $\begin{array}{l}\text { Solitary introduced rats can disperse } \\
\text { great distances (over water) }\end{array}$ & Russell et al. 2005 & Increased biosecurity measures for invaders \\
\hline $\begin{array}{l}\text { Invasive ants (Monomorium sydneyense) } \\
\text { are inefficient foragers }\end{array}$ & Stringer and Lester 2007 & $\begin{array}{l}\text { Potential biosecurity risks from these ants is very low, allowing managers to } \\
\text { focus on more costly invaders }\end{array}$ \\
\hline $\begin{array}{l}\text { Invasive brushtail possums are highly } \\
\text { polygynous; sterilizing females confers } \\
\text { negative fitness consequences to males }\end{array}$ & $\begin{array}{l}\text { Ji et al. } 2000, \text { Sarre et al. } \\
2000\end{array}$ & A sexually transmitted biological control measure may be highly effective \\
\hline \multicolumn{3}{|l|}{ Phylogeny } \\
\hline $\begin{array}{l}\text { Cladistic analysis of behavior } \\
\text { corresponds to molecular phylogenies } \\
\text { of seabirds }\end{array}$ & $\begin{array}{l}\text { Paterson et al. 1995, } \\
\text { Kennedy et al. } 1996\end{array}$ & Aid in resolving evolutionary significant units or management units \\
\hline $\begin{array}{l}\text { Social play in parrots predicted from } \\
\text { patterns of social development, } \\
\text { not taxonomy }\end{array}$ & Diamond et al. 2006 & $\begin{array}{l}\text { Raising captive chicks in social groups is a compulsory part of the kea and } \\
\text { kaka recovery plans, which improves the success of captive-bred birds in the } \\
\text { wild }\end{array}$ \\
\hline $\begin{array}{l}\text { Life-history patterns explained for recent } \\
\text { and early invasions of same stock }\end{array}$ & Fleming 1962, Bell 1991 & $\begin{array}{l}\text { Identifying behavioral tactics in } r \text {-selected common pukeko (recent colonizer) } \\
\text { and } K \text {-selected endangered takahe (flightless endemic) help to explain the } \\
\text { different conservation statuses of these species }\end{array}$ \\
\hline
\end{tabular}


early failures. We should now build on the recent successes that illustrate how we arrive at novel solutions when merging these two disciplines, and learn from failures that might have benefited from greater integration of behavior in conservation.

\section{Acknowledgments}

We would like to thank our colleagues who share and inspire our interest in conservation behavior in New Zealand and throughout the world. Specifically, we thank Ferne McKenzie and Gerald Cubitt from the New Zealand Department of Conservation for sharing photographs of conservation behavior in action, and Murray Williams for help in obtaining these photographs. We also thank George Gibbs, Hilary Miller, Kimberly Miller, and Nicola Nelson for helpful discussions on the manuscript. Funding was provided by Education New Zealand (doctoral scholarship to J. A. M.).

\section{References cited}

Altmann SA, Altmann J. 2003. The transformation of behaviour field studies. Animal Behaviour 65: 413-423.

Armstrong DP, Castro I, Alley JC, Feenstra B, Perrott JK. 1999. Mortality and behaviour of hihi, an endangered New Zealand honeveater, in the establishment phase following translocation. Biological Conservation 89: 329-339.

Bell BD. 1991. Recent avifaunal changes and the history of ornithology in New Zealand. Acta XX Congressus Internationalis Ornithologici 1: 193-230.

Bell BD, Merton DV. 2002. Critically endangered bird populations and their management. Pages 103-138 in Norris K, Pain DJ, eds. Conserving Bird Biodiversity: General Principles and Their Application. Cambridge (United Kingdom): Cambridge University Press.

Buchholz T. 2007. Behavioural biology: An effective and relevant conservation tool. Trends in Ecology and Evolution 22: 401-407.

Bunin JS, Jamieson IG. 1996a. A cross-fostering experiment between the endangered takahe (Porphyrio mantelli) and its closest relative, the pukeko (P. porphyrio). New Zealand Journal of Ecology 20: 207-213. . 1996b. Responses to a model predator of New Zealand's endangered takahe and its closest relative, the pukeko. Conservation Biology 10; 1463-1466.

Butler D, Merton D. 1992. The Black Robin: Saving the World's Most Endangered Bird. Auckland (New Zealand): Oxford University Press.

Caro T. 2007. Behavior and conservation: A bridge too far? Trends in Ecology and Evolution 22: 394-400.

Clout MN, Elliott GP, Robertson BC. 2002. Effects of supplementary feeding on the offspring sex ratio of kakapo: A dilemma for the conservation of a polygynous parrot. Biological Conservation 107: 13-18.

Cole RG. 1994. Abundance, size structure, and diver-oriented behavior of three large benthic carnivorous fishes in a marine reserve in northeastern New Zealand. Biological Conservation 70: 93-99.

Diamond J, Eason D, Reid C, Bond AB. 2006. Social play in kakapo (Strigops habroptilus) with comparisons to kea (Nestor notabilis) and kaka (Nestor meridionalis). Behaviour 143: 1397-1423.

Eason DK, Williams M. 2001. Captive rearing: A management tool for the recovery of the endangered takahe. Pages 80-95 in Lee WG, Jamieson IG, eds. The Takahe: Fifty Years of Conservation Management and Research. Dunedin (New Zealand): Otago University Press.

Fleming CA. 1962. History of the New Zealand land bird fauna. Notornis 9: $270-274$.

Gibbs GW. 2006. Ghosts of Gondwana. Nelson (New Zealand): Craig Potton.

Gummer H. 2003. Chick Translocation as a Method of Establishing New Surface-nesting Seabird Colonies: A Review. Wellington (New Zealand): New Zealand Department of Conservation. Science Internal Series 150.
Hoare JM, Pledger S, Nelson NJ, Daugherty CH. 2007. Avoiding aliens: Behavioural plasticity in habitat use enables large, noctural geckos to survive in Pacific rat invasions. Biological Conservation 136: 510-519.

ISI Research Soft. 2007. 1999 Journal Citation Reports: A Bibliometric Analysis of Science Journals in the ISI Database. Philadelphia: Thomson Institute for Scientific Information.

Ji WH, Clout MN, Sarre SD. 2000. Responses of male brushtail possums to sterile females: Implications for biological control. Journal of Applied Ecology 37: 926-934.

Jolly SE. 1993. Biological control of possums. New Zealand Journal of Zoology 20: 335-339.

Kennedy M, Spencer HG, Gray RD. 1996. Hop, step and gape: Do the social displays of the Pelecaniformes reflect phylogeny? Animal Behaviour 51: $273-291$.

Lee M. 2005. Failed attempts to reintroduce bellbirds (Anthornis melanura) to Waiheke Island, Hauraki Gulf, 1988-91. Notornis 52: 150-157.

Linklater WL. 2004. Wanted for conservation research: Behavioral ecologists with a broader perspective. BioScience 54: 352-360.

Lord A, Waas JR, Innes J, Whittingham MJ. 2001. Effects of human approaches to nests of northern New Zealand dotterels. Biological Conservation 98: 233-240.

McLean IG, Hölzer C, Studholme BJS. 1999. Teaching predator-recognition to a naive bird: Implications for management. Biological Conservation 87: $123-130$.

Paterson AM, Wallis GP, Gray RD. 1995. Penguins, petrels, and parsimony: Does cladistic analysis of behavior reflect seabird phylogeny? Evolution 49: 974-989.

Peters R. 1991. A Critique for Ecology. Cambridge (United Kingdom): Cambridge University Press.

Reed C, Merton D. 1991. Behavioural manipulation of endangered New Zealand birds as an aid towards species recovery. Acta XX Congressus Internationalis Ornithologici 4: 2514-2522.

Robertson BC, Elliott GP, Eason DK, Clout MN, Gemmell NJ. 2006. Sex allocation theory aids species conservation. Biology Letters 2: 229-231.

Rowe SJ, Bell BD. 2007. The influence of geographic variation in song dialect on post-translocation pair formation in North Island kokako (Callaeas cinerea wilsoni). Notornis 54: 28-37.

Rufaut CG, Gibbs GW. 2003. Response of a tree weta population (Hemideina crassidens) after eradication of the Polynesian rat from a New Zealand Island. Restoration Ecology 11: 13-19.

Russell JC, Towns DR, Anderson SH, Clout MN. 2005. Intercepting the first rat ashore. Nature 437: 1107 .

Sarre SD, Aitken N, Clout MN, Ji W, Robins J, Lambert DM. 2000. Molecular ecology and biological control: The mating system of a marsupial pest. Molecular Ecology 9: 723-733.

SolD, Timmermans S, Lefebvre L. 2002. Behavioural flexibility and invasion success in birds. Animal Behaviour 63: 495-502.

Stamps J, Swaisgood R. 2006. Someplace like home: Experience, habitat selection and conservation biology. Applied Animal Behaviour Science 102: 392-409.

Stringer LD, Lester PJ. 2007. Foraging characteristics and intraspecific behaviour of the exotic species Monomorium sydneyense (Hymenoptera: Formicidae) in New Zealand, with implications for its management. New Zealand Journal of Zoology 34: 25-34

Tinbergen N. 1963. On aims and methods of ethology. Zeitschrift fur Tierpsychologie 20: 410-433.

Tocher MD, Fletcher D, Bishop PJ. 2006. A modelling approach to determine a translocation scenario for the endangered New Zealand frog Leiopelma hamiltoni. Herpetological Journal 16: 97-106.

Trewenack AJ, Landman KA, Bell BD. 2007. Dispersal and settling of translocated populations: A general study and a New Zealand amphibian case study. Journal of Mathematical Biology: 575-604.

van Tets GF. 1965. A comparative study of some social communication patterns in the Pelecaniformes. Ornithological Monographs 2: 1-88.

doi:10.1641/B580513

Include this information when citing this material. 